\title{
Evaluation of the separation involved in recycling end-of-life (EOL) electronic equipment
}

\author{
Vivek Vasudevan \\ West Virginia University
}

Follow this and additional works at: https://researchrepository.wvu.edu/etd

\author{
Recommended Citation \\ Vasudevan, Vivek, "Evaluation of the separation involved in recycling end-of-life (EOL) electronic \\ equipment" (2004). Graduate Theses, Dissertations, and Problem Reports. 1471. \\ https://researchrepository.wvu.edu/etd/1471
}

This Thesis is protected by copyright and/or related rights. It has been brought to you by the The Research Repository @ WVU with permission from the rights-holder(s). You are free to use this Thesis in any way that is permitted by the copyright and related rights legislation that applies to your use. For other uses you must obtain permission from the rights-holder(s) directly, unless additional rights are indicated by a Creative Commons license in the record and/ or on the work itself. This Thesis has been accepted for inclusion in WVU Graduate Theses, Dissertations, and Problem Reports collection by an authorized administrator of The Research Repository @ WVU. For more information, please contact researchrepository@mail.wvu.edu. 


\title{
Evaluation of the Separation Involved in Recycling End-of-Life (EOL) Electronic Equipment
}

\author{
Vivek Vasudevan \\ Thesis Submitted to the \\ College of Engineering and Mineral Resources \\ at West Virginia University \\ in partial fulfillment of the requirements \\ for the degree of \\ Master of Science \\ in \\ Chemical Engineering \\ Richard Turton, Ph.D., Chair \\ John W. Zondlo, Ph.D. \\ Eung Ha H. Cho, Ph.D. \\ Department of Chemical Engineering \\ Morgantown, West Virginia \\ 2004
}

Keywords: EOL, plastics, recycling, ABS, HIPS, froth flotation, surfactants, FTIR 


\section{Abstract \\ Evaluation of the Separation Involved in Recycling End-of-Life (EOL) Electronic Equipment Vivek Vasudevan}

Due to increasing environmental concerns and public awareness, it has become essential to find an environmentally friendly and economic method to recycle EOL electronic equipment. This research work focuses on a froth flotation technique to separate two specific EOL plastics, namely High Impact Polystyrene (HIPS) and Acrylonitrile Butadiene Styrene copolymer (ABS).

The objective of this research was to investigate composition of keyboards and casings of personal computers, and other EOL components, as representative of postconsumer EOL equipment. The plastics were then characterized in terms of their density, qualitative composition and inorganic content. In particular, densities of ABS and HIPS were found to be in the range of 1.04 to $1.09 \mathrm{gm} / \mathrm{cm}^{3}$, with less than $1 \%$ ash content in most cases.

The frother investigated in the froth flotation study was methyl isobutyl carbinol (MIBC), while oleic acid and dodecylamine hydrochloride were investigated as representative surfactants from the anionic and cationic groups, respectively. HIPS and ABS were individually floated using these chemicals to study rates of flotation. The batch times of operation to achieve best possible separability was determined in each case. For example, a single stage flotation cell using $1 \mathrm{ml} \mathrm{MIBC}$ as frother operated for 6 minutes yielded HIPS and ABS at $67 \%$ and $63 \%$ purity as the top and bottom products, respectively.

Purities and yields possible in 2-stage and 3-stage flotation setups were also determined for surfactant - frother combinations. A 2-stage flotation setup with recycle gave about $77 \%$ pure plastics at a similar \% yield, while a 3-stage flotation setup with recycle resulted in about $87 \%$ pure plastics at an increased yield of $88 \%$. A cationic surfactant was found to be most suitable for achieving an acceptable degree of separation, albeit at the cost of high batch times. A 3-stage setup using 2 grams of dodecylamine hydrochloride with each stage operating at a batch time of 12 minutes yielded $94 \%$ pure PS at $80 \%$ yield, while a batch time of 14 minutes produced $92 \%$ pure $\mathrm{ABS}$ at about $83 \%$ yield.

A preliminary study was also made to assess the effect of inter-particle interactions when both plastics were floated simultaneously. It was observed that ABS purity increased to $93 \%$ at a lower yield of $62 \%$, while the reverse trend was observed for PS (yield: 95\% and purity: 71\%). 


\section{Acknowledgements}

I wish to express my sincere gratitude to my research advisor Dr. Richard Turton for his guidance and encouragement during the course of this work. It has been a great pleasure and honor to work with a gifted researcher and wonderful person like him. I am grateful to the members of my advisory committee, Dr. John W. Zondlo and Dr. Eung Ha Cho, for their useful comments and suggestions in helping me design and plan my experiments. I would also like to thank Dr. Peter G. Stansberry and his students in WVU Carbon Group for providing invaluable input and allowing me to use their lab facilities. I would like to make a special mention of Liviu Magean for his immense help in using the Elemental Analyzer. I sincerely appreciate Mr. Jim Hall for patiently building my experimental equipment and helping me troubleshoot problems during my work. I would also like to thank Linda Rogers and Bonita Helmick for handling all the paper work and other miscellaneous formalities.

I would also like to thank Mr. Bob Tarhi from Perkin Elmer Instruments for helping me learn the FTIR instrument. I also appreciate Mr. Phillippe Candelier and Mr. Luc Nocente at Norpix Inc. for helping out with Visilog \& StreamPix softwares. I would also like to thank US Department of Energy, NETL, Morgantown; US Environmental Protection Agency (US EPA) and Polymer Alliance Zone (PAZ) for their financial support for this project. I would like to thank all my current and ex-labmates for providing an excellent working atmosphere throughout the duration of my research at WVU. Lastly, I thank my parents for being a wonderful source of support and unconditional love throughout my life. 


\section{Table of Contents}

Evaluation of the Separation Involved in Recycling End-of-Life (EOL) Electronic

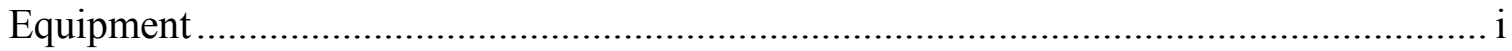

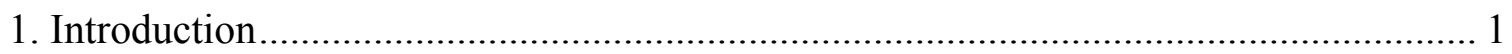

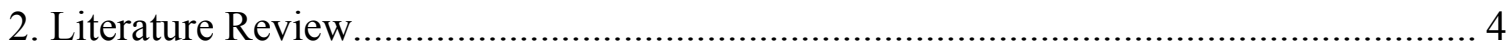

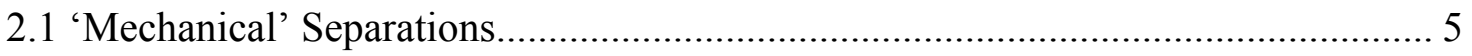

2.1.1 Heavy Media Separation........................................................................... 5

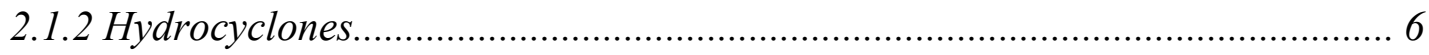

2.2 ‘Surface Based’ Separation ......................................................................... 7

2.2.1 Froth Flotation …………………............................................................... 7

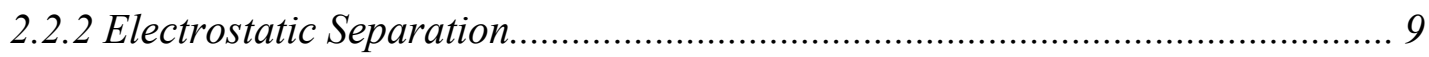

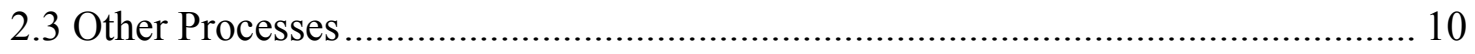

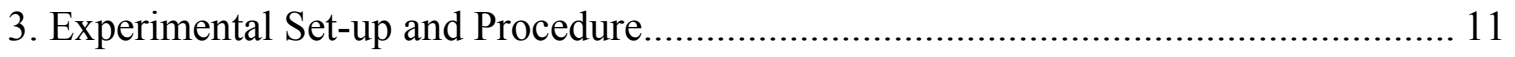

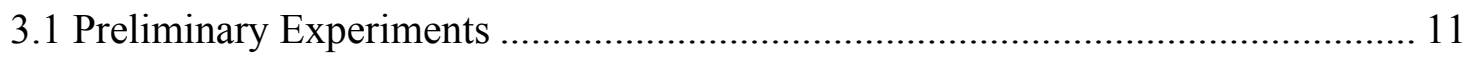

3.1.1 Dismantling of EOL Equipment................................................................. 11

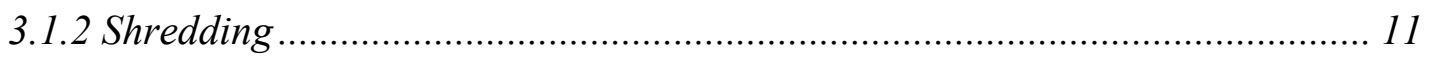

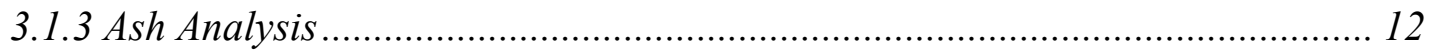

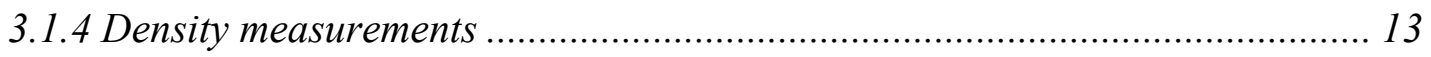

3.1.5 Plastics Identification ………………................................................... 13

3.1.6 Settling Velocity Measurements............................................................... 18

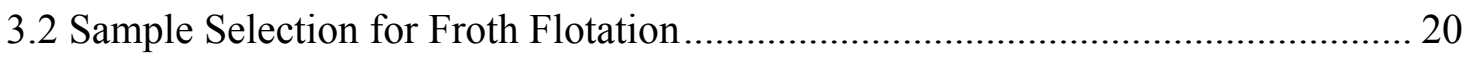

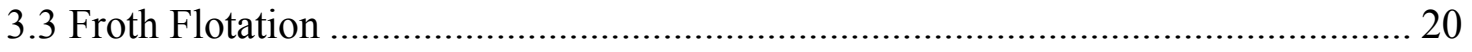

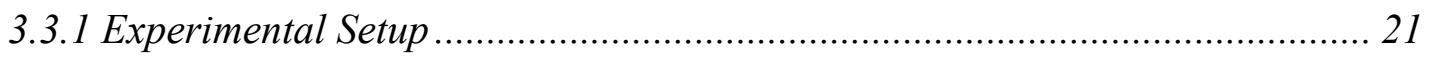


3.3.2 Experimental Matrix …………….......................................................... 24

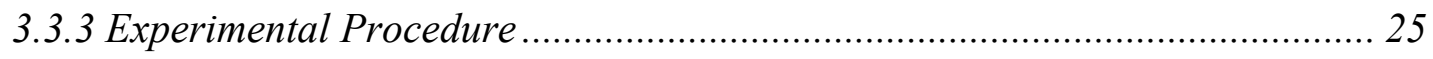

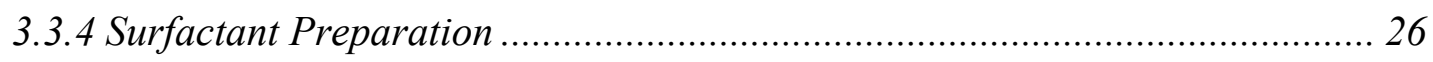

3.3.5 Calculation of 'Mixed' Plastics composition.................................................. 26

- Elemental Analysis .................................................................................. 26

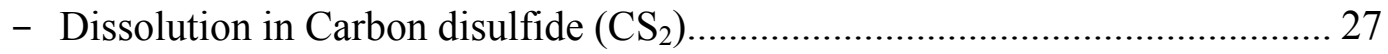

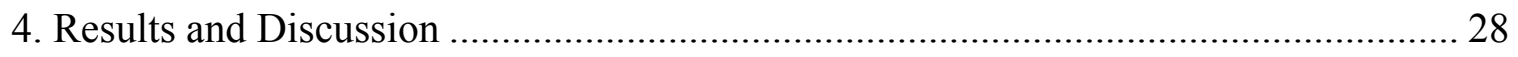

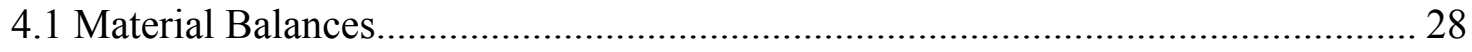

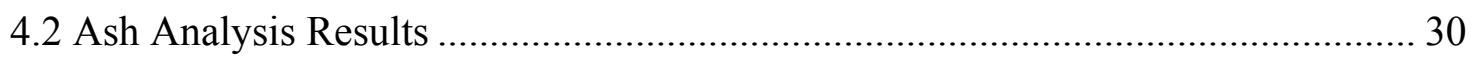

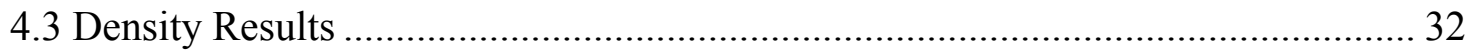

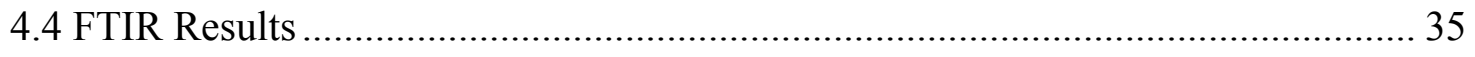

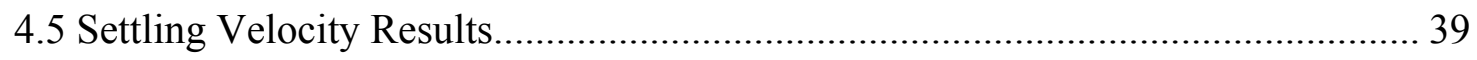

4.6 Froth Flotation Results..................................................................................... 40

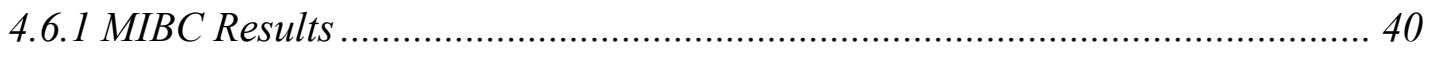

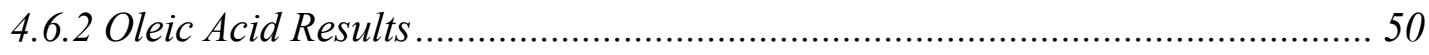

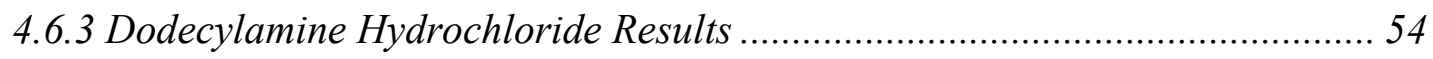

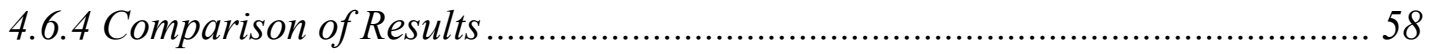

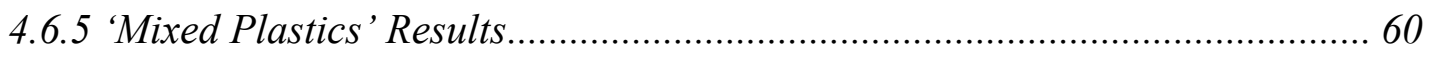

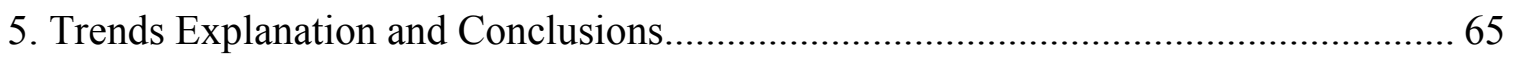

5.1 EOL Equipment Material Balances and Plastic Identification .............................. 65

5.2 Summary of Ash Analysis and Density Results ...................................................... 65

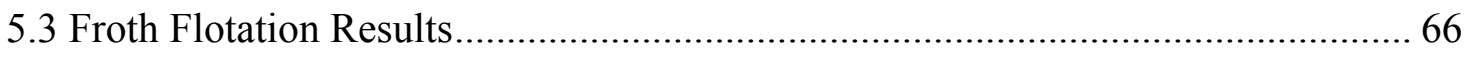

5.3.1 Single stage vs multi-stage flotation setups ………………………………..... 66 


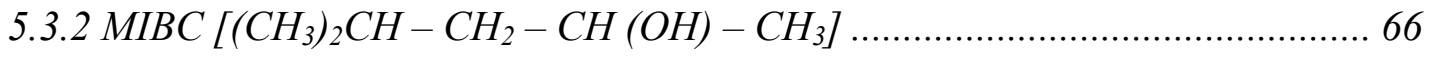

5.3.3 Oleic acid Emulsion in $\mathrm{NaOH}\left[\mathrm{C}_{17} \mathrm{H}_{33} \mathrm{COO}^{-} \mathrm{Na}^{+}\right]$....................................6. 67

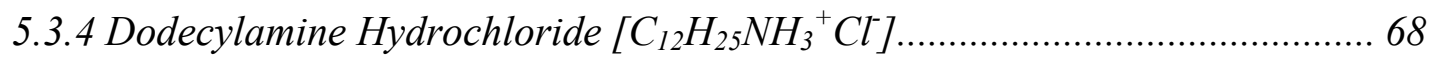

5.3.5 Comparison of flotation results in a 3-stage flotation setup with recycle ....... 68

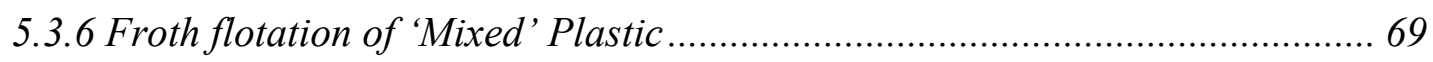

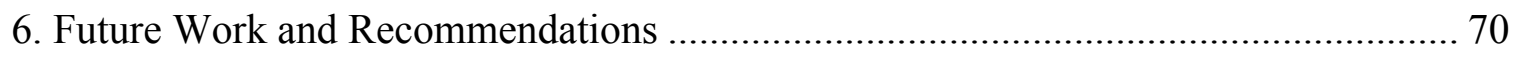

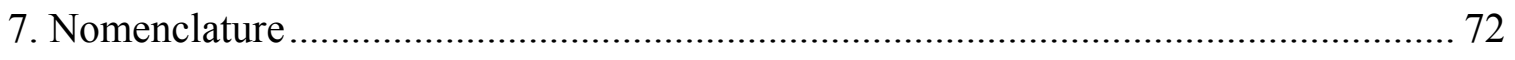

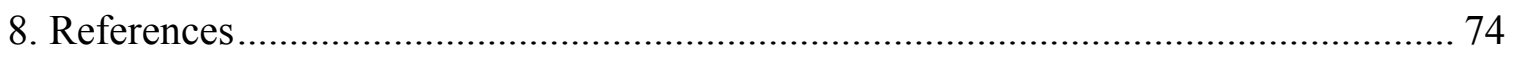

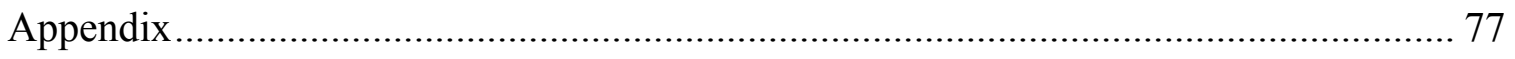

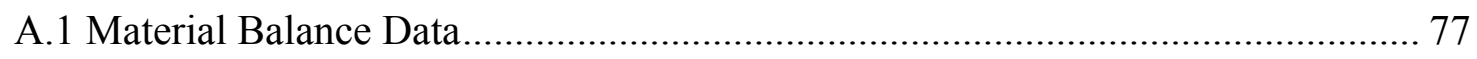

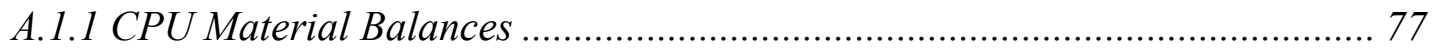

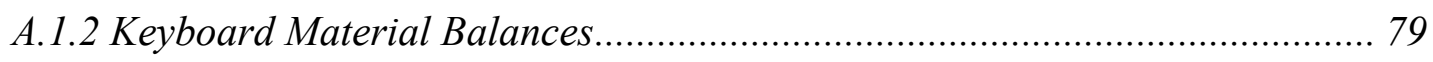

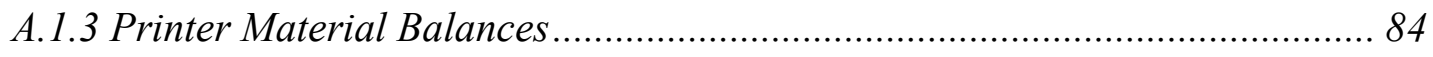

A.2 Ash Analysis, Density and FTIR Plastic Identification Data............................ 85

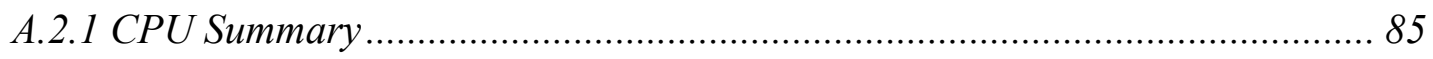

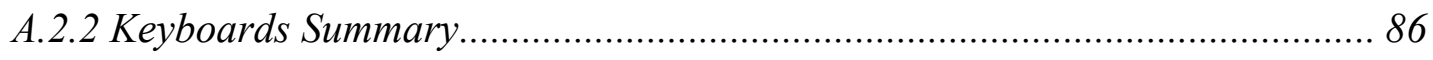

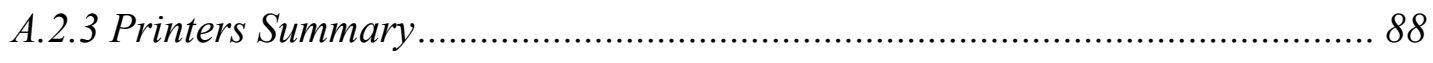

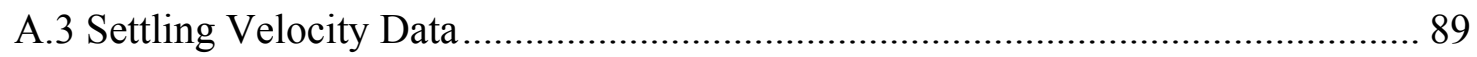

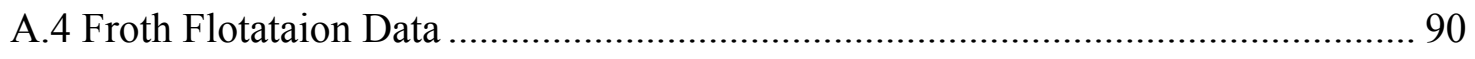




\section{List of Figures}

Figure 3.1 FRITSCH Power Cutting Mill “pulverisette 25” ...................................... 12

Figure 3.2 FT-IR Spectrum for SAN plastic..................................................... 15

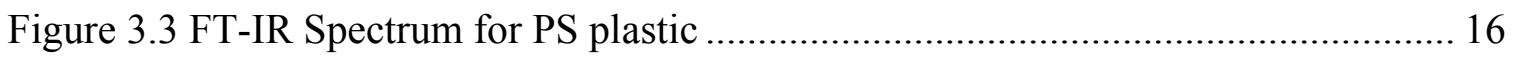

Figure 3.4 FT-IR Spectrum for PC plastic............................................................. 17

Figure 3.5 Camera and Computer Set-up for settling velocity measurements. ............... 18

Figure 3.6 Settling Tank for velocity measurements ............................................... 19

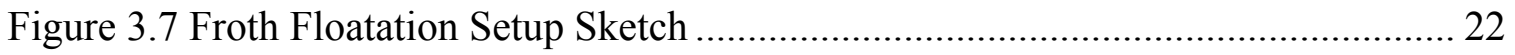

Figure 3.8 Froth Floatation Experimental Setup................................................ 23

Figure 3.9 Experimental Matrix for Froth Flotation ............................................... 25

Figure 4.1 SAN \%Ash Distribution in all CPUs, keyboards and printer samples............ 31

Figure 4.2 PS \%Ash Distribution in all CPUs, keyboards and printer samples .............. 32

Figure 4.3 SAN Density Distribution in all CPUs, printers and keyboard samples ........ 33

Figure 4.4 PS Density Distribution for all CPUs, keyboards and printer samples .......... 34

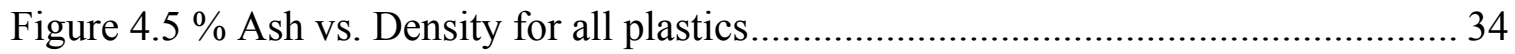

Figure 4.6 Comparison of sample SAN and reference SAN spectra ........................... 36

Figure 4.7 Comparison of sample PS and reference PS spectra .................................. 37

Figure 4.8 Comparison of sample PC and reference PC spectra ................................. 38

Figure 4.9 Sequence of images showing settling of ABS plastic in water ..................... 39

Figure 4.10 Effect of MIBC on ABS Floatability................................................... 40

Figure 4.11 Effect of MIBC on PS Floatability ..................................................... 41

Figure $4.12 \%$ Yield and \% Purity of PS in the top fraction when using $1 \mathrm{ml} \mathrm{MIBC} \ldots . . .43$

Figure $4.13 \%$ Yield and \% Purity of ABS in the top fraction when using $1 \mathrm{ml}$ MIBC... 43 
Figure $4.14 \%$ Yield and \% Purity of ABS in the bottom fraction when using $1 \mathrm{ml} \mathrm{MIBC}$

Figure 4.15 Material Balance for Two-Stage Floatation Setup (no recycle) using 1ml MIBC \& batch time of 6 minutes 46

Figure 4.16 Material Balance for Three-stage Floatation Setup (no recycle) using $1 \mathrm{ml}$ MIBC \& batch time of 6 minutes

Figure 4.17 Material Balance for Two-Stage Floatation Setup (with recycle) using 1ml MIBC \& batch time of 6 minutes 48

Figure 4.18 Material Balance for Three-stage Floatation Setup (with recycle) using $1 \mathrm{ml}$ MIBC \& batch time of 6 minutes

Figure 4.19 Effect of Oleic Acid on ABS Floatability ............................................. 51

Figure 4.20 Effect of Oleic Acid on PS Floatability................................................. 52

Figure $4.21 \%$ Yield and \% Purity of PS in the top fraction when using $1 \mathrm{ml} \mathrm{MIBC}$ and $10 \mathrm{ml}$ oleic acid emulsion

Figure $4.22 \%$ Yield and \% Purity of ABS in the top fraction when using $1 \mathrm{ml} \mathrm{MIBC}$ and $10 \mathrm{ml}$ oleic acid emulsion 53

Figure $4.23 \%$ Yield and \% Purity of ABS in the bottom fraction when using $1 \mathrm{ml} \mathrm{MIBC}$ and $10 \mathrm{ml}$ oleic acid emulsion 53

Figure 4.24 Effect of Dodecylamine Hydrochloride on ABS Floatability ...................... 55

Figure 4.25 Effect of Dodecylamine Hydrochloride on PS Floatability ........................ 55 Figure $4.26 \%$ Yield and \% Purity of PS in the top fraction when using $1 \mathrm{ml} \mathrm{MIBC}$ and 2 gm amine 56 
Figure $4.27 \%$ Yield and \% Purity of ABS in the top fraction when using $1 \mathrm{ml} \mathrm{MIBC}$ and 2 gm amine. 56

Figure $4.28 \%$ Yield and \% Purity of ABS in the bottom fraction when using $1 \mathrm{ml} \mathrm{MIBC}$ and 2 gm amine 57

Figure 4.29 Yields and Purities for PS with different surfactant-frother combinations ... 59

Figure 4.30 Yields and Purities for ABS with different surfactant-frother combinations 60

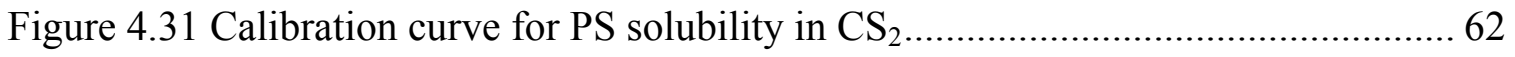

Figure 4.32 Flotation results for 'pure' and 'mixed' ABS using only $1 \mathrm{ml} \mathrm{MIBC} \mathrm{\ldots .......} 62$

Figure 4.33 Flotation results for 'pure' and 'mixed' PS using only $1 \mathrm{ml} \mathrm{MIBC}$ 63 


\section{List of Tables}

Table 3.1 Surfactant type and amounts used in the experimental matrix 24

Table 4.1 CPU Plastics Composition Summary .................................................. 28

Table 4.2 Keyboard Composition Summary …...................................................... 29

Table 4.3 Printer Composition Summary ............................................................... 30

Table 4.4 Purity and Yield for ABS and PS in various multi-stage floatation set-ups using

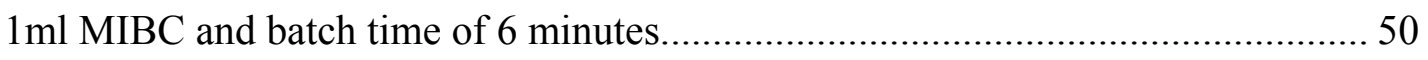

Table 4.5 Purity and Yield for ABS and PS in various multi-stage floatation set-ups (with recycle) using $1 \mathrm{ml} \mathrm{MIBC,} 10 \mathrm{ml}$ oleic acid emulsion and a batch time of 4 minutes

Table 4.6 Purity and Yield for ABS and PS in various multi-stage floatation set-ups (with recycle) using $1 \mathrm{ml}$ MIBC and 2 gm amine 57

Table 4.7 Calibration Data for PS Solubility in $\mathrm{CS}_{2}$

Table 4.8 Comparison of purity and yield for 'pure' and 'mixed' ABS and PS in multistage flotation set-ups using only $1 \mathrm{ml} \mathrm{MIBC}$ at a batch time of 6 minutes........

Table A.1 Settling Velocity Data for Dell QuietKey Keyboard Casing (HIPS) 89

Table A.2 Settling Velocity Data for PCS CPU Unit Creamish Plastic (ABS). 89

Table A.3 Flotation Data for ABS with only MIBC frother. 90

Table A.4 Flotation Data for PS with only MIBC frother 90

Table A.5 Flotation Data for ABS with MIBC Frother and Dodecylamine Hydrochloride surfactant 90

Table A.6 Flotation Data for PS with MIBC Frother and Dodecylamine Hydrochloride as surfactant 91 
Table A.7 Flotation Data for ABS with MIBC Frother and Oleic Acid - $\mathrm{NaOH}$ emulsion

Table A.8 Flotation Data for PS with MIBC Frother and Oleic Acid - NaOH emulsion 91

Table A.9 Flotation Data for 'Pure' and 'Mixed' ABS with $1 \mathrm{ml} \mathrm{MIBC}$ Frother and no

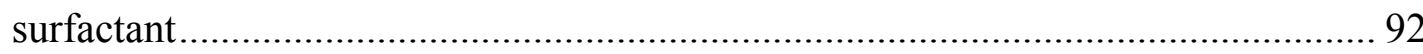

Table A.10 Flotation Data for 'Pure' and 'Mixed' PS with $1 \mathrm{ml}$ MIBC Frother and no

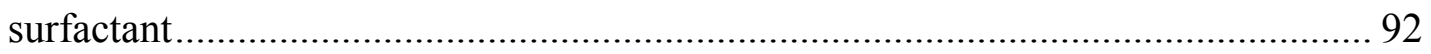




\section{Introduction}

Plastics are used in the manufacture of electronic goods because they are durable, lightweight, flexible, cost-effective, corrosion-resistant, and have excellent insulation properties. These properties allow manufacturers to produce highly engineered electronics products, while also allowing rapid response to changing consumer demands [1].

In the past, nearly all electronic equipment was either land-filled or incinerated for its fuel value. Recently, a loose network of recycling and refurbishing companies have started to disassemble end-of-life (EOL) electronics products and extract the precious metals, and other valuable components while disposing of the remaining parts. However, due to increasing environmental concerns and public awareness, it is essential to find an environmental and economic method to recycle EOL electronic equipment. It is difficult to determine the best practice to recycle because of a lack of information on reasonable estimates of the quantity of EOL goods discarded, variability in the quantity, type and composition of these goods with time and location, and a paucity of existing technologies to satisfactorily separate constituent plastics having properties comparable to the virgin polymers [2].

Post-manufacturing EOL equipment is relatively easy to handle and recycle. This is because, although they are generally comprised of off-spec and inferior quality goods from a manufacturing unit, their composition is well defined. Post-consumer EOL goods are much more difficult to segregate and recycle because they come from a highly distributed source and their composition is much broader than post-manufacturing EOL equipment. In addition, these EOL-derived plastics are strengthened and treated with a 
wide variety of additives such as fillers, fire-retardants, dyes, and surface coatings that are required in order to meet consumer needs. Also, post-consumer EOL goods tend to be much older than post-industrial EOL goods and hence, pose a greater challenge for recovering the polymers.

According to a study by the U.S. EPA [3], almost half of all post-consumer EOL goods are composed of metals while plastics make up one-third of their weight. The difficulty in handling post-consumer EOL goods on an industrial scale, apart from the sheer volume, is the unpredictability in the variety and composition of mixed plastics in the input stream. This makes the automation of the process almost impossible, and manual pre-sorting of the input stream becomes an important step in the effective separation of the mixed plastics. Moreover, the composition of mixed plastics in the input stream will change with time as the "new and improved" consumer electronic goods of today become the EOL components of tomorrow.

Commingled plastics can be used as filler in asphalt or other space-filling applications, but higher returns can be achieved if the plastics can be economically sorted and used in a high-end application. To make the EOL recycling economically attractive, the recycled polymers should have mechanical and rheological properties comparable to those of the virgin polymers. An alternative would be to use blends of virgin and recycled polymers such that the properties of the blended polymer are comparable to those of the virgin material.

The objective of this research is to investigate the composition of keyboards and casings of personal computers, and other EOL components, as representative of postconsumer EOL equipment. Specifically, the characterization of these plastics in terms of 
their density, qualitative composition and inorganic content will be investigated. In addition, a froth flotation method based on surface chemistry differences between plastics will be investigated to evaluate the degree of separation and yield that can be achieved using multiple stages of these units. 


\section{Literature Review}

Efforts to recycle plastic (mainly PET) were made almost as soon as they were introduced in the market in the late 1970's. Today, recycling of beverage bottles and soda containers is an established technology. Most of the plastics recycled today are polyethylene terephthalate (PET), polyethylene (PE), polyvinyl chloride (PVC) and polypropylene (PP). The early 1990's saw an increasing public awareness in the recycle of engineering plastics such as High Impact Polystyrene (HIPS) and Acrylonitrile Butadiene-Styrene copolymers (ABS). However, because of the versatility and flexibility of these engineering plastics, it is difficult to design an automated recycling facility capable of handling all of them [4]. Diminished physical properties resulting from polymer-polymer incompatibility, discoloration, and degradation result in a relatively low price for mixed plastics as compared to virgin polymers. Hence, selective separation of post-consumer products appears to be one of the weakest links in the plastic recycling industry [5]. In addition, when many polymers are granulated, inhomogenities in the micro-voids, fillers or levels of crystallinity that get averaged in larger particles become more important, further spreading the density distribution of polymers.

The variability of the EOL waste plastics, supplied by recyclers, requires a presorting step to produce streams containing a 'prominent' type of plastic prior to using various other separation techniques. The plastic parts obtained from equipment recyclers are either manually or automatically identified and pre-sorted using near-infrared (NIR/FTIR) and mid-infrared (MIR) spectroscopy. The 'pre-sorted' streams are then shredded and dry-processed during which metal and other contaminants are removed. Magnets remove much of the ferrous metal, while some of the non-ferrous metals are 
ejected from the mix by eddy current separation. An air classification system is used to blow the lighter contaminants such as foam, cork and labels $[6,7]$.

The streams are then 'mechanically' separated using float-sink techniques and hydrocyclones, which utilize the differences in the bulk density of the polymers to achieve a degree of separation. However, as many polymers in the mixed plastic stream have very similar densities, it is sometimes necessary to supplement the 'mechanical' separation techniques with 'surface based' processes. These so called 'surface based' separation techniques rely on the differences in surface properties of the various polymers to achieve separation. 'Surface based' separation techniques such as froth flotation and triboelectric separations have been successfully applied to mixed plastic streams to yield 'high purity' recycled polymers $[8,9]$.

Both the 'mechanical' and 'surface based' techniques used to separate plastics have been derived from those used in the mineral processing industry. Gravity separation methods have been used to treat a great variety of minerals such as heavy metal sulfides, tin ores, iron and tungsten ores and even coal [10]. 'Surface based' techniques such as froth flotation have been used in the mineral industry in the recovery of phosphate rock, sulfide ores and iron and copper ores [11].

\section{1 'Mechanical' Separations}

\subsubsection{Heavy Media Separation}

Heavy media separation is based on the principle that, if particles with a range of specific gravities are placed in a medium of fixed specific gravity, those with specific

gravities lower than that of the medium will float and can be collected by skimming, and 
those particles with specific gravities higher than that of the medium will sink and can be collected by sedimentation and filtration [5].

Heavy media separation has been used to pre-concentrate iron, tin and tungsten ores as well as non-metallic ores of fluorite and even diamonds. Jigs are another form of basic gravity separators that have been used for a long time in the mineral industry. The separation of materials of different specific gravities is accomplished in a bed that is rendered fluid-like by a pulsating current of water so as to produce stratification. Jigs have been used in the treatment of gold, diamonds, iron ore, etc., as well as coal cleaning devices.

Shaking tables have also been used to achieve lateral separation of materials with different specific gravities by employing slurries of materials to flow over an inclined, flat, vibrating table. They are primarily used for the concentration of ores of tin, iron and mica, as well as for coal cleaning [10].

It has been reported that a mixed stream of PET and PVC can be separated from mixed plastics by using aqueous solutions of $\mathrm{Ca}\left(\mathrm{NO}_{3}\right)_{2}$ using a combination of heavy media separators and hydrocyclones [5]. Application of similar technology for plastics from EOL equipment has also been indicated in a WVU Report by MBA Polymers Inc [12].

\subsubsection{Hydrocyclones}

A hydrocyclone transfers fluid pressure energy into rotational fluid motion, which causes relative motion of particles suspended in the fluid, thus permitting separation of the materials [8]. Hydrocyclones can be used to 'classify' a solid mixture into two streams - the 'underflow' and the 'overflow'. If the slurry or liquid media has density 
intermediate to those of the components to be separated, the heavier components 'sink' to the underflow, while the lighter components 'float' to the overflow.

Hydrocyclones have been used as a density separation device in the coal industry and paper / pulp industry. In the coal industry, they are primarily used in the removal of rocks from coal, while they are used to separate sand from paper pulp in the paper and pulp industry [9].

In many cases, density techniques can be used to separate polymers within the same family containing different additives. As density based separations make use of bulk material properties, they are more predictable and reliable than techniques exploiting surface characteristics that can easily vary with surface contamination such as dirt, oils, coatings, etc. According to a study conducted by MBA Polymers Inc. [12], the densities of plastics used in EOL goods ranges from as low as $0.90 \mathrm{gm} / \mathrm{cm}^{3}$ to as high as 1.45 $\mathrm{gm} / \mathrm{cm}^{3}$, with more than one plastic present in every $0.01 \mathrm{gm} / \mathrm{cm}^{3}$ density increment. This necessitates the use of 'chemical' separation techniques to further separate the 'cuts' obtained by density separation.

\section{2 'Surface Based' Separation}

\subsubsection{Froth Flotation}

The basic principle of froth flotation lies in the different affinities exhibited by the solid particles for the liquid media. In the case of aqueous media, the hydrophobic particles rise to the top, while the hydrophilic particles remain in the bulk liquid phase. Certain chemicals known as surfactants are used to enhance this difference in affinities so as to facilitate easier separation of the solid particles. Surfactants are classified based on 
their function and on their chemical composition [13]. A surfactant whose primary role is to render the solid surface hydrophobic is called a collector. Surfactant whose primary role is to lend the required stability to the top froth layer in a flotation cell by providing adequate stability to the air bubbles in the system are referred to as frothers. These are usually non-ionic surfactants that can enhance the rate of film thinning and contribute to the stability of particle-bubble aggregates. In addition, salts can be used to alter the density of the liquid medium [14].

Froth flotation has long been used in the mineral industry in the beneficiation of metal ores and in the coal industry for purposes of coal cleaning [15]. Flotation techniques have been used to treat sulfide ores of copper, zinc and lead; treatment of nonmetallic ores of fluorite, phosphate and fine coal. Specific separations from complex ores of lead-zinc, copper-zinc have also been possible through froth flotation.

Although plastics are generally hydrophobic, their wetting characteristics can be selectively adjusted by addition of surfactants. ABS and HIPS are completely incompatible with each other to the extent that $2 \%$ contamination of HIPS in ABS significantly lowers the mechanical properties of ABS [16]. The very close densities of ABS (1.04-1.13 gm/ $\left.\mathrm{cm}^{3}\right)$ and HIPS (1.02-1.09) render the density separation techniques only partially effective.

The separation of ABS / HIPS from mixed plastics has been reported by a patented process [17] which suggests multistage froth floatation tanks of increasing media specific gravity from $1.0 \mathrm{gm} / \mathrm{cm}^{3}$ to $1.5 \mathrm{gm} / \mathrm{cm}^{3}$. The separation is carried out in a tank having solution density between $1.055 \mathrm{gm} / \mathrm{cm}^{3}$ and $1.07 \mathrm{gm} / \mathrm{cm}^{3}$, surface tension between 22 dynes $/ \mathrm{cm}$ to 40 dynes $/ \mathrm{cm}$ and $\mathrm{pH}$ in the range of 1.77 to 2.05 . Acetic acid is used to 
achieve the desired range of density, $\mathrm{pH}$ and surface tension, while salt, $\mathrm{HCl}$ and surfactants are used to 'fine tune' them, respectively. Along similar lines, strongly alkaline solutions of $\mathrm{NaOH}$ and $\mathrm{KOH}$ with a non-ionic surfactant, Rhodasurf $91-6\left(\mathrm{C}_{9^{-}}\right.$ $\mathrm{C}_{11}$ ethoxylated alcohols), have been used to separate PET / PVC mixtures [18].

\subsubsection{Electrostatic Separation}

The principle on which a triboelectric separator works is that when dissimilar particles are rubbed against each other, a transfer of electric charge occurs and the resulting differences in surface charges can be used to separate the particles in an electric field [19].

The particles are allowed to rub against each other in a rotating aluminum drum where the transfer of surface charges takes place. They are then allowed to fall through an intensive horizontal electric field. The charged particles are attracted towards the opposite electrode, while the uncharged / neutral particles fall undeflected through the field. The walls of the charged chamber can be altered to manipulate the intensity of the electric field that, in turn, affects the particle residence time and hence, the efficiency of separation. A number of compartments can be used to collect and fractionate the falling particles. An optimal separation would produce high purity products at the extreme compartments with low weight percentages in the middle chambers. The "mixed" material collected in the middle chambers is either discarded or recycled to the charging drum to achieve better separation. Multiple stages can be employed to achieve the desirable purity and yield. In the mineral processing industry, electrostatic separators have been used to clean zircon, monazite, and ilmenite concentrates [10]. 
It is reported that a mixture of HIPS / ABS can be separated to a $98 \%$ purity, while a PC / PVC mixture can be separated into a stream of 95\% PVC.

\subsection{Other Processes}

As a variant of the froth flotation process, a recent patent [20] describes a differential density alteration (DDA) device that heats an aqueous slurry of mixed plastics under pressure to cause a change in the apparent density of one or more of the polymers by at least $0.03 \mathrm{gm} / \mathrm{cm}^{3}$. A foaming mixture of water, steam, $\mathrm{CO}_{2}$ and a hydrocarbon is also added to the slurry. Releasing the pressure causes the 'lighter' polymers to float to the surface with the foaming agent, thus facilitating the separation of 'near density' polymers.

Another recent patent [21] discusses a solvent process to recover plastics from automobile shredder residue (ASR). A plastic-rich stream, after the removal of fines, is sequentially contacted, under essentially atmospheric pressure, with a series of solvents such as hexane for the removal of automotive fluids; acetone to remove ABS; EDC, THF or a low-boiling ketone to remove PVC; and a mixture of xylene and toluene to remove PP and PE. The solvents are subsequently recovered from the streams by evaporation; thereby yielding streams rich in ABS, PVC and one or more of PP and PE. 


\section{Experimental Set-up and Procedure}

The primary purpose of this research was to collect keyboards, printers and CPUs as representative samples of EOL equipment, dismantle them, generate data for the typical quantities of plastics used in them, and characterize the plastics in terms of their densities, main composition, ash contents, and settling velocities. It was further desired to design a froth flotation scheme to separate a binary mixture of plastics using appropriate surfactants.

\subsection{Preliminary Experiments}

\subsubsection{Dismantling of EOL Equipment}

Obsolete keyboards, printers and CPUs were obtained from the WVU Surplus House. The Federal Communications Commission (FCC) Identification Number was noted and then each piece of equipment was carefully dismantled to retrieve as many plastic components as possible. A material balance was established based on the amount of plastic and metals for each component.

\subsubsection{Shredding}

The plastic components were fed into a FRITSCH Power Cutting Mill "pulverisette 25" (Figure 3.1) to obtain shredded samples using a $4 \mathrm{~mm}$ sieve casket. The shredded samples obtained also had an average size of about $4 \mathrm{~mm}$. They were stored in labeled bottles for further use. A database of information such as percent ash content, bulk density, and bulk composition was established for these plastics. 


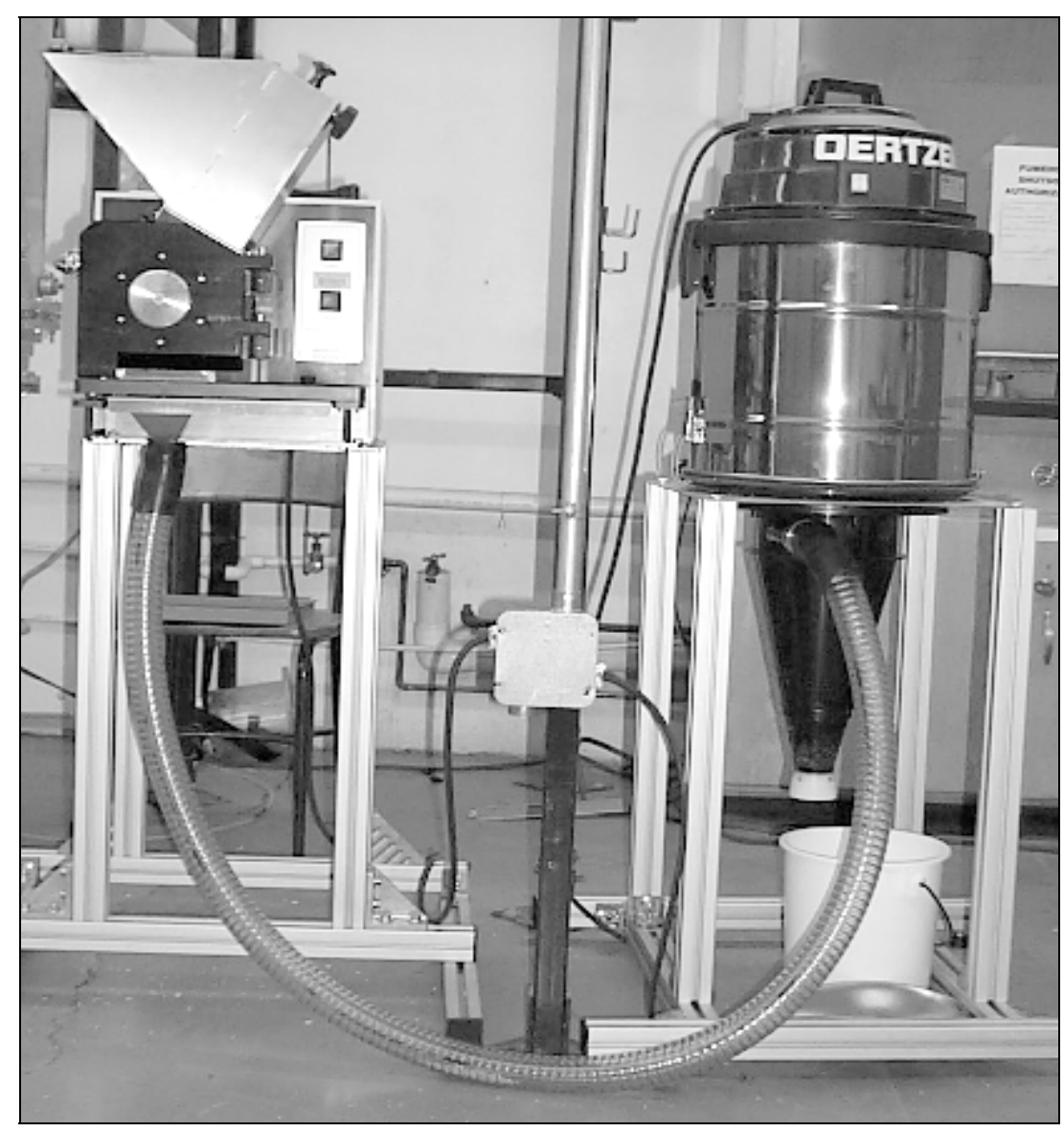

Figure 3.1 FRITSCH Power Cutting Mill "pulverisette 25"

\subsubsection{Ash Analysis}

A large number of organo-metallic compounds are used as additives in engineering plastics to enhance their mechanical and physical properties. Additives such as lubricants, antioxidants, antistatic agents, colorants, flame-retardants, plasticizers, heat \& UV stabilizers are commonly found in the plastics used in computer parts. An ash analysis was performed on the plastic samples in order to estimate the fraction of inorganic binder material present in them. A few grams of the shredded samples were heated in air in a Fisher Scientific Isotemp ${ }^{\circledR}$ Programmable Muffle Furnace (650-750 Series) at a temperature of $900{ }^{\circ} \mathrm{C}$ for an hour in silica crucibles in accordance with 
ASTM D-5630. The difference in the weights of the samples and ash in the crucibles was used to estimate the percent ash content in the plastic samples.

\subsubsection{Density measurements}

Bulk density of the samples was determined using an AccuPyc 1330 Helium Pycnometer from Micrometrics ${ }^{\circledR}$. It employs Archimides' principle of fluid displacement to determine the volume of solid objects. A known amount of sample (approximately 3 to 4 grams) was placed in the measurement cell and five replicate volume measurements were taken by the instrument, which were then used to calculate the average density. The typical density values of the plastics used in this work varied in the range of $1.03 \mathrm{gm} / \mathrm{cm}^{3}$ to $1.41 \mathrm{gm} / \mathrm{cm}^{3}$, with an approximate standard deviation of about $0.001 \mathrm{gm} / \mathrm{cm}^{3}$.

\subsubsection{Plastics Identification}

The shredded particles were analyzed using a Spectrum One FT-IR Spectrometer from Perkin Elmer Instruments. The major composition of the plastic particles from every EOL equipment was determined by comparing the sample IR spectra with the built-in database. A qualitative study of the major composition of plastics was possible by locating, specifically, patterns characteristic to key functional groups in the polymer molecule.

The Spectrum One software does not recognize butadiene separately in the ABS plastic as the peaks corresponding to bonds in butadiene, viz. $\mathrm{C}-\mathrm{C}$ and $\mathrm{C}=\mathrm{C}$ bonds, overlap with those present in the styrene and acrylonitrile polymers in ABS. Hence, the software reports the sample spectrum as Styrene-Acrylonitrile (SAN) copolymer. The spectra for SAN copolymer obtained from a Professional Computer Systems (PCS) CPU 
unit is shown in Figures 3.2. The characteristic peak for nitrile bond $(C \equiv N)$ is observed at $2230 \mathrm{~cm}^{-1}$. The peaks around $3000 \mathrm{~cm}^{-1}$ correspond to the $\mathrm{C}-\mathrm{H}$ bonds in the aliphatic chains and aromatic rings in the molecule, while the peaks at $1500 \mathrm{~cm}^{-1}$ and $750 \mathrm{~cm}^{-1}$ are simply their overtones. The insert in Figure 3.2 shows the repeating molecular structure of ABS copolymer.

Figure 3.3 shows a spectra for PS polymer taken from the keyboard casing of a Dell Quietkey Keyboard. Comparing with Figure 3.2, the spectrum appears to be composed of all the same peaks except for the absence of the nitrile peak in the PS spectrum, which can be verified from the absence of the $\mathrm{C} \equiv \mathrm{N}$ bond in the insert in the PS spectrum as against the presence of the bond in the ABS insert. A spectrum for PC plastic taken from an HP 870 printer is shown in Figure 3.4. A peak around wave number of $1730 \mathrm{~cm}^{-1}$ indicates the presence of a carbonyl group $(\mathrm{C}=\mathrm{O})$, characteristic of polycarbonate (PC). The insert in Figure 3.4 shows the repeating molecular structure for polycarbonate. 


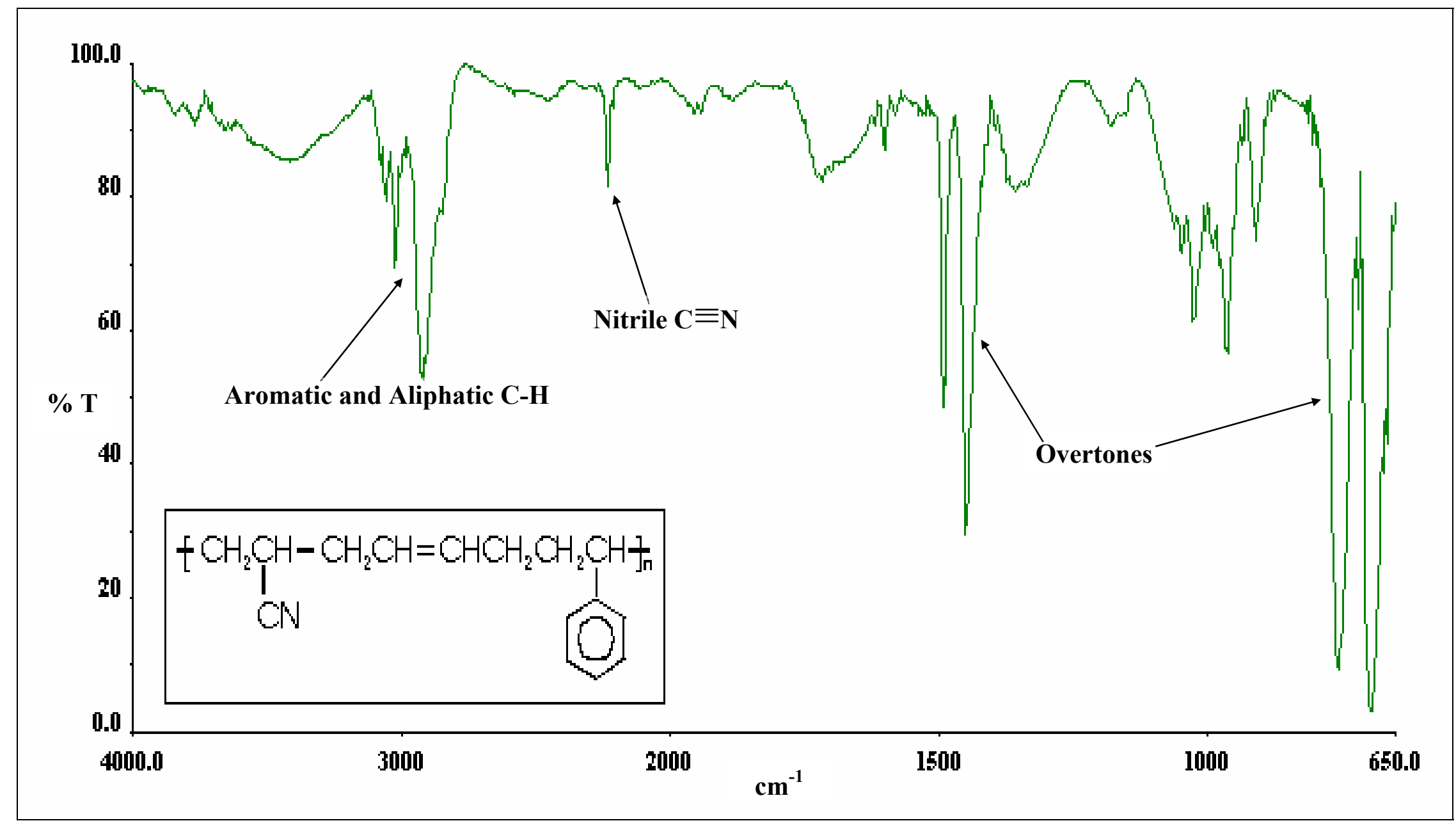

Figure 3.2 FT-IR Spectrum for SAN plastic 


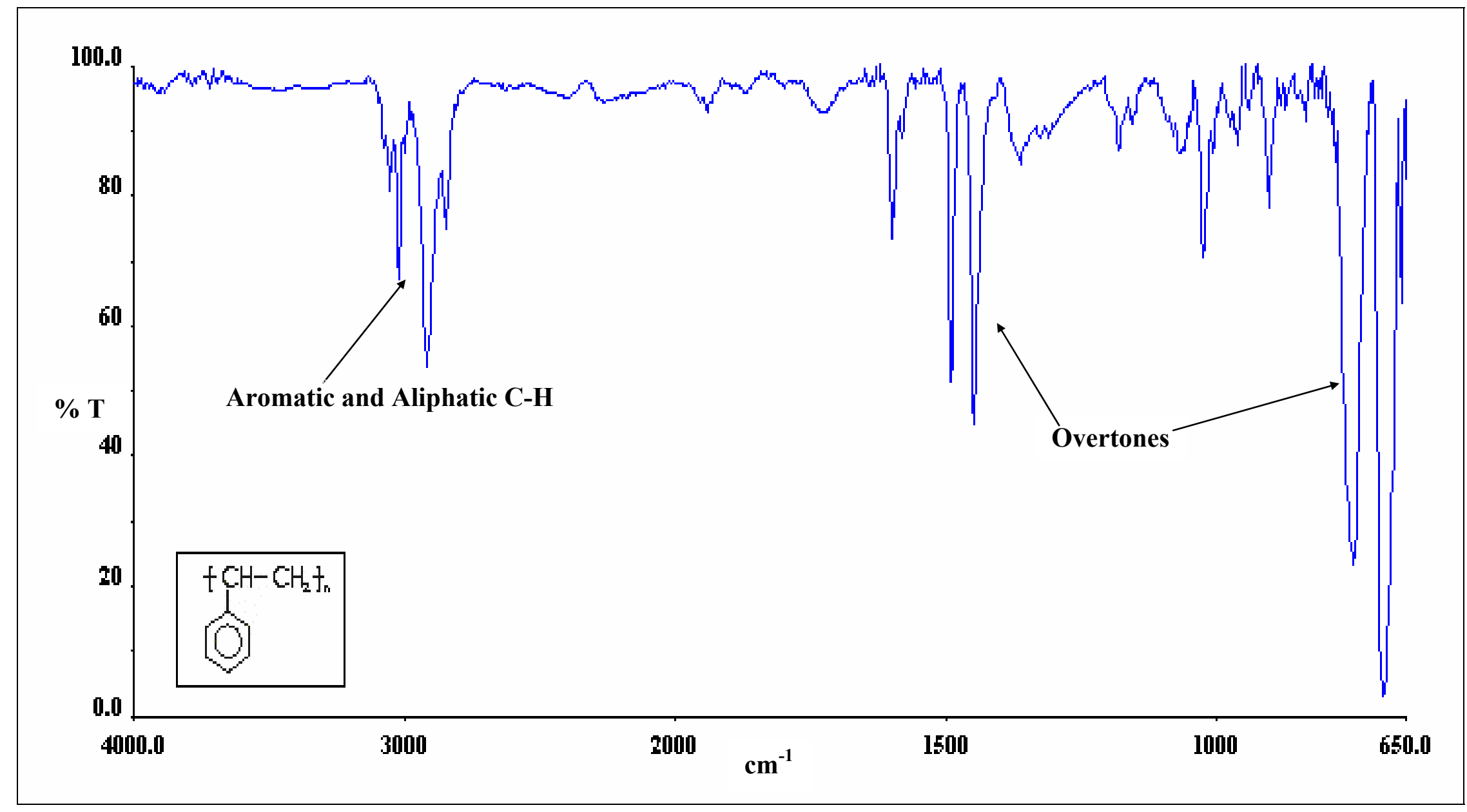

Figure 3.3 FT-IR Spectrum for PS plastic 


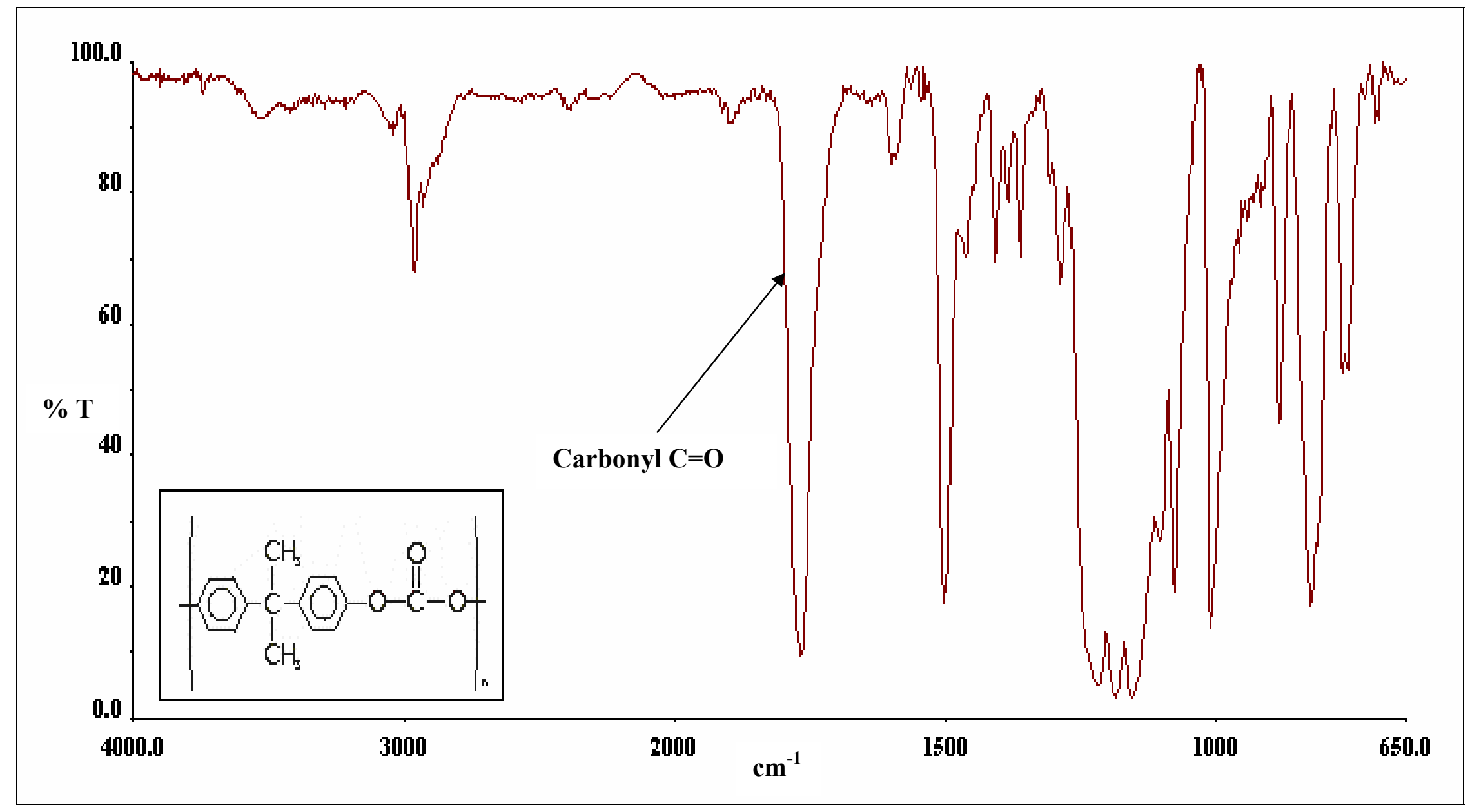

Figure 3.4 FT-IR Spectrum for PC plastic 


\subsubsection{Settling Velocity Measurements}

A gravity separation technique was attempted to separate the plastic particles based on their settling velocities. The terminal velocities for particles with simple geometric shape could be easily calculated from theory. However, for the shredded plastics in the current work, such calculations yielded unrealistic or erroneous results. Therefore, a series of experiments was performed to obtain settling velocity data.

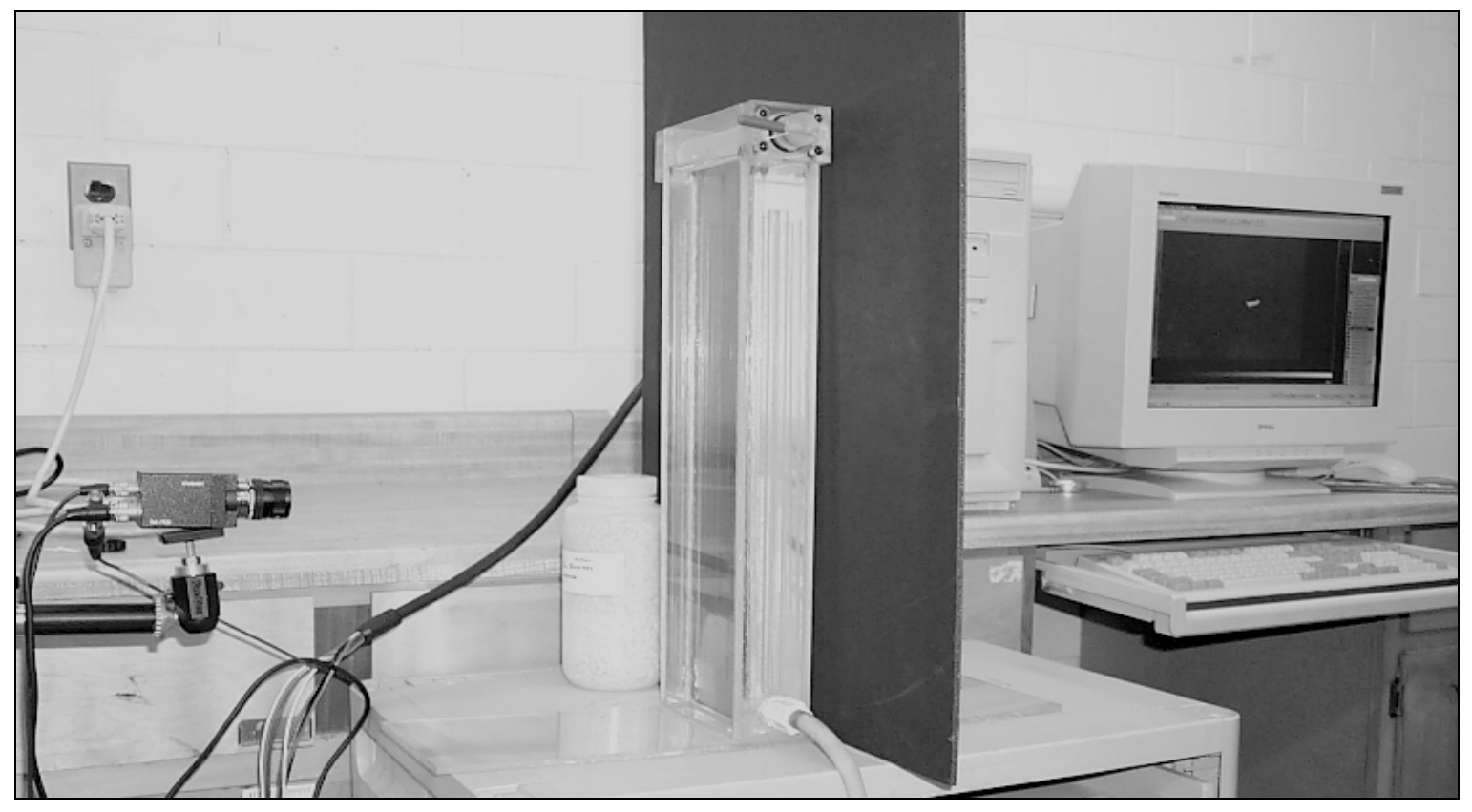

Figure 3.5 Camera and Computer Set-up for settling velocity measurements.

The settling experiments were conducted in a rectangular tank $(12 \mathrm{~cm} \times 50 \mathrm{~cm} \times 5$ $\mathrm{cm}$ ) made of plexiglass ${ }^{\circledR}$, (Figures 3.5 and 3.6). The tank was made rectangular so as to reduce image distortion due to a curved surface, which is a factor in circular columns. Two 15 -inch $(38.1 \mathrm{~cm})$ rulers were attached vertically to the sides of the tank so as to help calibrate the images of the settling particles. A rotating inlet arrangement was 
provided for the particles to be 'soaked' in water before they were allowed to fall in the tank. A few drops of soap solution were also added to the water, to reduce surface tension and minimize any air bubbles from attaching to the settling particles.

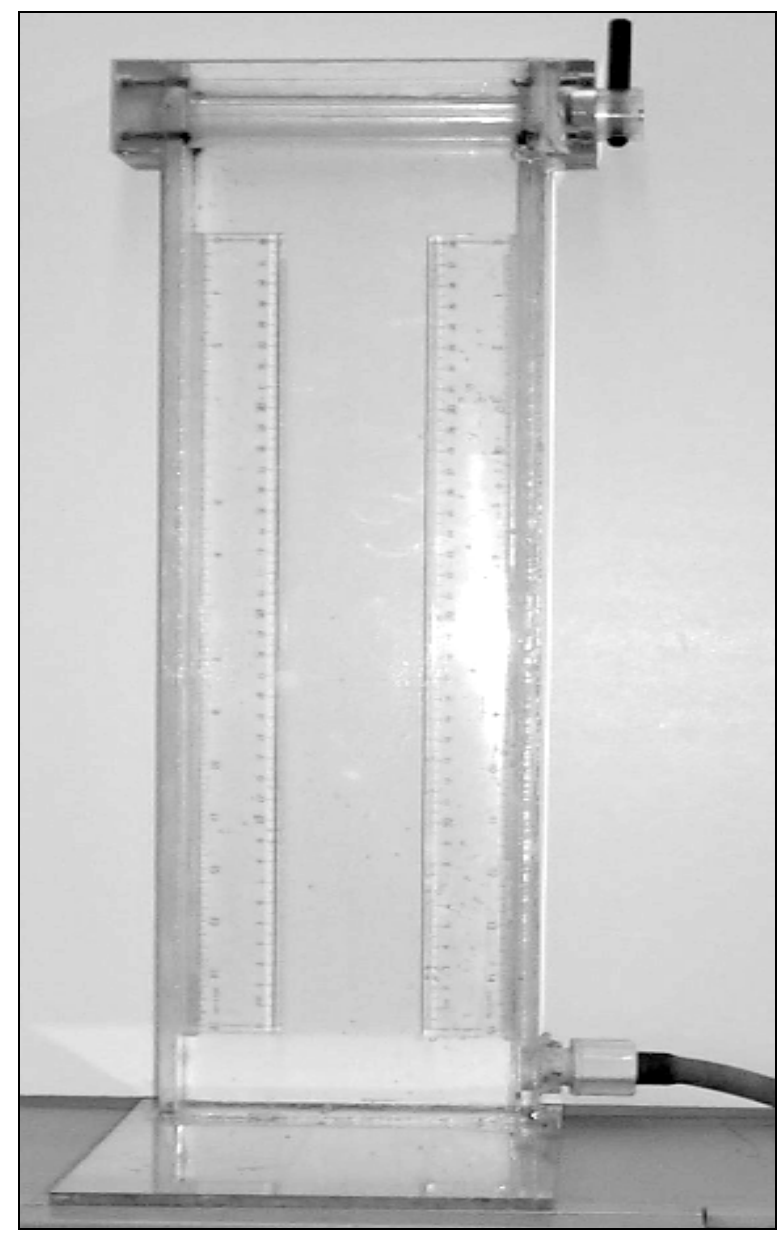

Figure 3.6 Settling Tank for velocity measurements

A Pulnix (TM-7CN) CCD camera was used to photograph the motion of the falling particles at 30 frames / sec. Video imaging software (StreamPix v 2.1.0) was used to capture video sequences of the falling particles. From a recorded video sequence of the particles falling through a distance of about $10 \mathrm{~cm}$, a number of consecutive frames were saved as image files. Image analysis software (Visilog Pro v 5.4) was used to analyze 
these image files to identify the particles and estimate the co-ordinates of their centroid, thus enabling an estimate of their settling velocities. Preliminary estimates of the settling velocities of the EOL plastic samples were computed using video analysis to ensure that the particles have indeed reached their terminal settling velocities in the field of view of the camera.

\subsection{Sample Selection for Froth Flotation}

The HIPS sample was selected from a Dell QuietKey Keyboard Casing unit. The selected HIPS sample had a density of $1.0345 \mathrm{gm} / \mathrm{cm}^{3}$ and an ash content of $0.4979 \%$. The ABS sample was selected from a Professional Computer Systems (PCS) CPU Unit having a density of $1.0583 \mathrm{gm} / \mathrm{cm}^{3}$ and an ash content of $0.8726 \%$. The choice of ABS and HIPS samples was arbitrary; however care was taken that the densities of both samples were close to each other and that neither had a very high ash content.

\subsection{Froth Flotation}

A basic flotation vessel was designed to separate ABS and HIPS, since they cannot be satisfactorily separated by heavy media separation alone. This was achieved by sparging air bubbles of appropriate size into a batch of mixed plastics in water through a rectangular steel sparger. The minimum size of air bubbles required to float the $4 \mathrm{~mm}$ plastic particles was determined from settling velocity measurement data. The air flow rate required was also based on settling velocity data. A factor of two was included in the selection of both the rectangular steel plate as sparger for air bubble dimensions as well as for the air flow rate that was maintained constant in the work. Typically, surfaceactive agents (surfactants) were used to alter preferentially the surface characteristics of 
specific plastics, thereby causing them to adhere to the rising bubbles. For a mixture of different particles, the 'hydrophobic' particles adhere to the air bubbles and rise to form a froth layer on the surface of the flotation vessel, while the 'hydrophilic' particles fall to the bottom of the vessel.

\subsubsection{Experimental Setup}

A rectangular tank of dimensions $15.24 \mathrm{~cm}$ x $15.24 \mathrm{~cm}$ x $121.92 \mathrm{~cm}(6$ " x 6" x 4') was made of $0.95 \mathrm{~cm}(3 / 8 ")$ thick plexiglass ${ }^{\circledR}$. A metallic plate sparger of dimensions 8.89 cm x $13.34 \mathrm{~cm} \times 0.32 \mathrm{~cm}$ thick $\left(3 \frac{1 / 2 "}{2} \times 5 \frac{1 / 4 "}{4} \times 1 / 8 "\right)$ was fitted to the bottom of the tank to aerate the column. Circular holes of approx. $1 \mathrm{~mm}(3 / 32$ ") dia. were drilled at a triangular pitch of about $3.2 \mathrm{~mm}(1 / 8$ "). A circular opening of 1 " dia. was made just above the sparger to drain the liquid and collect the 'heavies' after each run. A household strainer was used to collect the 'lighter' material floating with the froth at regular intervals. Figure 3.7 shows a sketch of the experimental setup of the froth flotation cell used in this work and Figure 3.8 shows an image of the flotation column. 


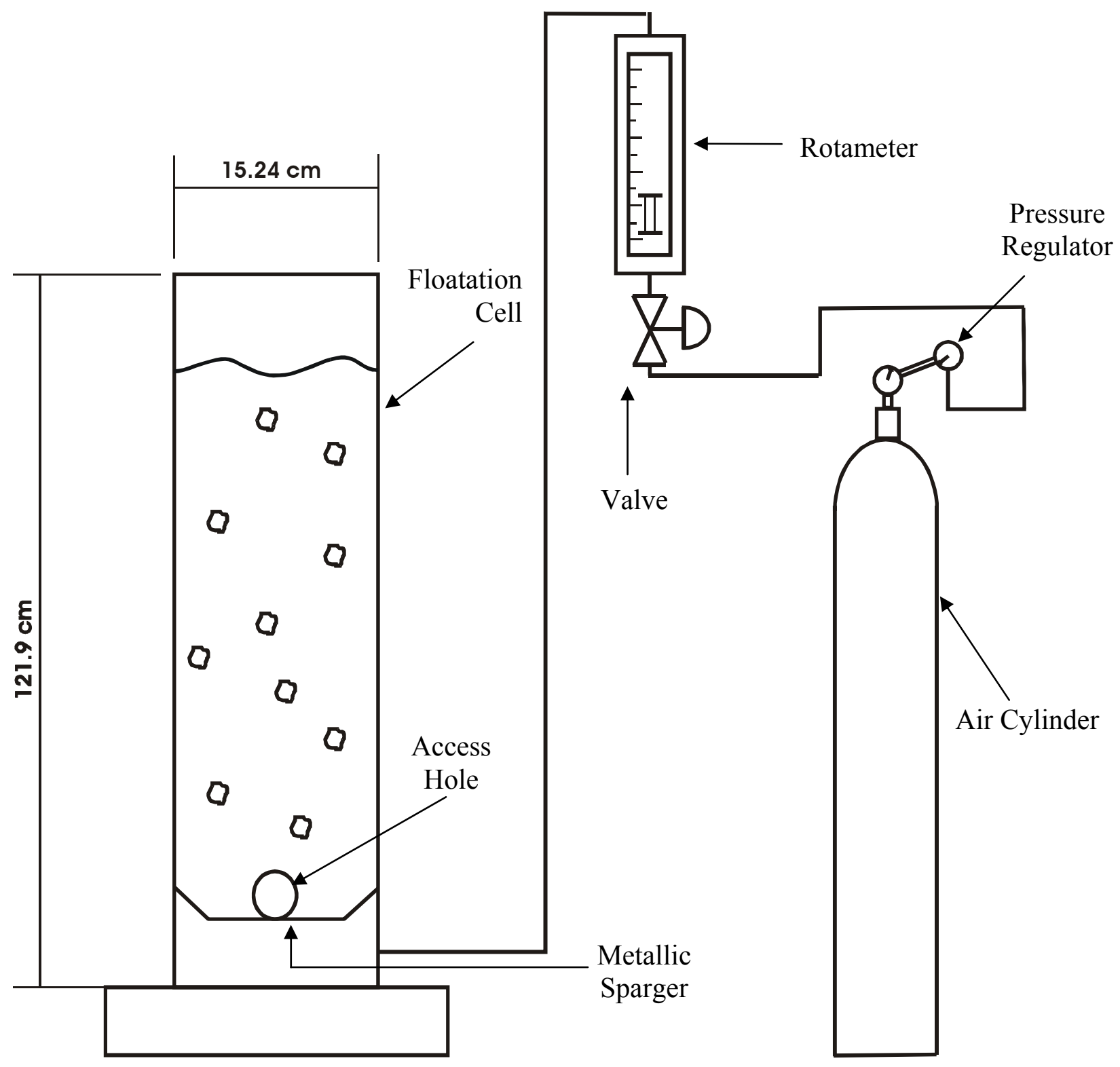

Figure 3.7 Froth Floatation Setup Sketch 


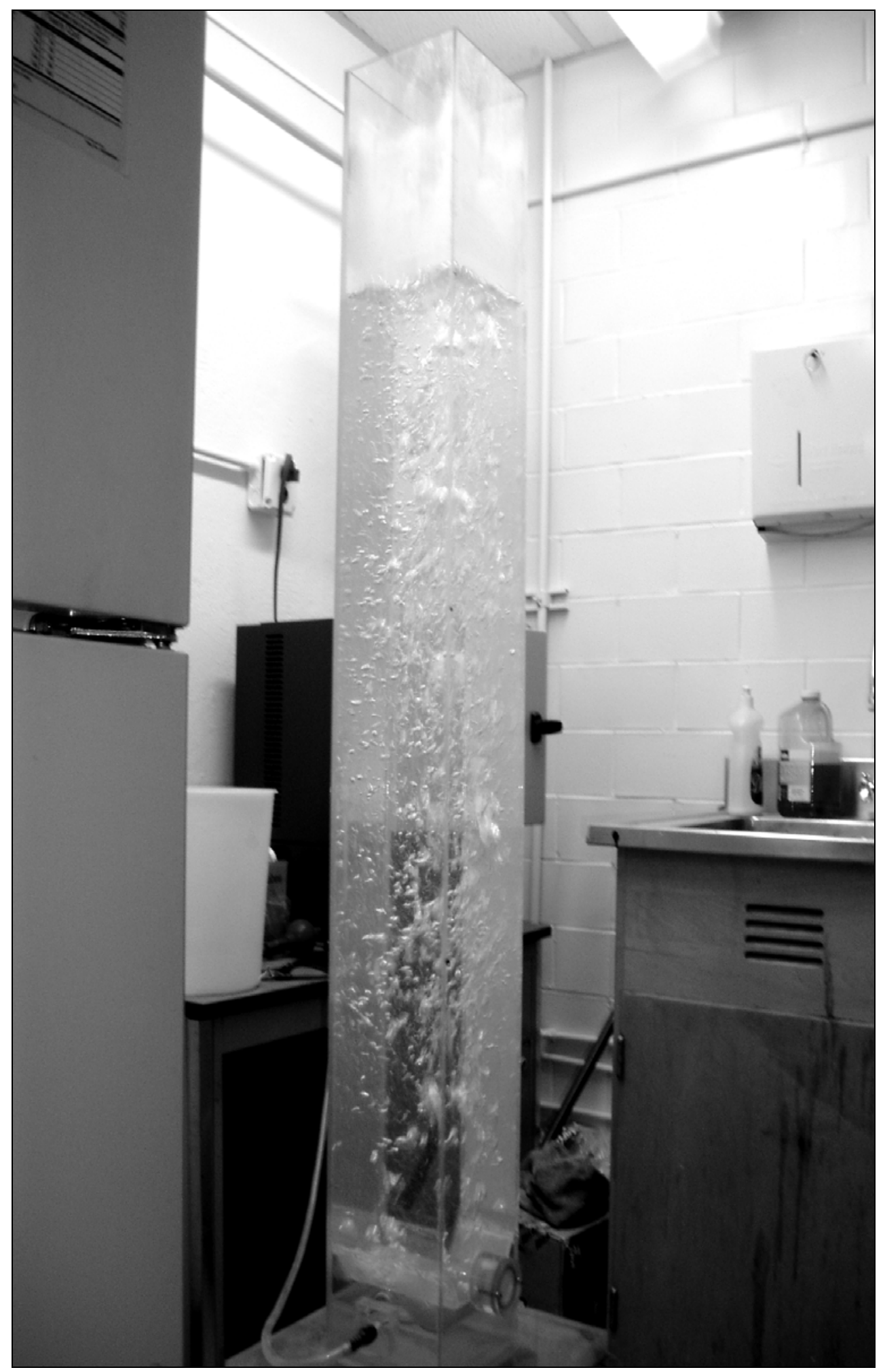

Figure 3.8 Froth Floatation Experimental Setup 


\subsubsection{Experimental Matrix}

The level of frother and two ionic surfactants were used as independent variables in the experimental matrix. Experimental runs were carried out at 3 different concentration levels of each chemical. Methyl isobutyl carbinol (MIBC) was used as the frother, while oleic acid and n-dodecylamine hydrochloride were used as the two surfactants. It was desired to observe the effect of completely different surfactants on the flotation and separation efficiency. It was decided to observe the effect of oppositely charged surfactant ions on the flotation and separation efficiency of HIPS and ABS. Hence, n-dodecylamine hydrochloride was chosen as the cationic surfactant, while oleic acid was representative of the anionic surfactant group.

Table 3.1 Surfactant type and amounts used in the experimental matrix

\begin{tabular}{|c|c|c|c|}
\cline { 2 - 4 } \multicolumn{1}{c|}{} & \multicolumn{3}{c|}{ Type } \\
\cline { 2 - 4 } \multicolumn{1}{c|}{} & Anionic & Neutral & Cationic \\
\hline Surfactant / Frother & Oleic Acid & MIBC & $\begin{array}{c}\text { Dodecylamine } \\
\text { hydrochloride }\end{array}$ \\
\hline Amount & $(0,10,20) \mathrm{ml}$ & $(1,3,5) \mathrm{ml}$ & $(0,2,4) \mathrm{gm}$ \\
\hline
\end{tabular}

The experimental matrix utilizing different amounts of MIBC, oleic acid emulsion and quaternary amine is shown in the following sketch (Figure 3.9). The matrix is represented in the form of volume of MIBC (in $\mathrm{ml}$ ), volume of oleic acid (in $\mathrm{ml}$ ) and weight of amine (in grams) used in each experimental run, viz (MICB, Acid, Amine). Only the points along the axes were considered for the experimental matrix. Since oleic acid and amine are found to have opposing effects on the floatability of both plastics, only one of them was considered in each experimental run as a surfactant along with 
MIBC in order to achieve separation with reasonable yield and purity. Further elaboration is given in section 4.6.4.
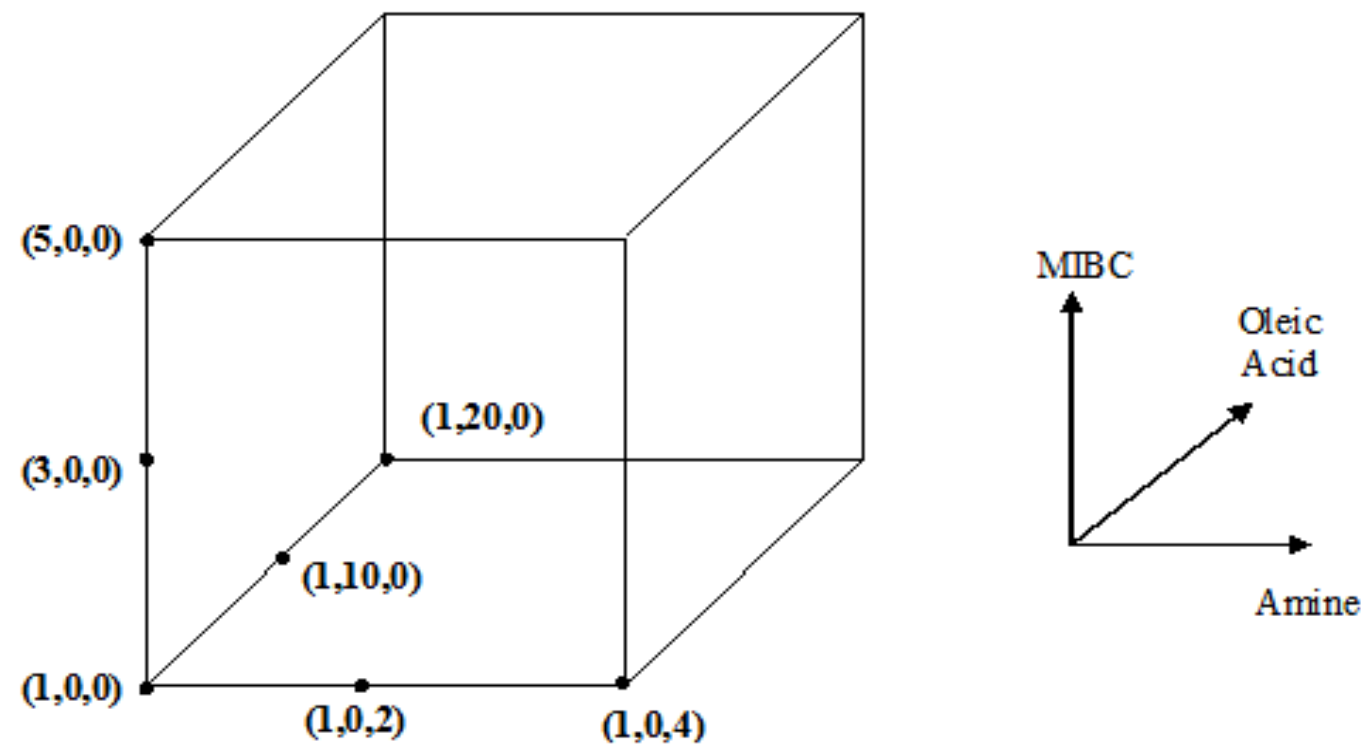

Figure 3.9 Experimental Matrix for Froth Flotation

\subsubsection{Experimental Procedure}

The tank was filled to a level of about $96.52 \mathrm{~cm}\left(3^{\prime 2} 2^{\prime \prime}\right)$ with water. A compressed air cylinder from Airgas, Inc. was used to supply air at $1.681 \mathrm{~atm}$ (10 psig). The flowrate of air was kept constant at 20 liters $/ \mathrm{min}\left(0.7062 \mathrm{SCFM}\right.$ or $\left.1.2 \mathrm{~m}^{3} / \mathrm{hr}\right)$ using an inline rotameter (Model No: VMRI - 010030) from Cole-Parmer. First, the chemicals were well mixed in the system by sparging air for about 5 minutes. Then the plastic samples were conditioned in the stagnant medium of previously added chemicals for 15 minutes, after which air was sparged again at 20 liters/min. The samples floating at the top were collected continuously at two-minute intervals for about 14 minutes. The remaining 
plastic particles were collected after draining the tank. The collected samples were washed, dried and weighed to yield cumulative floating weight fraction versus time data. The entire column was flushed with water after each experimental run to ensure the removal of all surfactants and dirt from the walls of the column.

\subsubsection{Surfactant Preparation}

$\underline{M I B C}$ : As MIBC is readily miscible in water on sufficient aeration, it is directly added to the flotation column in volumes of $1 \mathrm{ml}, 3 \mathrm{ml}$ and $5 \mathrm{ml}$.

Oleic Acid: Oleic acid is a liquid that is immiscible in water even on prolonged aeration. Hence, an emulsion is prepared by stirring a mixture of $50 \mathrm{ml}$ oleic acid and $900 \mathrm{ml} 0.1 \mathrm{M}$ $\mathrm{NaOH}$ and then diluting to make 1 liter with distilled water. This emulsion is then added to the column in volumes of $10 \mathrm{ml}$ and $20 \mathrm{ml}$.

Dodecylamine Hydrochloride: As dodecylamine hydrochloride is readily soluble in water on sufficient aeration, it is added to the column in amounts of 2 gm and 4 gms.

In all cases, as the amount / volume of surfactant / frother added was very small as compared to the volume of water present in the tank ( 22 liters), $\mathrm{pH}$ was not affected to a great extent and was almost close to a neutral value of 7.0.

\subsubsection{Calculation of 'Mixed' Plastics composition}

Different techniques were tried in order to determine the composition of the mixture of plastics floating at the top during 'mixed' plastic experiments.

\section{- Elemental Analysis}

NMP (N-methyl pyrrolidone) solvent was added to the mixture of plastics to dissolve all possible PS in the mixture. The resultant solution was vacuum filtered to obtain 
the PS solution in NMP and the residual solids comprised mostly of ABS. The residue was washed with water to remove as much NMP as possible. The washed residue was then dried in a vacuum oven at about $95^{\circ} \mathrm{C}$ and weighed. This residue was then carefully ground to a powder and tested in an Elemental Analyzer to test for

$\% \mathrm{C}, \mathrm{H}, \mathrm{N}$ and $\mathrm{S}$ compositions. However, due to inconclusive results arising from a variety of reasons such as instrument error, uncertainty in calibration, incomplete evaporation and removal of NMP, etc., this method was discarded as inappropriate.

\section{- Dissolution in Carbon disulfide $\left(\mathrm{CS}_{2}\right)$}

It was observed on dissolution of individual plastics that PS dissolved entirely in $\mathrm{CS}_{2}$, while ABS was almost insoluble. This was confirmed by dissolving a mixture of PS and $\mathrm{ABS}$ of known concentrations in $\mathrm{CS}_{2}$ (Section 4.5.5). Thus, a difference in the weights of the total mixed plastics recovered from the top during flotation experiments and the weight of recovered insoluble ABS from $\mathrm{CS}_{2}$-PS solution after washing and drying was utilized to calculate $\%$ purity of the mixed plastic fraction. A sample calculation is shown as to how $\%$ purity was determined in each case.

Total mixture weight collected from top of the column was taken as X grams.

Weight of $\mathrm{CS}_{2}$ - insoluble solids (ABS) recovered was taken to be as y grams.

Hence, weight of dissolved PS was calculated as $(X-y)=x$ grams

$\therefore$ PS purity $=\frac{\mathrm{x}}{\mathrm{X}} * 100 \%$

$\therefore$ ABS purity $=\frac{\mathrm{y}}{\mathrm{X}} * 100 \%$ 


\section{Results and Discussion}

\subsection{Material Balances}

The amount of plastic found in CPUs of obsolete computers was, in most cases, observed to constitute less than $5 \%$ of the total weight of the CPU unit, with the typical mass being around 300 grams of plastic out of a total CPU weight of about $8 \mathrm{kgs}$. A summary of the different types of plastic found in the CPU units studied in this work is given in Table 4.1 along with the $\%$ weights of each plastic type. The abbreviations for each plastic are explained in the Nomenclature section. Plastic components included those from CD drives, Floppy drives, front panels and the chasses of CPU units. It was seen that PS (HIPS) and SAN (ABS) were present in most of the CPU cases.

Table 4.1 CPU Plastics Composition Summary

\begin{tabular}{|c|c|c|c|c|c|c|}
\hline CPU Model & $\%$ Plastic & $\begin{array}{c}\text { Plastic Weight* } \\
(\mathrm{gm})\end{array}$ & $\begin{array}{c}\text { CPU Weight } \\
\text { (gm) }\end{array}$ & $\begin{array}{l}\text { Component } \\
\text { Plastic Type }\end{array}$ & $\begin{array}{c}\text { Component } \\
\% \text { Weight }\end{array}$ & $\begin{array}{l}\text { Component } \\
\text { Weight (gm) }\end{array}$ \\
\hline CCS 386 & 3.55 & 276 & 7777 & $\begin{array}{l}\text { PS } \\
\text { SAN }\end{array}$ & $\begin{array}{c}2.649 \\
0.9001\end{array}$ & $\begin{array}{c}206 \\
70\end{array}$ \\
\hline $\begin{array}{c}\text { Gateway } \\
2000\end{array}$ & 7.48 & 1181 & 15790 & $\begin{array}{l}\text { S-B } \\
\text { S-B } \\
\text { PBT } \\
\text { PPO }\end{array}$ & $\begin{array}{l}6.4090 \\
0.6333 \\
0.2343 \\
0.2027 \\
\end{array}$ & $\begin{array}{c}1012 \\
100 \\
37 \\
32 \\
\end{array}$ \\
\hline GIC 486 & 3.91 & 318 & 8133 & $\begin{array}{l}\text { PS } \\
\text { SAN }\end{array}$ & $\begin{array}{c}3.541 \\
0.3689 \\
\end{array}$ & $\begin{array}{c}288 \\
30 \\
\end{array}$ \\
\hline PC Importers & 5.19 & 335 & 6450 & $\begin{array}{l}\text { SAN } \\
\text { SAN }\end{array}$ & $\begin{array}{c}4.341 \\
0.8526 \\
\end{array}$ & $\begin{array}{c}280 \\
55 \\
\end{array}$ \\
\hline $\begin{array}{c}\text { Professional } \\
\text { Computer } \\
\text { Systems }\end{array}$ & 4.32 & 394 & 9114 & $\begin{array}{l}\text { SAN } \\
\text { SAN } \\
\text { SAN } \\
\text { S-B }\end{array}$ & $\begin{array}{l}0.307 \\
3.182 \\
0.505 \\
0.329\end{array}$ & $\begin{array}{c}28 \\
290 \\
46 \\
30\end{array}$ \\
\hline
\end{tabular}

"The metal framework, circuit boards and wires made for the remainder of the CPU weights

The keyboards were found to be composed of a larger percentage of plastic components. In most cases, plastics accounted for about $50-60 \%$ of the total weight, 
while the majority of the remaining weight was composed of metal parts. Typical values of the actual weights are shown in Table 4.2. Most of the keyboards weighed in the range of 1.1-1.4 kgs. Most of the plastic came from the keyboard casing and the keys. In addition to HIPS and ABS being present in all keyboards, it was also observed that most keyboard casings were made of HIPS, while the keys were made of ABS.

Table 4.2 Keyboard Composition Summary

\begin{tabular}{|c|c|c|c|c|c|c|}
\hline Keyboard Model & $\%$ Plastic ${ }^{*}$ & $\%$ Metal $^{*}$ & $\begin{array}{l}\text { Keyboard } \\
\mathrm{Wt}^{*}(\mathrm{gm})\end{array}$ & Plastic Type & $\begin{array}{c}\text { Component } \\
\% \text { Weight }\end{array}$ & $\begin{array}{c}\text { Plastic Wt } \\
\text { (gm) }\end{array}$ \\
\hline \multirow{3}{*}{ Apple Design - I } & \multirow{3}{*}{61.4} & \multirow{3}{*}{23.5} & \multirow{3}{*}{1090} & PS & 48.44 & 528 \\
\hline & & & & SAN & 9.45 & 103 \\
\hline & & & & PA & 3.49 & 38 \\
\hline \multirow{3}{*}{ Apple Design - II } & \multirow{3}{*}{62.3} & \multirow{3}{*}{24.8} & \multirow{3}{*}{1213} & PS & 47.47 & 576 \\
\hline & & & & SAN & 10.63 & 129 \\
\hline & & & & PA & 4.20 & 51 \\
\hline \multirow{2}{*}{ Dell Quietkey } & \multirow{2}{*}{56.8} & \multirow{2}{*}{31.3} & \multirow{2}{*}{1172} & PS & 45.40 & 532 \\
\hline & & & & SAN & 11.44 & 134 \\
\hline \multirow{4}{*}{ Fujitsu Ltd } & \multirow{4}{*}{47.4} & \multirow{4}{*}{36.7} & \multirow{4}{*}{1994} & PS & 26.43 & 527 \\
\hline & & & & PS & 7.67 & 153 \\
\hline & & & & PA & 6.67 & 133 \\
\hline & & & & PBT & 6.67 & 133 \\
\hline \multirow{2}{*}{ Gateway Anykey } & \multirow{2}{*}{64.0} & \multirow{2}{*}{24.8} & \multirow{2}{*}{1412} & PS & 52.83 & 746 \\
\hline & & & & SAN & 11.19 & 158 \\
\hline \multirow{2}{*}{ IBM } & \multirow{2}{*}{60.8} & \multirow{2}{*}{27.7} & \multirow{2}{*}{2228} & PBT & 12.61 & 281 \\
\hline & & & & $\mathrm{VC} / \mathrm{VA} / \mathrm{VOH}$ & 48.15 & 1073 \\
\hline \multirow{3}{*}{ Micron Keytronic } & \multirow{3}{*}{55.8} & \multirow{3}{*}{33.0} & \multirow{3}{*}{1188} & PS & 34.01 & 404 \\
\hline & & & & PS & 10.69 & 127 \\
\hline & & & & SAN & 11.11 & 132 \\
\hline \multirow{2}{*}{ Microsoft Monoblock } & \multirow{2}{*}{84.6} & \multirow{2}{*}{1.1} & \multirow{2}{*}{955} & PS & 70.37 & 836 \\
\hline & & & & SAN & 14.24 & 169 \\
\hline Mitsumi & 57.9 & 28.4 & 974 & PS & 48.15 & 469 \\
\hline & & & & SAN & 9.75 & 95 \\
\hline PC Concepts & 80.2 & 2.1 & 617 & SAN & 16.86 & 104 \\
\hline & & & & S-B & 63.37 & 391 \\
\hline Zenith Data Systems & 43.9 & 2.2 & 1877 & $\begin{array}{l}\text { SAN } \\
\text { PRT }\end{array}$ & $\begin{array}{c}7.99 \\
3586\end{array}$ & 150 \\
\hline & & & & PBT & 35.86 & 673 \\
\hline
\end{tabular}

" The circuit boards and wires made for the remainder of the Keyboard weights

Two HP DeskJet printers were also dismantled to study the material balance and plastic composition. Plastics were mainly present in the printer chassis, paper-loading 
trays, and printer cartridges. PS made up a large part of the plastic fraction of the printer. Some of the plastic percentages were estimated due to difficulty in dismantling plastic from the associated metal parts. Unlike in CPUs and keyboards, PC was found to be present in the printer cartridges and paper loading trays. A summary of the material balances for printers is shown in Table 4.3 .

\section{Table 4.3 Printer Composition Summary}

\begin{tabular}{|c|c|c|c|c|c|}
\hline Printer Model & \% Plastic* & $\begin{array}{c}\text { Printer Weight* } \\
(\mathrm{gm})\end{array}$ & Plastic Type & $\begin{array}{c}\text { Component } \\
\% \text { Weight }\end{array}$ & $\begin{array}{c}\text { Component } \\
\text { Weight (gm) }\end{array}$ \\
\hline & & & PS & 21.00 & 356 \\
& \multirow{3}{*}{31.86} & \multirow{2}{*}{1696} & SAN & 1.60 & 27 \\
& & & PC & 2.72 & 46 \\
& & & PC & 5.26 & 89 \\
& & & PC & 1.28 & 22 \\
\hline \multirow{3}{*}{ HP DJ 870C } & \multirow{2}{*}{51.38} & \multirow{2}{*}{2980} & PS & 39.26 & 1170 \\
& & & PS & 6.04 & 180 \\
& & & SAN & 1.40 & 42 \\
& & PC & 4.69 & 140 \\
\hline
\end{tabular}

The metal framework, circuit boards, wires, paper feeding trays, printer ink cartridges, etc made up for the remainder of the Printer weights

Since PS (HIPS) and SAN (ABS) were observed to be present in almost all equipment in considerable quantities, it was decided to focus attention on the separation of these two specific EOL plastics.

\subsection{Ash Analysis Results}

Figures 4.1 and 4.2 indicate the number of occurrences in which plastic from a particular source had $\%$ ash content in a given interval. The number of occurrences was normalized with the total number of plastic sources analyzed in this work. Sample of plastic from a given source was assumed to represent the properties of all plastics from that source. Some of the key results observed from ash analysis data were: 
- The highest ash content (as high as $25 \%$ ) was found to be present in PC samples obtained from printer cartridges. This could be due to residual ink present in the cartridges, in addition to fillers and fire retardants used in the EOL plastics.

- The two polymers under study, PS and SAN, contained less than $1 \%$ ash content on most occasions. However, there were a few cases where up to $5 \%$ ash content was observed. This could be due to a higher amount of fire retardants and other additives used in them. The \% ash distributions for SAN and PS are shown in Figure 4.1 and Figure 4.2 respectively.

- The polyacetal key supports used in some of the keyboards were found to be completely ash free.

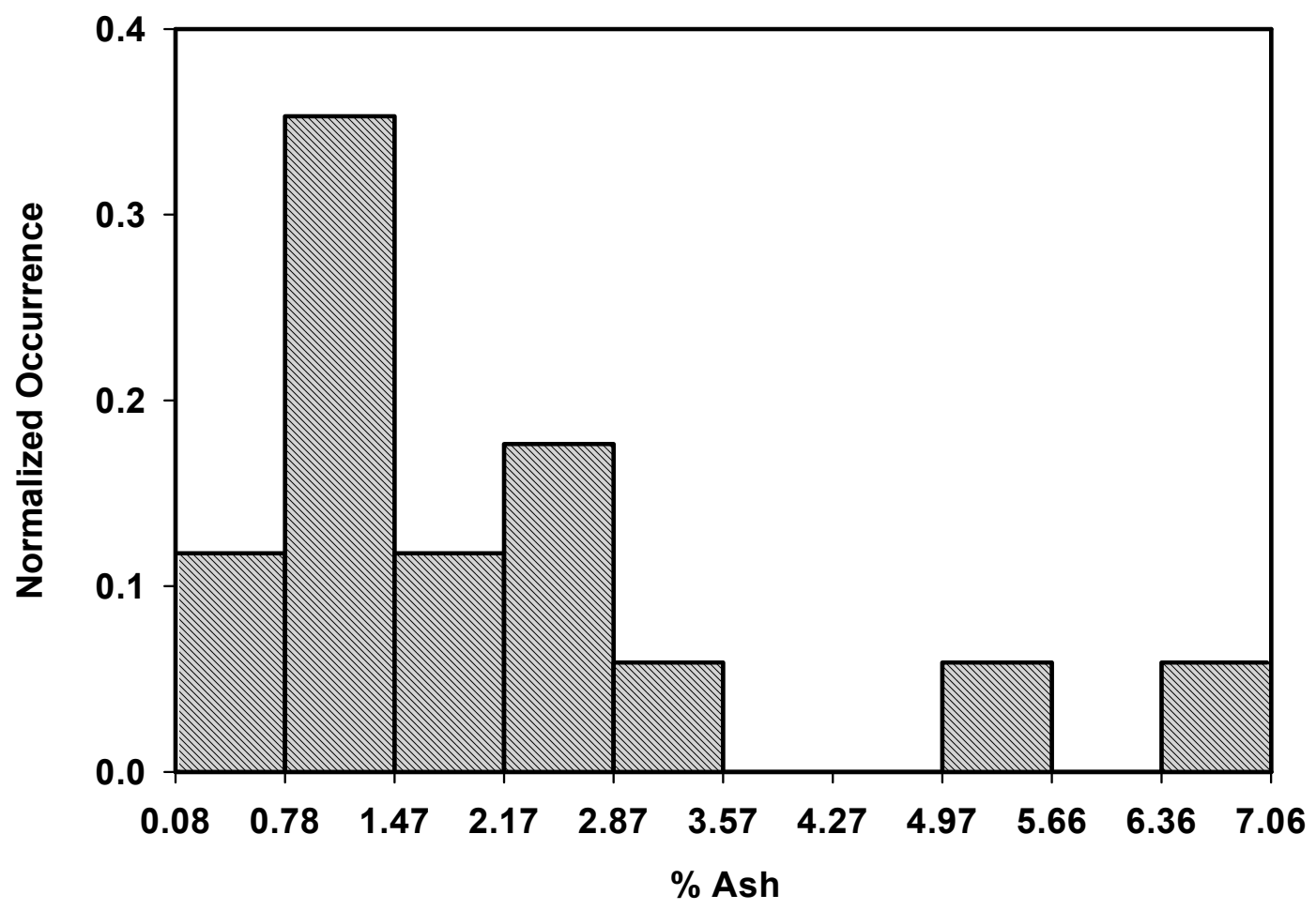

Figure 4.1 SAN \%Ash Distribution in all CPUs, keyboards and printer samples 


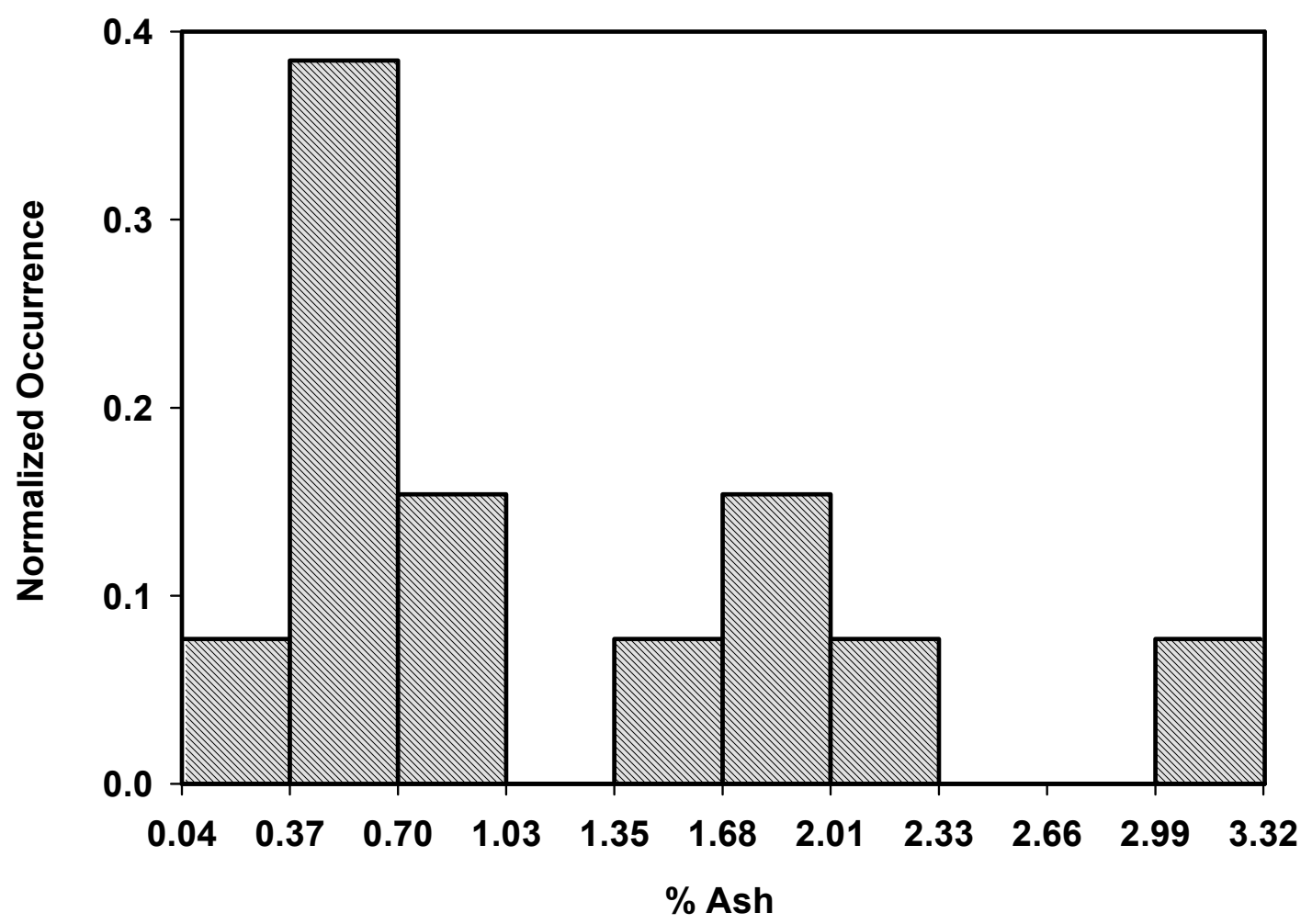

Figure 4.2 PS \%Ash Distribution in all CPUs, keyboards and printer samples

\subsection{Density Results}

Figures 4.3 and 4.4 indicate the number of occurrences in which plastic from a particular source had density in a given interval. As in \% ash content, the number of occurrences was normalized with the total number of plastic sources analyzed in this work. Some of the key results observed from density analysis were:

- PC and polyacetal were observed to be the most dense plastics with densities of about $1.35 \mathrm{gm} / \mathrm{cm}^{3}$ and $1.41 \mathrm{gm} / \mathrm{cm}^{3}$, respectively.

- As seen from the density distributions of SAN (Figure 4.3) and PS (Figure 4.4), both were observed to have very close density ranges of about $1.03 \mathrm{gm} / \mathrm{cm}^{3}$ to 1.09 $\mathrm{gm} / \mathrm{cm}^{3}$. It was hence decided to setup a froth flotation column to effect their 
separation, as it would be almost impossible to separate them on the basis of their densities alone.

- As seen from Figure 4.5, in general, plastics with high ash content were observed to have a higher density, with the exception of polyacetal key supports that had a density of $1.41 \mathrm{gm} / \mathrm{cm}^{3}$, in spite of having no ash content.

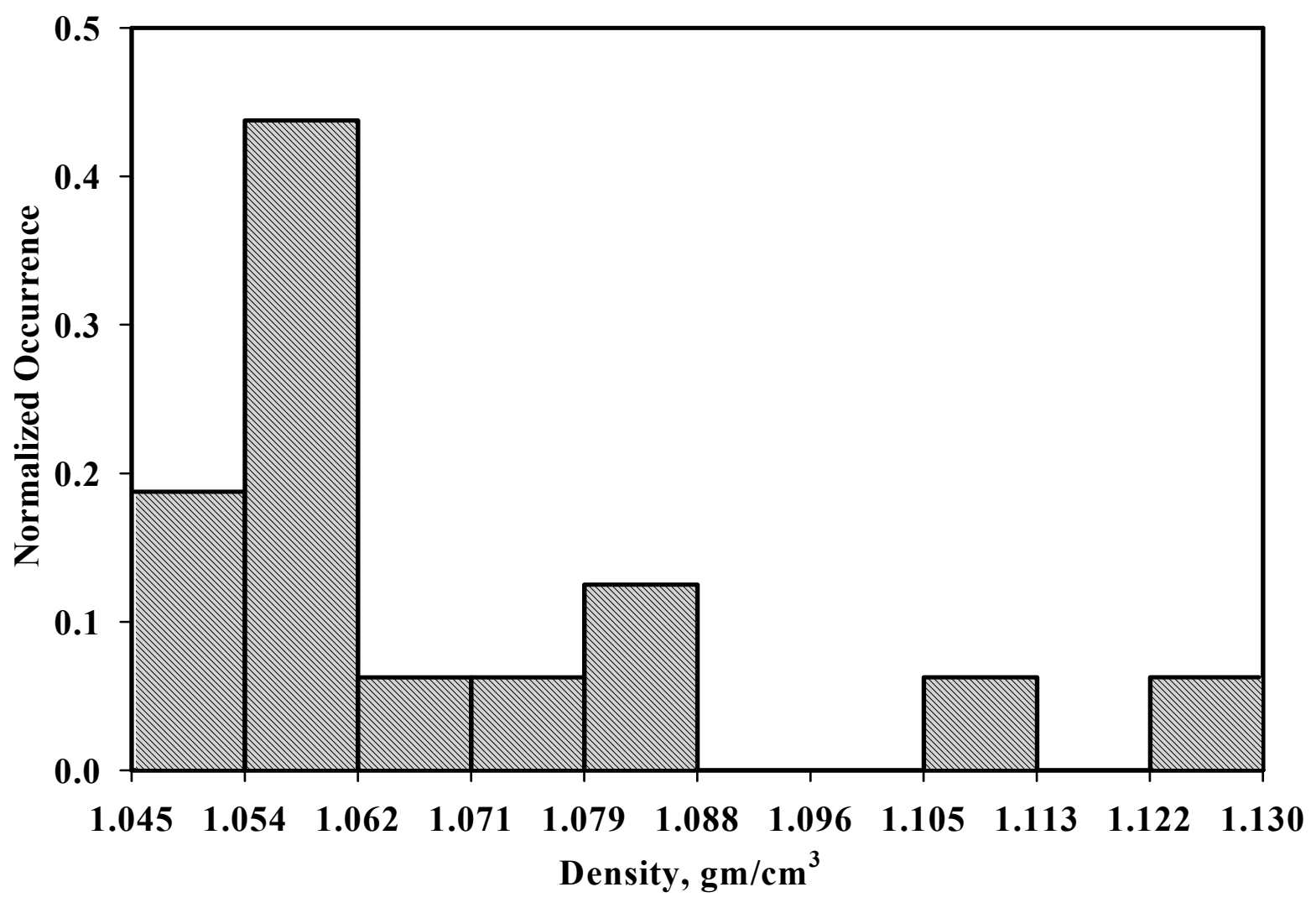

Figure 4.3 SAN Density Distribution in all CPUs, printers and keyboard samples 


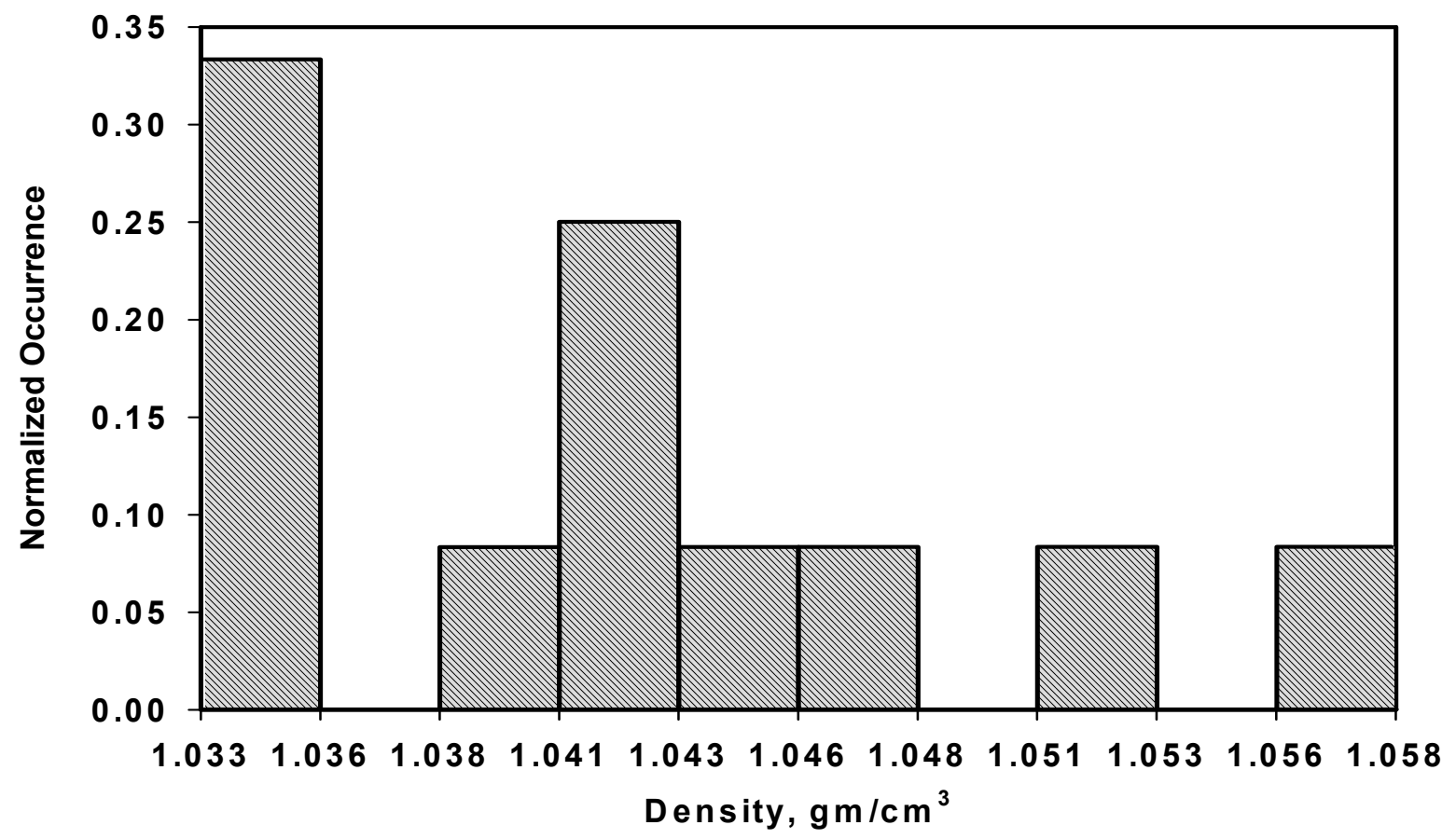

Figure 4.4 PS Density Distribution for all CPUs, keyboards and printer samples

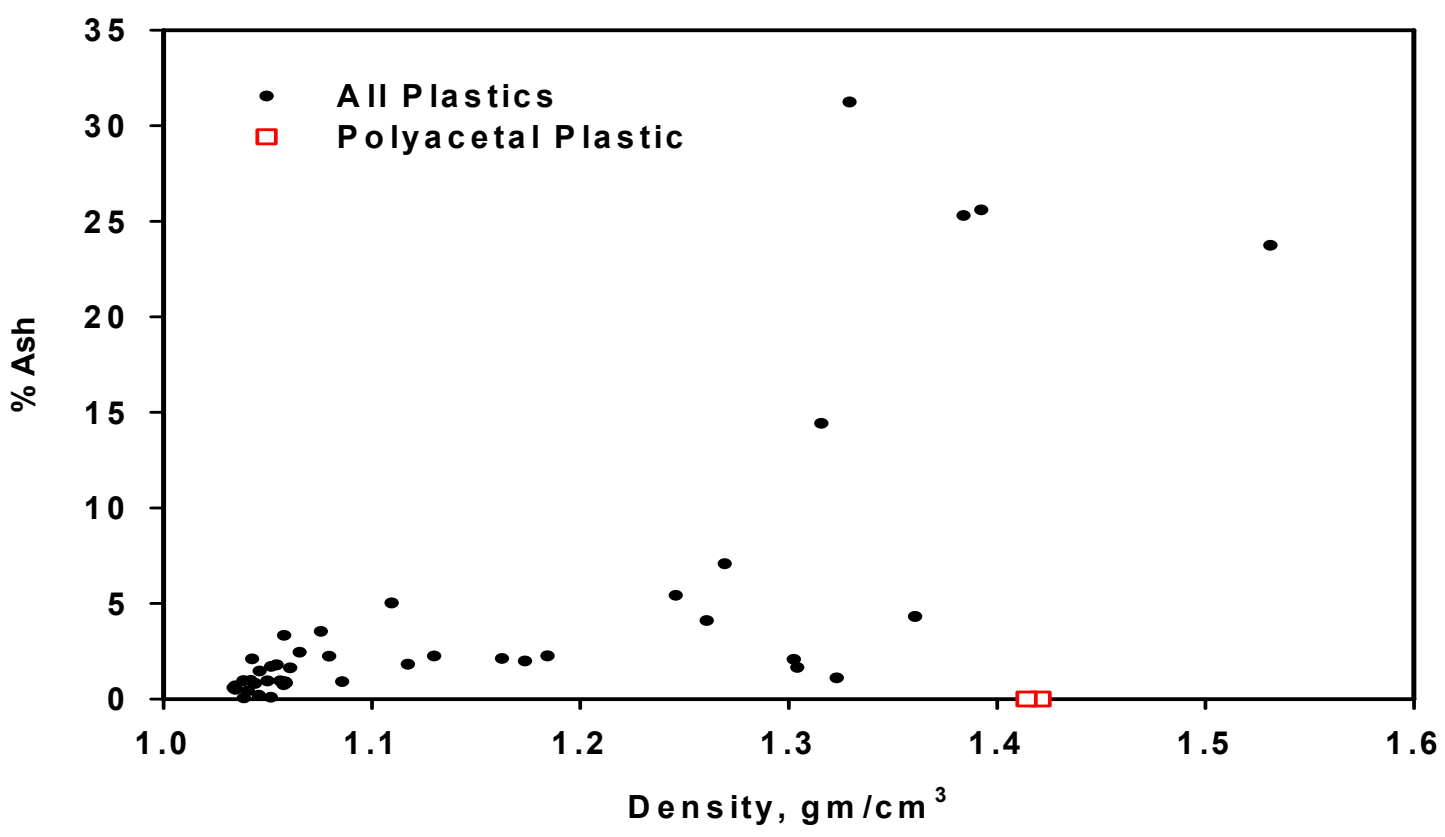

Figure 4.5 \% Ash vs. Density for all plastics 


\subsection{FTIR Results}

A comparison of the spectra obtained from each type of plastic sample (ABS, PS and PC) and the corresponding reference spectra from the FTIR software database is shown in Figure 4.6, Figure 4.7 and Figure 4.8, respectively. The Spectrum One software compares the peaks from the sample spectrum with its spectral database and comes up with a list of spectra that match closely to that of the sample. A match of greater than $80 \%$ was considered to be a good match. Most of the samples identified in this work had average matches of about $80 \%-85 \%$. The sample SAN, PS and PC turned up with matches of $95 \%, 96 \%$ and $89 \%$, respectively.

In Figure 4.6, the peak at $2230 \mathrm{~cm}^{-1}$ in the sample spectrum lines up with the characteristic peak for $\mathrm{C} \equiv \mathrm{N}$ bond of the reference spectrum, thereby confirming the presence of the nitrile bond. Figure 4.7 shows the match of peaks around $3000 \mathrm{~cm}^{-1}$ in the sample spectrum with those corresponding to aliphatic and aromatic $\mathrm{C}-\mathrm{H}$ peaks. The exact presence of these peaks and the overtones confirms that the sample spectrum is that

of polystyrene. Figure 4.8 shows the prominent presence of a peak at $1730 \mathrm{~cm}^{-1}$ that matches with the characteristic carbonyl peak in the reference spectrum of polycarbonate. 


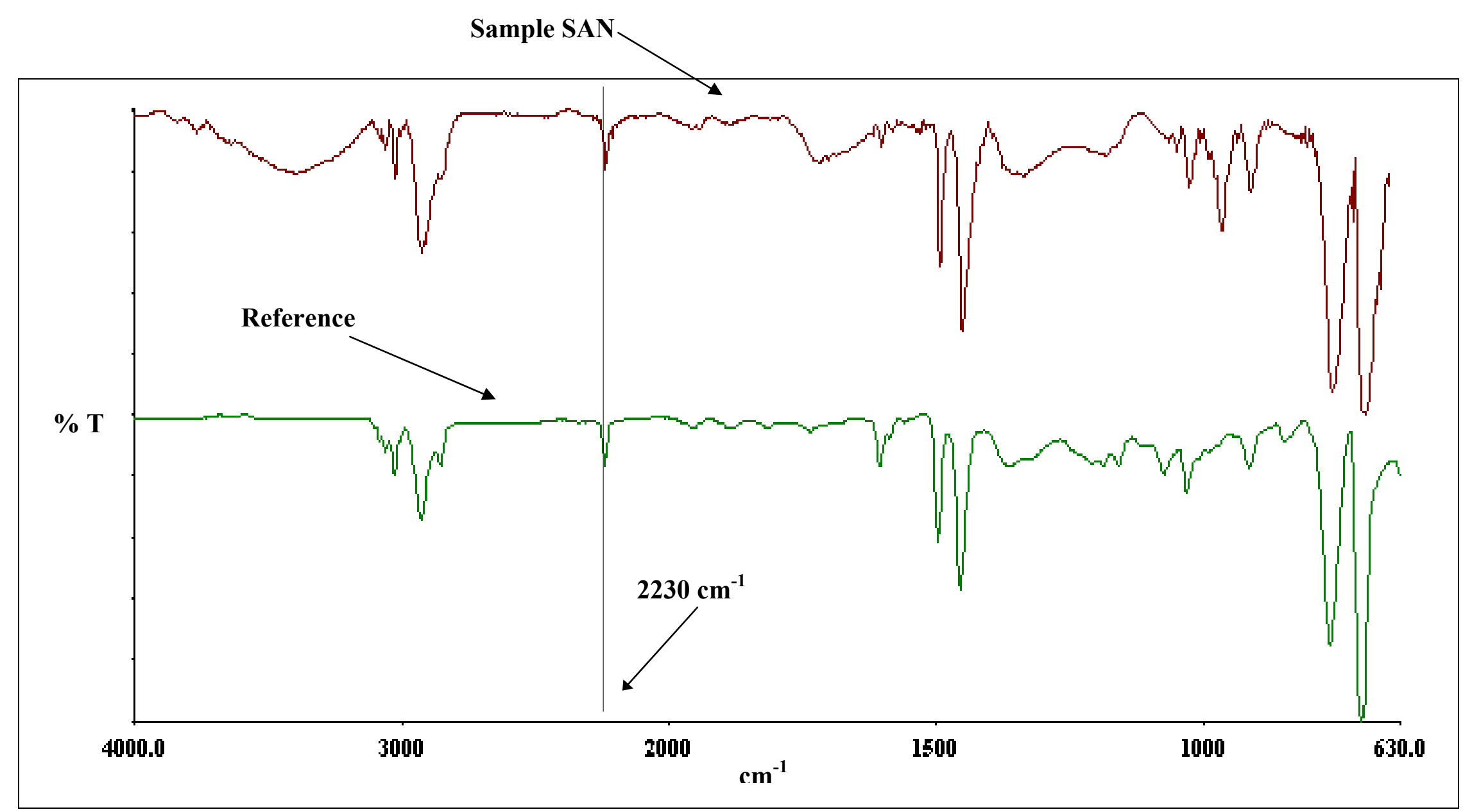

Figure 4.6 Comparison of sample SAN and reference SAN spectra 


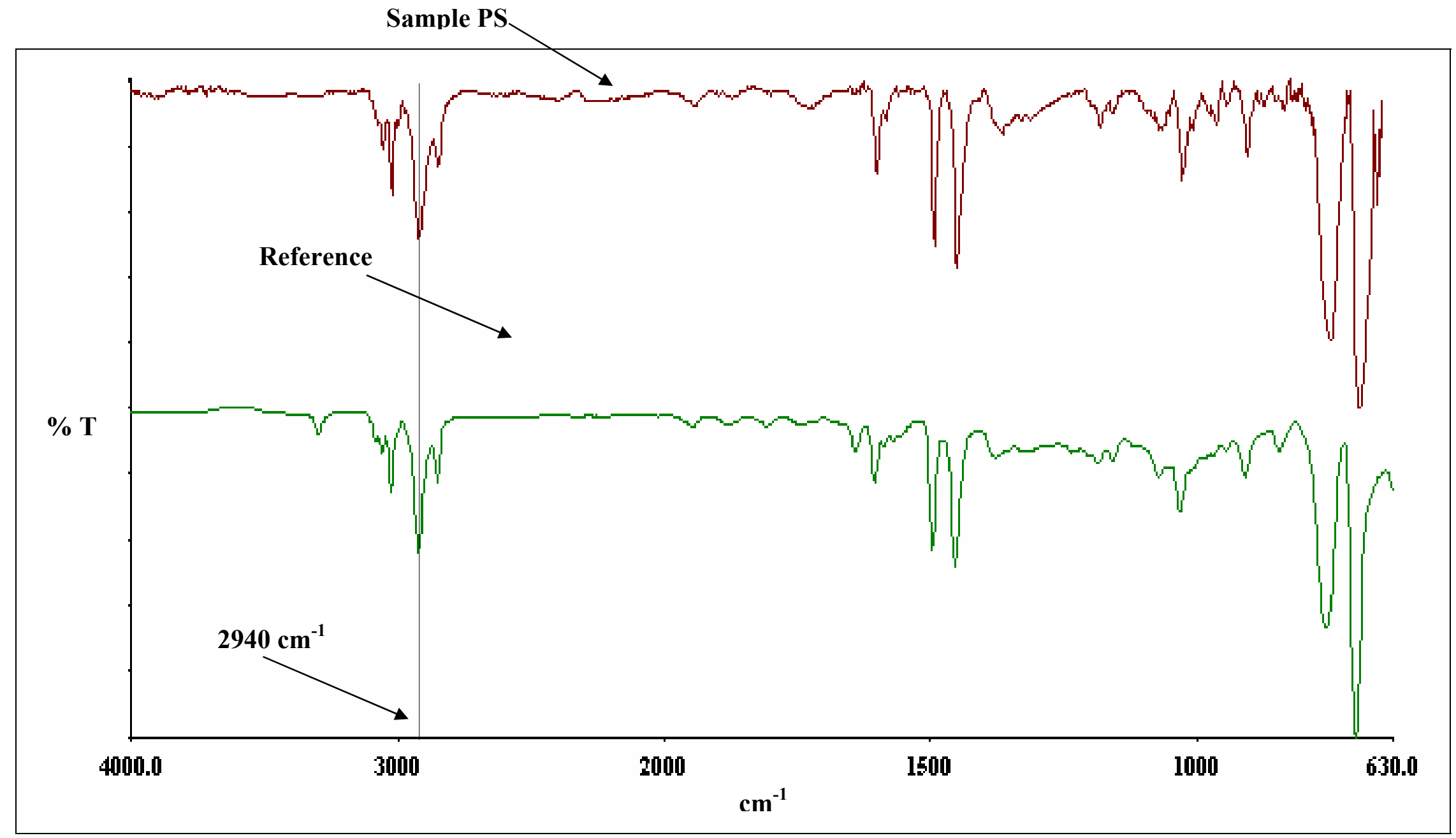

Figure 4.7 Comparison of sample PS and reference PS spectra 


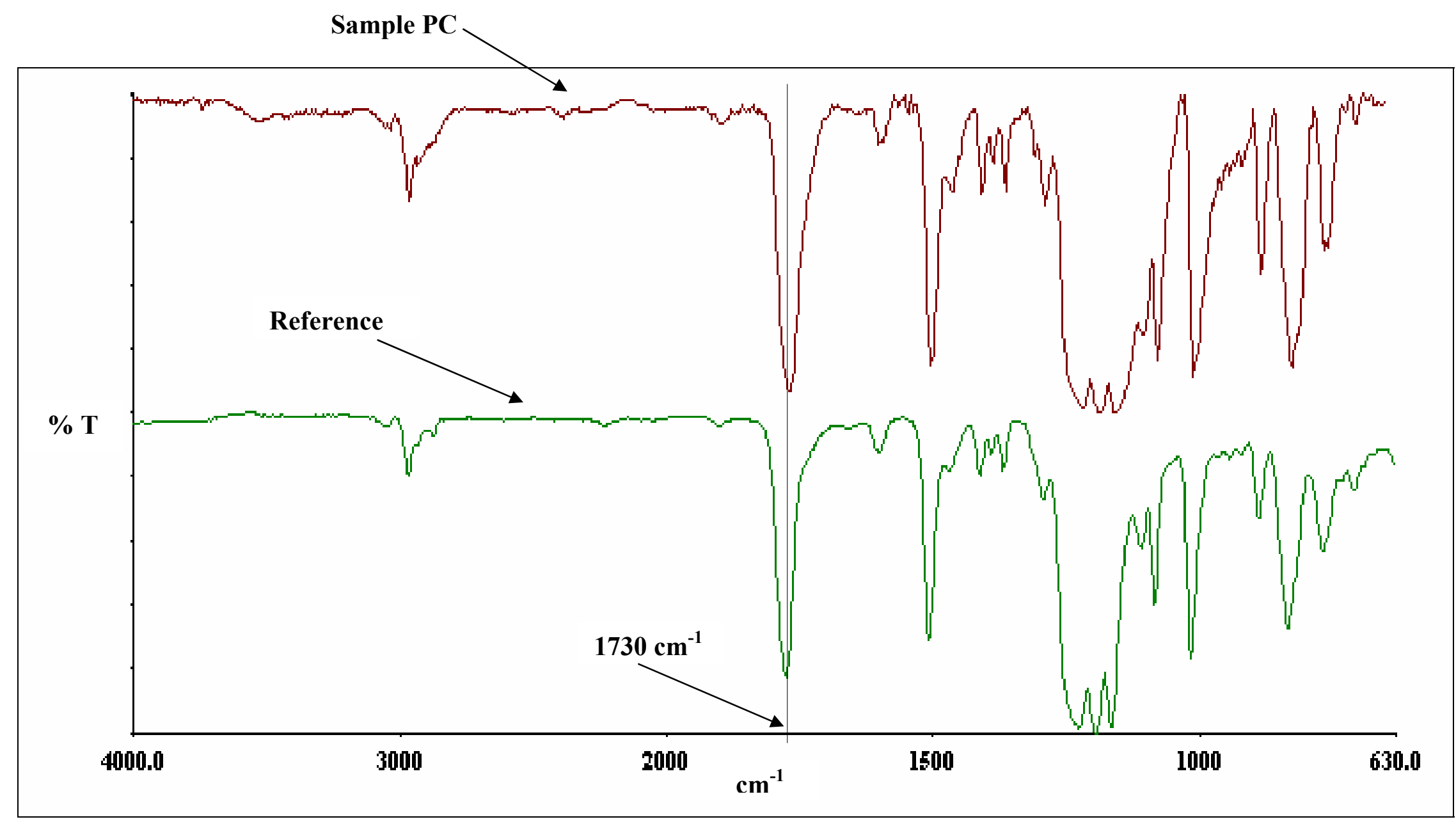

Figure 4.8 Comparison of sample PC and reference PC spectra 


\subsection{Settling Velocity Results}

Figure 4.9 shows a series of images of a plastic particle settling in the liquid medium. It was observed that the particle 'flutters' while settling down, thereby making the settling velocity calculations a bit tricky. The change in $\mathrm{x}$ and $\mathrm{y}$ co-ordinates of the centroid of the particle was tracked through successive images (frames) using Visilog Software and the differences in the y co-ordinates gave an indication of the settling velocity. It was seen that due to the similar densities, the two plastics chosen for separation (HIPS and ABS) had very close settling velocities (about $22-25 \mathrm{~mm} / \mathrm{sec}$ ). This further confirmed that a float sink technique would not be suitable to effect a reasonable separation of HIPS and ABS.

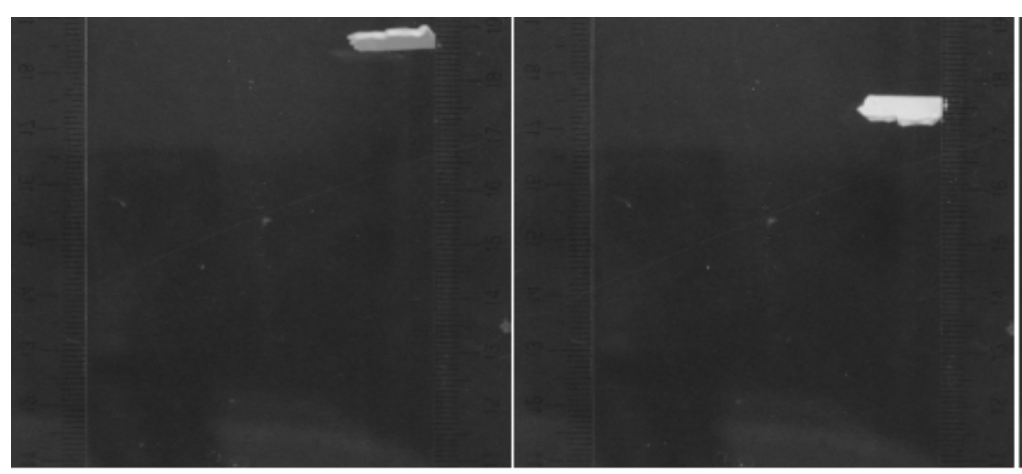

[a]

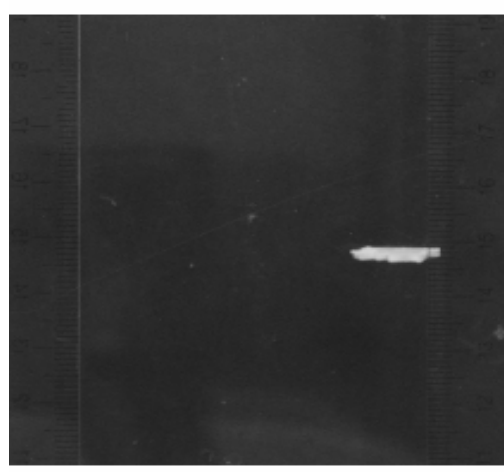

(d) (b)

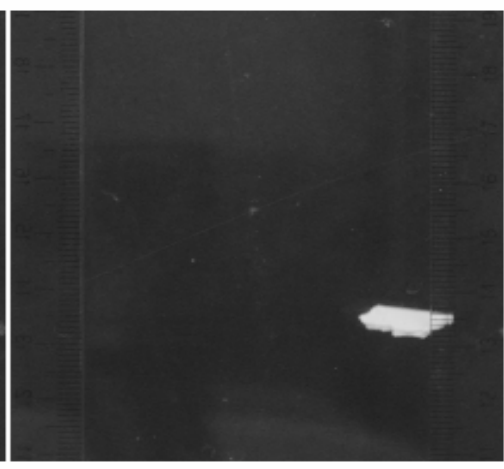

$[e]$

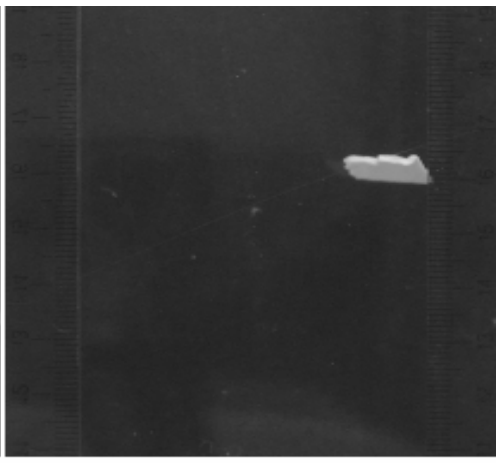

[c]

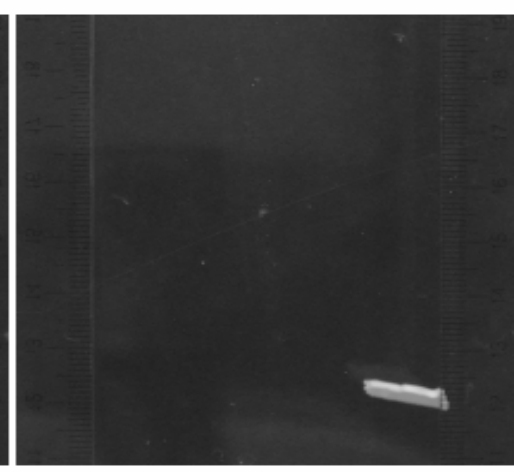

[f]

Figure 4.9 Sequence of images showing settling of ABS plastic in water 


\subsection{Froth Flotation Results}

\subsubsection{MIBC Results}

Samples of 10 grams of plastic were floated using only MIBC as the frothing agent in different experimental runs, in the absence of any surfactant. The flotation curves for different amounts of MIBC for ABS plastic are shown in Figure 4.10. It is observed that addition of MIBC decreases the hydrophobicity of the ABS plastic surface, thereby hindering its floatability and reducing the amount of ABS that floats to the surface at any given time. Figure 4.11 shows the effect of addition of MIBC on the floatability of PS. As can be seen from the graph, addition of $1 \mathrm{ml} \mathrm{MIBC}$ increases the floatation of PS, while any further addition has no significant effect. Further explanation on the observed trends in given in Section 5.3.2.

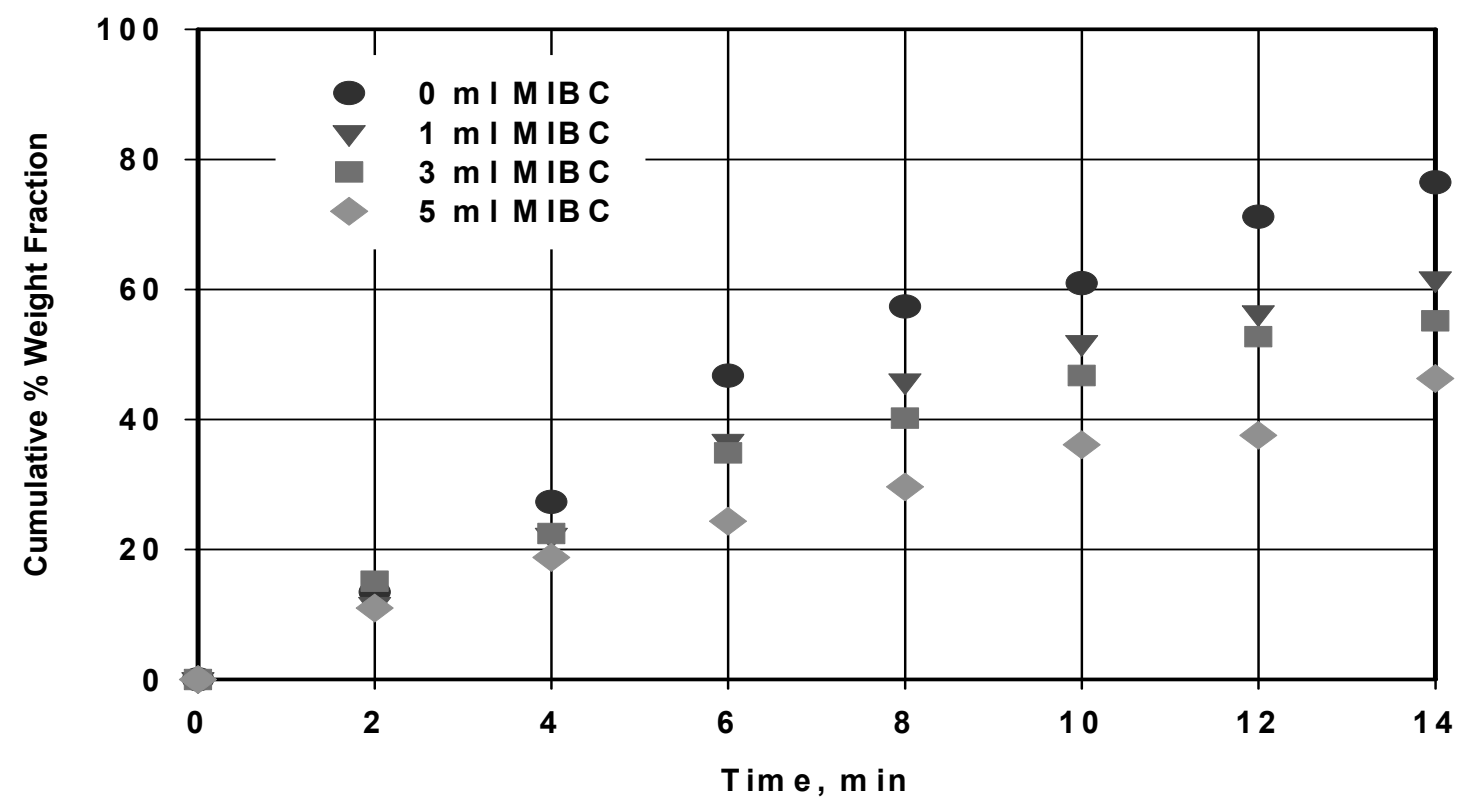

Figure 4.10 Effect of MIBC on ABS Floatability 


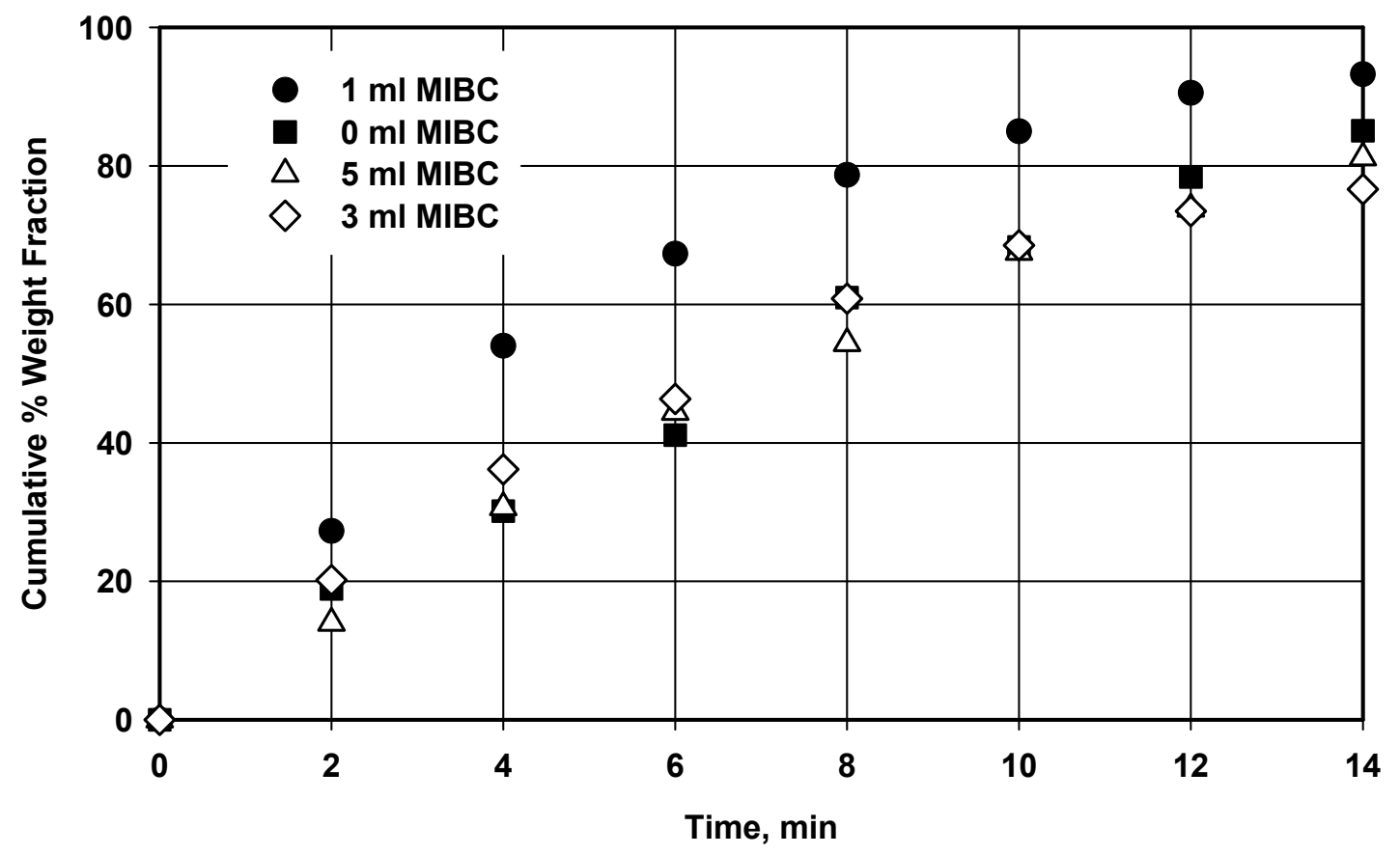

Figure 4.11 Effect of MIBC on PS Floatability

The yields and purities of ABS and PS was then calculated assuming that flotation behavior observed when both plastics are floated simultaneously would be same as that observed when they were floated separately. In other words, the presence of more solids or presence of another plastic was assumed to have no effect on the floatability behaviour of the individual plastic. A set of experiments were later performed to observe the effect of inter-particle interactions when both plastics were floated simultaneously (Section 4.6.5).

Figures 4.12 and 4.13 show an analysis of the \% purity and \% yield of PS and ABS obtained as top products at all time intervals respectively. The \% yield is calculated as the $\%$ of a particular plastic that is obtained as top or bottom product as compared to the original amount of that plastic fed to the column. At any instant, the plastic that 
remains in the column and does not float to the top along with the froth is considered as the bottom product. Hence, at $\mathrm{t}=0$, since all the plastic is present in the tank, the yield of the top product is $0 \%$ and that of the bottom product is $100 \%$. A comparison of the figures shows that although yields of both PS and ABS increases with time, purity of PS increases while ABS is obtained at lower purities at the top of the column. On the other hand, Figure 4.14 shows that purity of $\mathrm{ABS}$ increases at the bottom of the column with time, albeit at a decreasing yield. A comparison of Figures 4.12 and 4.14 shows opposing trends in both yields and purities of PS and ABS, when they are considered as top product and bottom product respectively. It was necessary to perform further analysis by selecting a particular batch time at which both plastics were obtained at reasonable yields and purities. It can be seen that at a batch time of about 6 minutes, both PS and ABS are obtained at yields of about $64 \%$ and $62 \%$ at the top of the column respectively. Also, for the same batch time, the purities obtained are $62 \%$ and $61 \%$ for PS and ABS. Hence, a batch time of 6 minutes was arbitrarily chosen as the residence time in each flotation stage to perform a theoretical multi-stage analysis. A 2-stage and 3-stage floatation scheme is designed to calculate the overall yield and purity of PS and ABS. It was assumed that identical separations are achieved in each flotation cell of the multistage setup. 


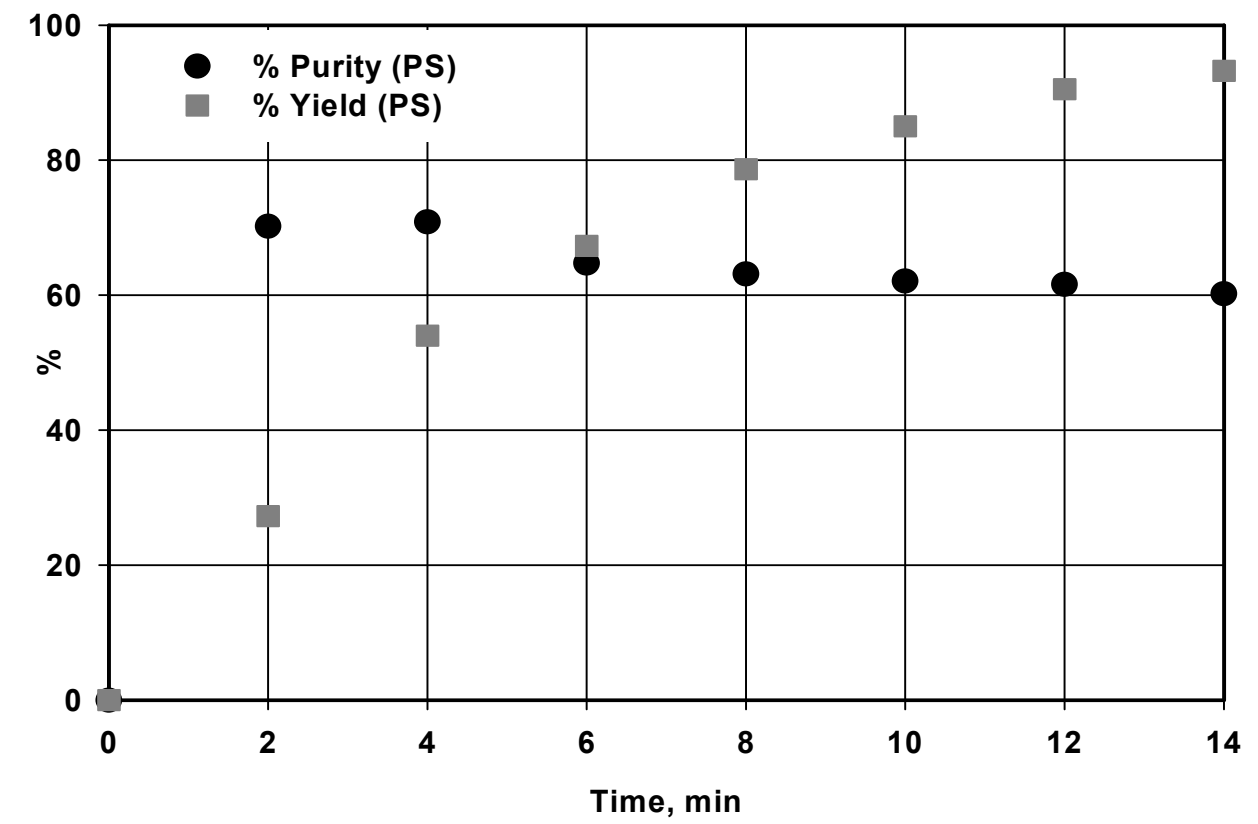

Figure $4.12 \%$ Yield and \% Purity of PS in the top fraction when using $1 \mathrm{ml}$ MIBC

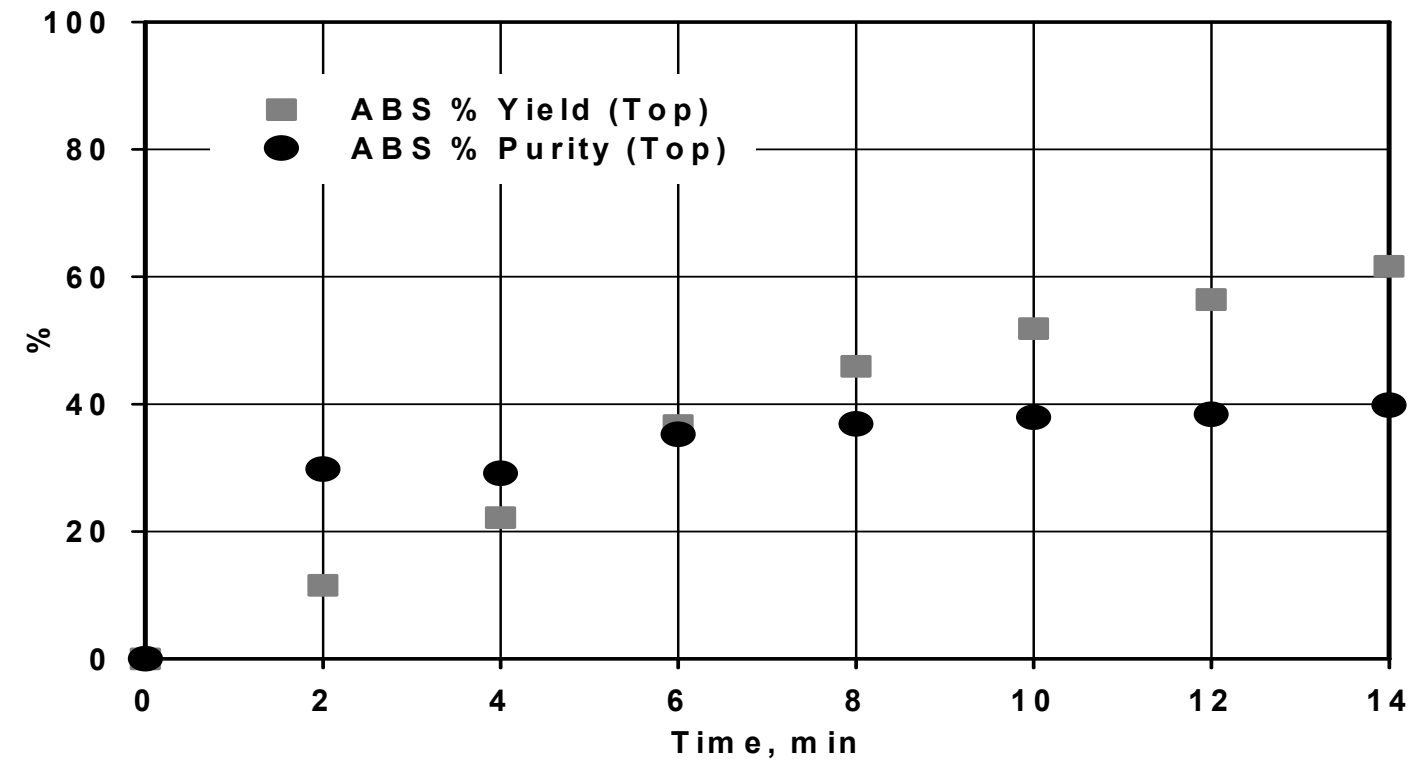

Figure $4.13 \%$ Yield and \% Purity of ABS in the top fraction when using $1 \mathrm{ml}$ MIBC 


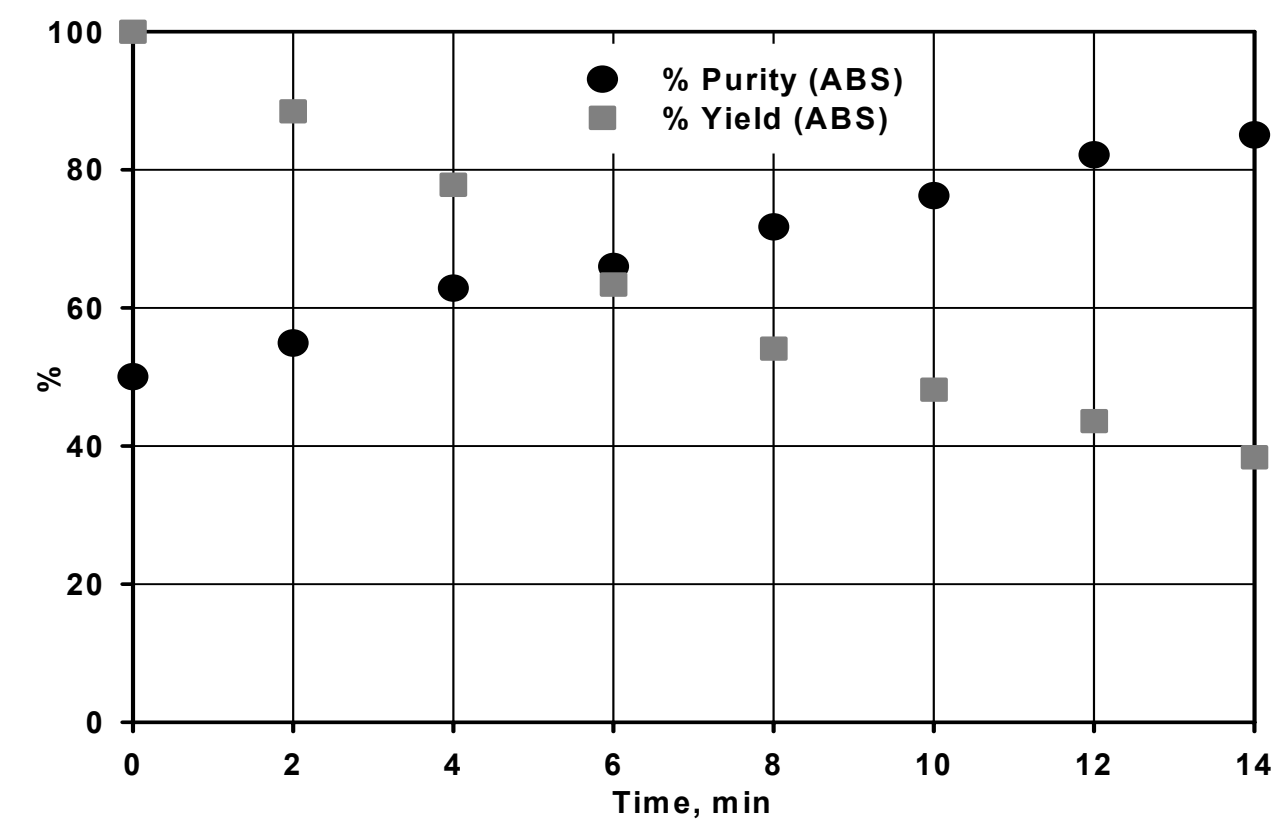

Figure $4.14 \%$ Yield and \% Purity of ABS in the bottom fraction when using 1 ml MIBC

Figure 4.15 shows a theoretical schematic diagram of a 2-stage froth flotation setup for the separation of PS and ABS based on the flotation data collected separately for the individual plastics. The feed consists of 10 grams ABS and 10 grams of PS plastic. A material balance for the case of 6 minutes residence time in each flotation cell is also shown in the figure. PS is collected from the top of column II, while ABS is collected from the bottom of column III and the remaining streams are discarded as 'waste' streams. It should be noted that although the process shown in the figure appears to be a continuous separation, each piece of equipment is run in a batch mode and materials are transferred after the end of each separation.

Although both PS and ABS are obtained at purities of $77 \%$ and $79 \%$ respectively, the plastics are obtained at very low yields of $45 \%$ and $40 \%$. A 3-stage scenario (Figure 
4.16) operated in a similar fashion is considered in an effort to obtain higher purities. In this case, PS is collected from the top of column IV at $86 \%$ purity, while $88 \%$ pure ABS is collected from the bottom of column V. However, increase in purity is compensated by extremely low yields of the two plastics, viz. $31 \%$ and $25 \%$ respectively.

In order to achieve both higher yields and reasonable purities, similar 2-stage and 3-stage schemes are theoretically designed where the 'waste' streams are recycled back into the system. It can be observed from Figure 4.17 that PS is obtained at $76 \%$ purity and $81 \%$ yield. The purity and yield for $\mathrm{ABS}$ are $80 \%$ and $75 \%$ respectively. In the 3stage setup, as seen from Figure 4.18, both purity and yield increases. PS is obtained about $85 \%$ pure at almost $90 \%$ yield, while the purity and yield for ABS are $89 \%$ and $84 \%$ respectively.

The purities and yields of PS and ABS obtained from the various multi-stage flotation set-ups are summarized in Table 4.4. 


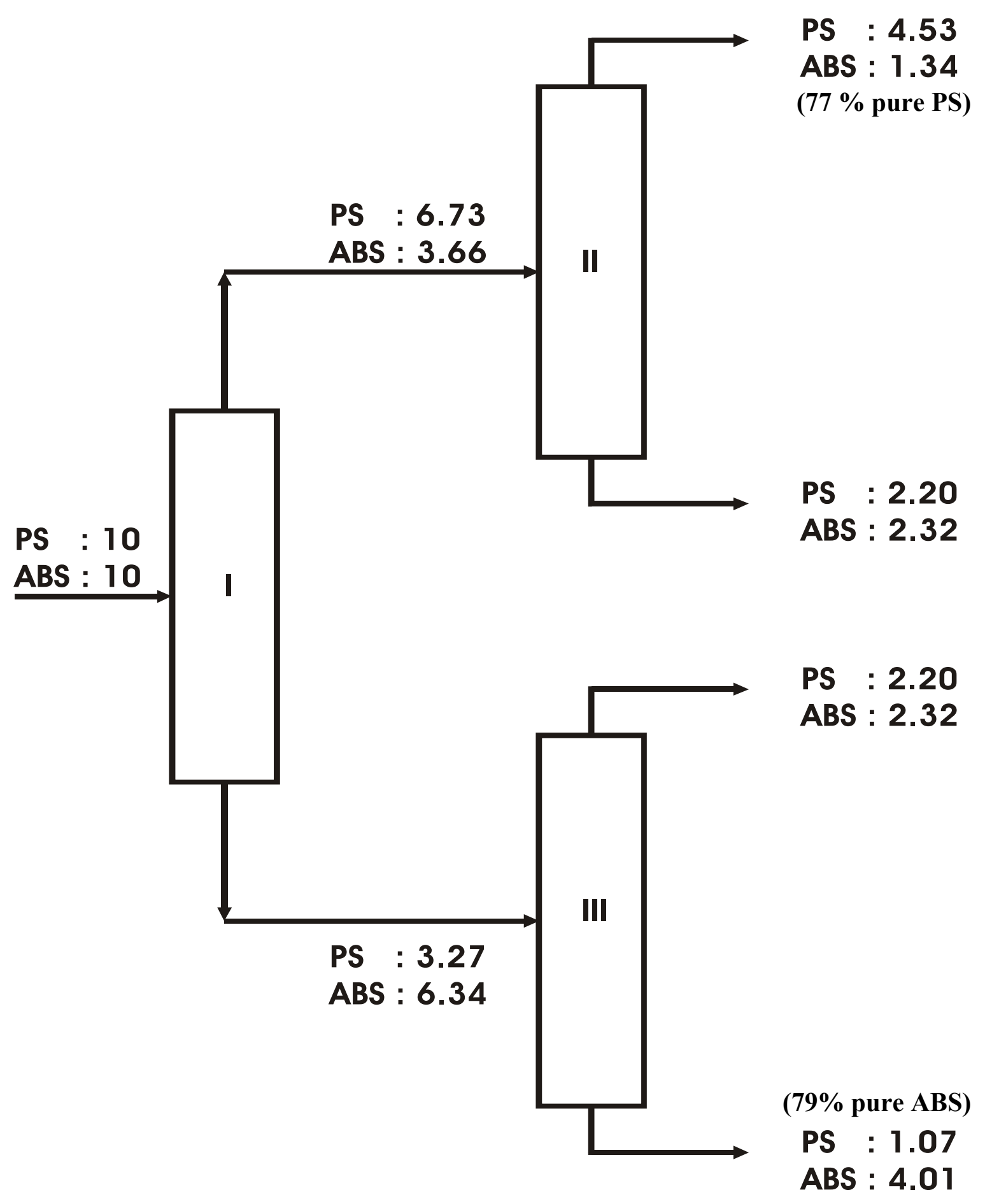

Figure 4.15 Material Balance for Two-Stage Floatation Setup (no recycle) using $1 \mathrm{ml}$ MIBC \& batch time of 6 minutes 


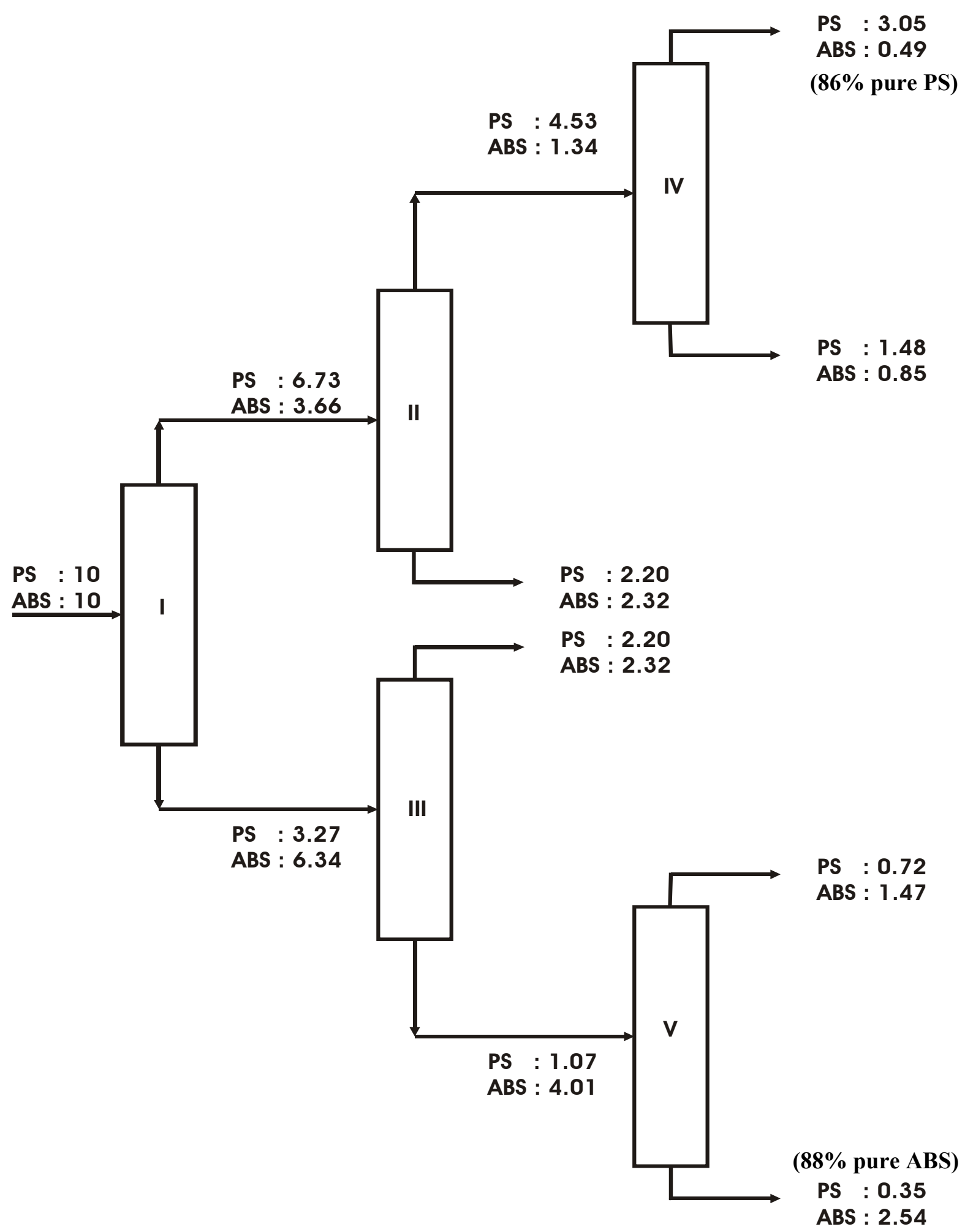

Figure 4.16 Material Balance for Three-stage Floatation Setup (no recycle) using

$1 \mathrm{ml}$ MIBC \& batch time of 6 minutes 


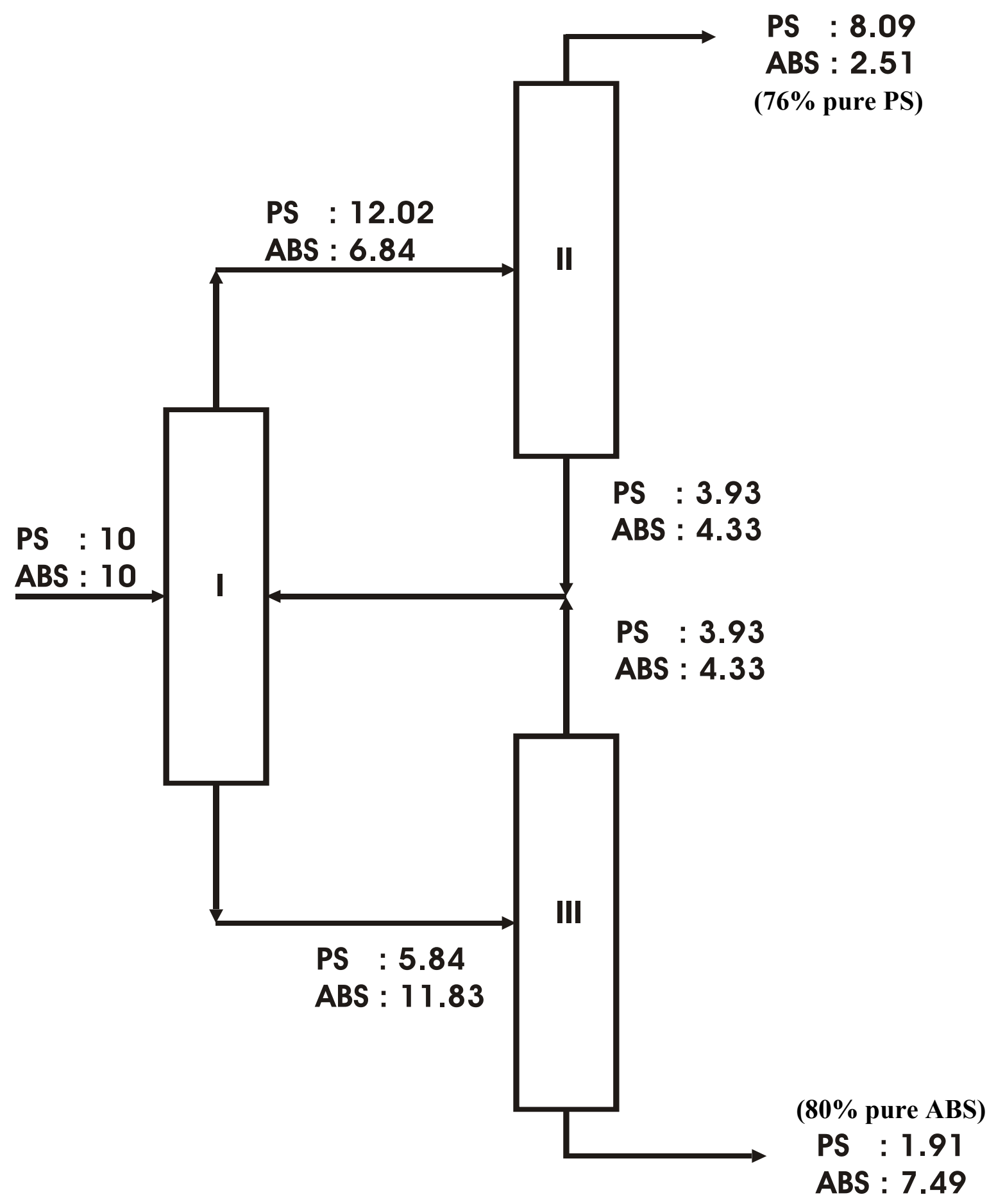

Figure 4.17 Material Balance for Two-Stage Floatation Setup (with recycle) using $1 \mathrm{ml}$ MIBC \& batch time of 6 minutes 


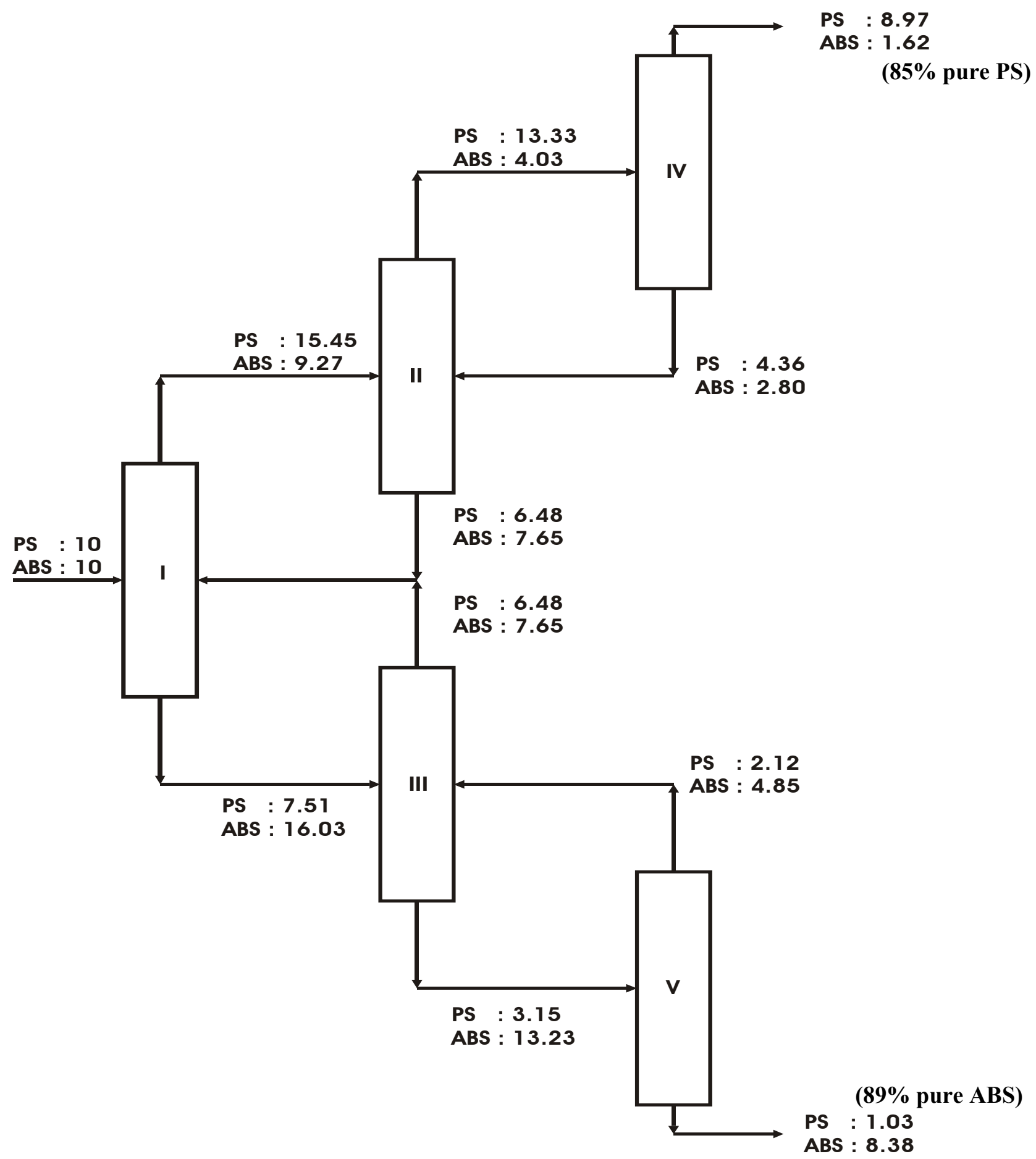

Figure 4.18 Material Balance for Three-stage Floatation Setup (with recycle) using $1 \mathrm{ml}$ MIBC \& batch time of 6 minutes 
Table 4.4 Purity and Yield for ABS and PS in various multi-stage floatation set-ups using $1 \mathrm{ml}$ MIBC and batch time of 6 minutes

\begin{tabular}{|c|c|c|c|c|c|c|c|c|}
\cline { 2 - 8 } \multicolumn{1}{c|}{} & \multicolumn{4}{c|}{ No Recycle } & \multicolumn{4}{c|}{ With Recycle } \\
\cline { 2 - 9 } & \multicolumn{2}{|c|}{ 2-Stage } & \multicolumn{2}{c|}{ 3-Stage } & \multicolumn{2}{c|}{ 2-Stage } & \multicolumn{2}{c|}{ 3-Stage } \\
\cline { 2 - 9 } & Yield & Purity & Yield & Purity & Yield & Purity & Yield & Purity \\
\hline PS & $45 \%$ & $77 \%$ & $31 \%$ & $86 \%$ & $81 \%$ & $76 \%$ & $90 \%$ & $85 \%$ \\
\hline ABS & $40 \%$ & $79 \%$ & $25 \%$ & $88 \%$ & $75 \%$ & $80 \%$ & $84 \%$ & $89 \%$ \\
\hline
\end{tabular}

It can be concluded that on recycling the 'waste' streams, although the purity of the plastics remains almost the same, there is a significant increase in the overall yield of both ABS and PS.

\subsubsection{Oleic Acid Results}

Samples of 10 grams of plastic were floated using oleic acid emulsion along with $1 \mathrm{ml} \mathrm{MIBC}$ as frothing agent in different experimental runs. Figures 4.19 and 4.20 show the effect of addition of oleic acid emulsion and 1ml MIBC on ABS and PS floatabilities respectively. It is seen that addition of acid significantly increases the floatability of both plastics. An analysis of \% yield for PS and ABS as top product (Figures 4.21 and 4.22) shows that both plastics are obtained at high yields at the top. However, \% purity of ABS increases marginally while that of PS decreases marginally with time. A batch time of 4 minutes was arbitrarily chosen to perform multi-stage analysis using $10 \mathrm{ml}$ oleic acid as both PS and ABS were obtained at reasonable yields and purities at a batch time of 4 minutes as top and bottom products respectively (Figures 4.21 and 4.23). Table 4.5 summarizes the yields and purities of the plastics in multi-stage set-ups using $1 \mathrm{ml}$ MIBC 
and $10 \mathrm{ml}$ oleic acid emulsion with each floatation cell operated for a batch time of 4 minutes.

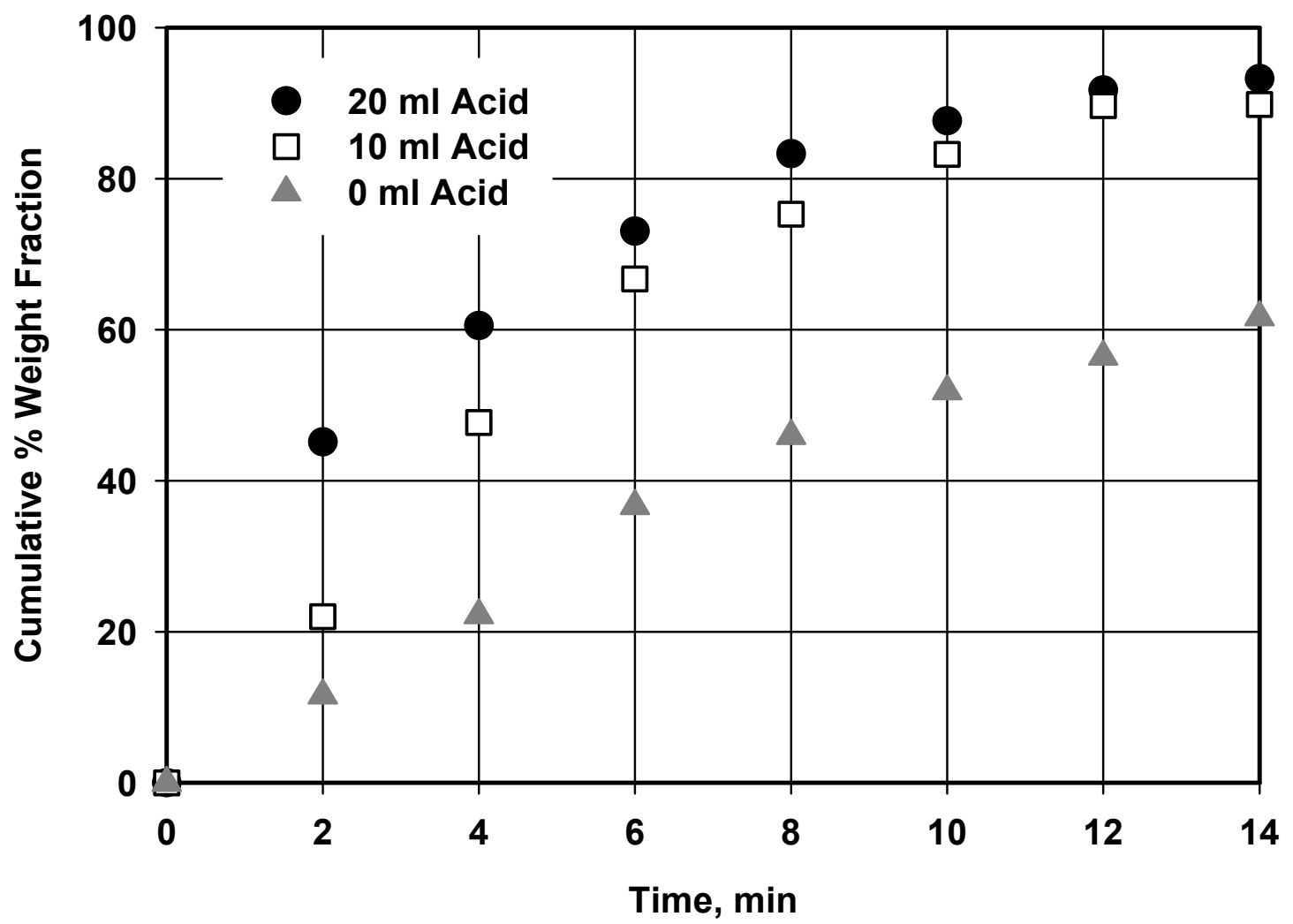

Figure 4.19 Effect of Oleic Acid on ABS Floatability 


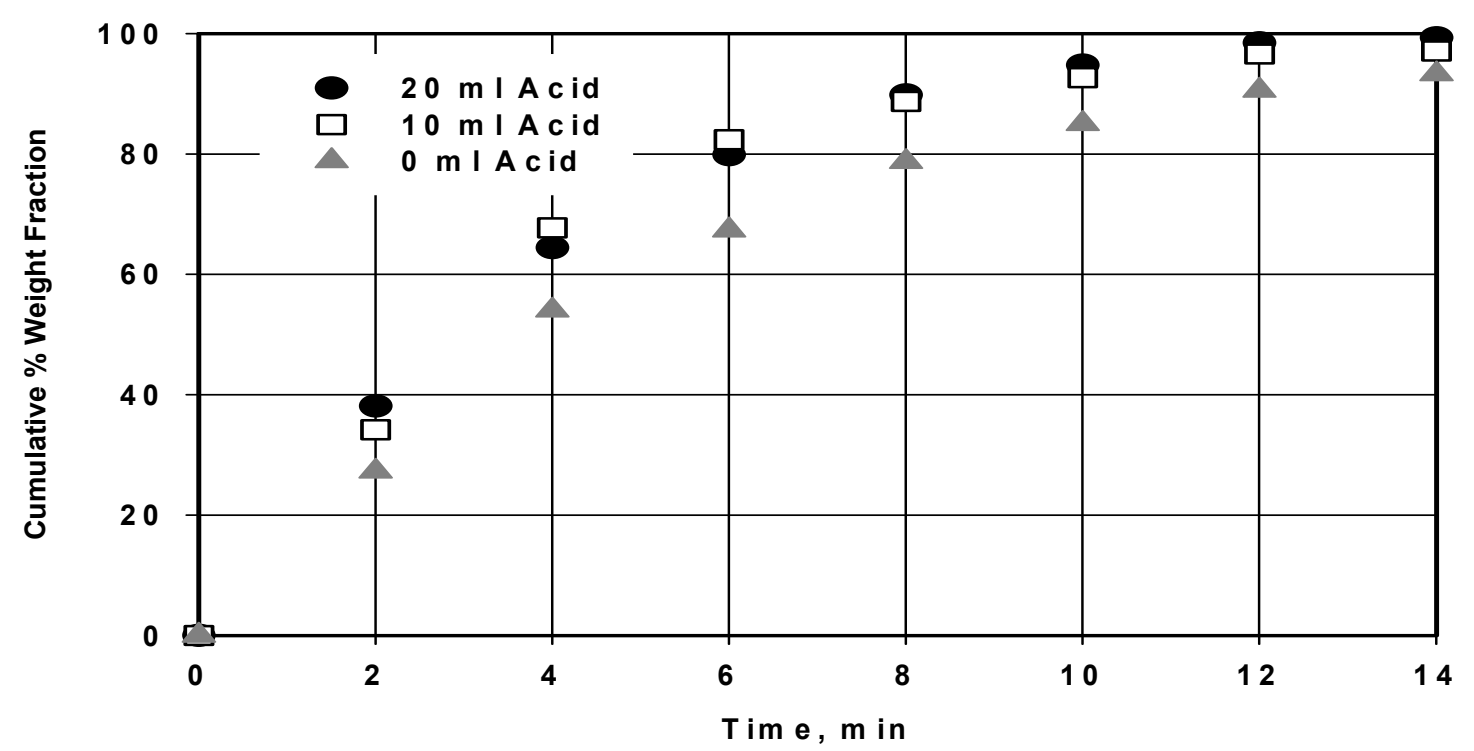

Figure 4.20 Effect of Oleic Acid on PS Floatability

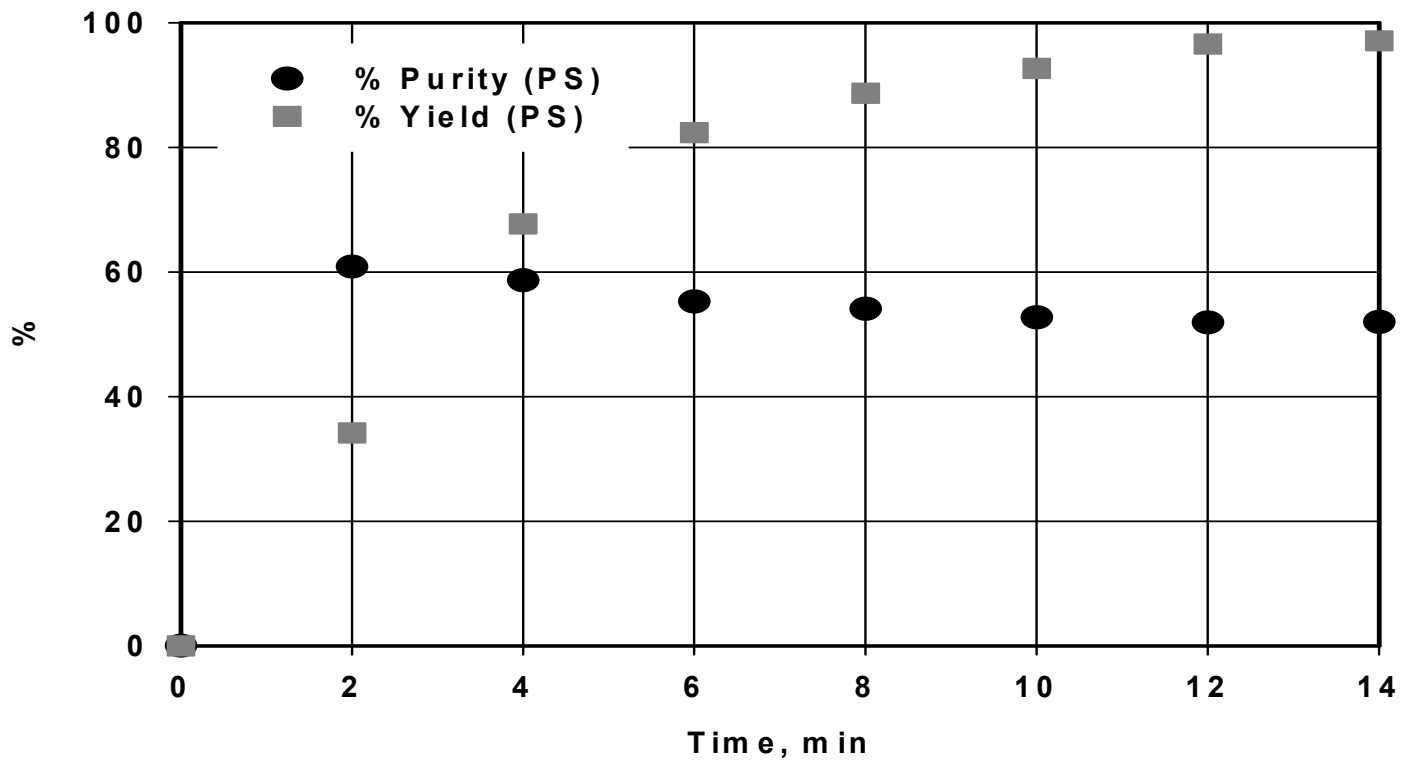

Figure $4.21 \%$ Yield and \% Purity of PS in the top fraction when using $1 \mathrm{ml}$ MIBC and $10 \mathrm{ml}$ oleic acid emulsion 


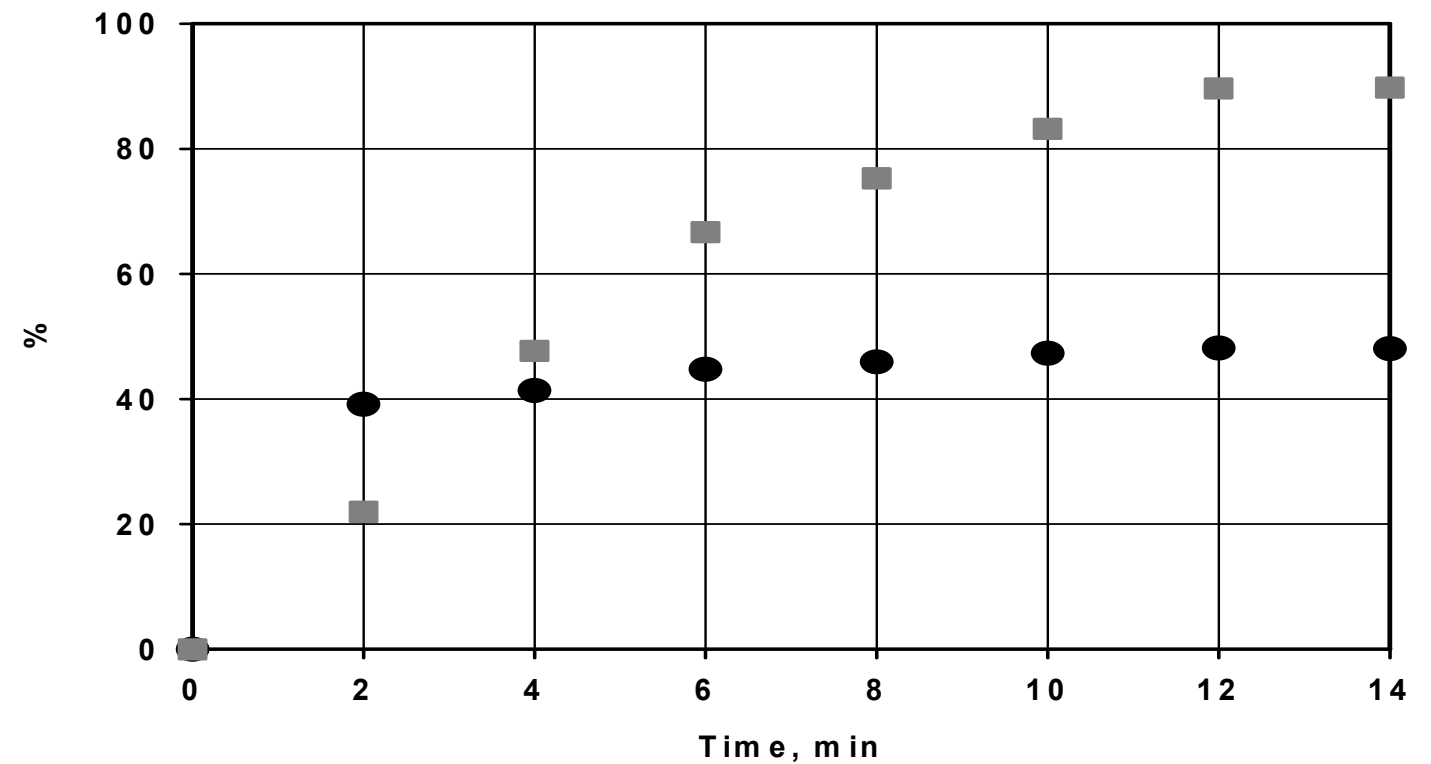

Figure $4.22 \%$ Yield and \% Purity of ABS in the top fraction when using $1 \mathrm{ml}$ MIBC and $10 \mathrm{ml}$ oleic acid emulsion

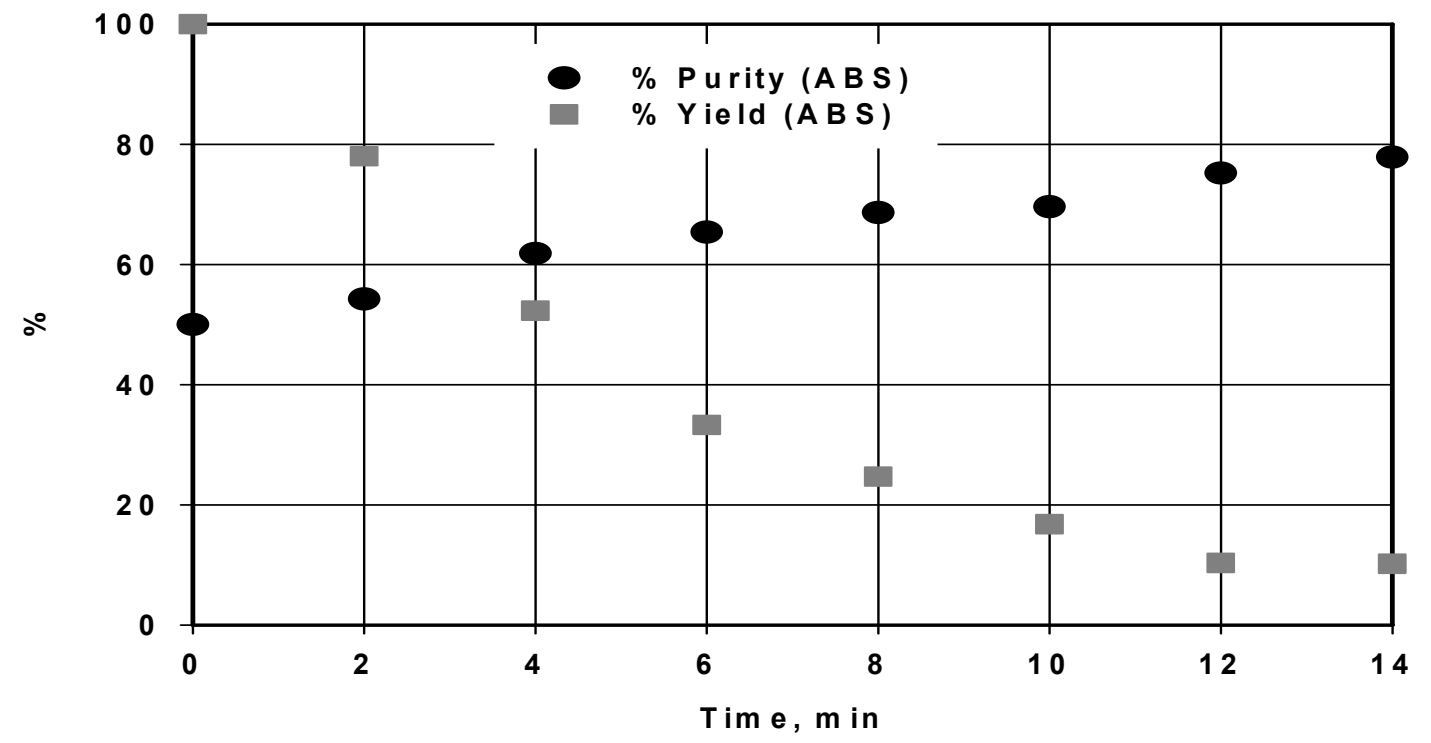

Figure $4.23 \%$ Yield and \% Purity of ABS in the bottom fraction when using $1 \mathrm{ml}$ MIBC and $10 \mathrm{ml}$ oleic acid emulsion 
Table 4.5 Purity and Yield for ABS and PS in various multi-stage floatation set-ups (with recycle) using $1 \mathrm{ml}$ MIBC, $10 \mathrm{ml}$ oleic acid emulsion and a batch time of 4 minutes

\begin{tabular}{|c|c|c|c|c|}
\cline { 2 - 5 } \multicolumn{1}{c|}{} & \multicolumn{2}{c|}{ 2-Stage } & \multicolumn{2}{c|}{ 3-Stage } \\
\cline { 2 - 5 } \multicolumn{1}{c|}{} & Yield & Purity & Yield & Purity \\
\hline PS & $82 \%$ & $64 \%$ & $90 \%$ & $68 \%$ \\
\hline ABS & $55 \%$ & $75 \%$ & $57 \%$ & $85 \%$ \\
\hline
\end{tabular}

It was observed that the purities and yields are obtained using MIBC and oleic acid are lower than those obtained when using only MIBC.

\subsubsection{Dodecylamine Hydrochloride Results}

Samples of 10 grams of plastic were floated using dodecylamine hydrochloride along with $1 \mathrm{ml} \mathrm{MIBC}$ as frothing agent in different experimental runs. Figures 4.24 and 4.25 show the effect of addition of amine and $1 \mathrm{ml}$ MIBC on ABS and PS floatabilities respectively. It is seen that addition of amine significantly decreases the floatability of both plastics. An analysis of \% purity and \% yield for PS and ABS as top products (Figures 4.26 and 4.27) shows that ABS is obtained at extremely low yields while PS yield also decreases due to addition of amine. However, PS and ABS were obtained at reasonable yields and purities as top and bottom products (Figures 4.26 and 4.28) at batch times of 12 and 14 minutes. Hence, multi-stage analysis was performed for both arbitrarily chosen batch times. Table 4.6 summarizes the yields and purities of the plastics in multi-stage set-ups using $1 \mathrm{ml}$ MIBC and 2 grams amine with each floatation cell operated for a batch time of 12 and 14 minutes. 


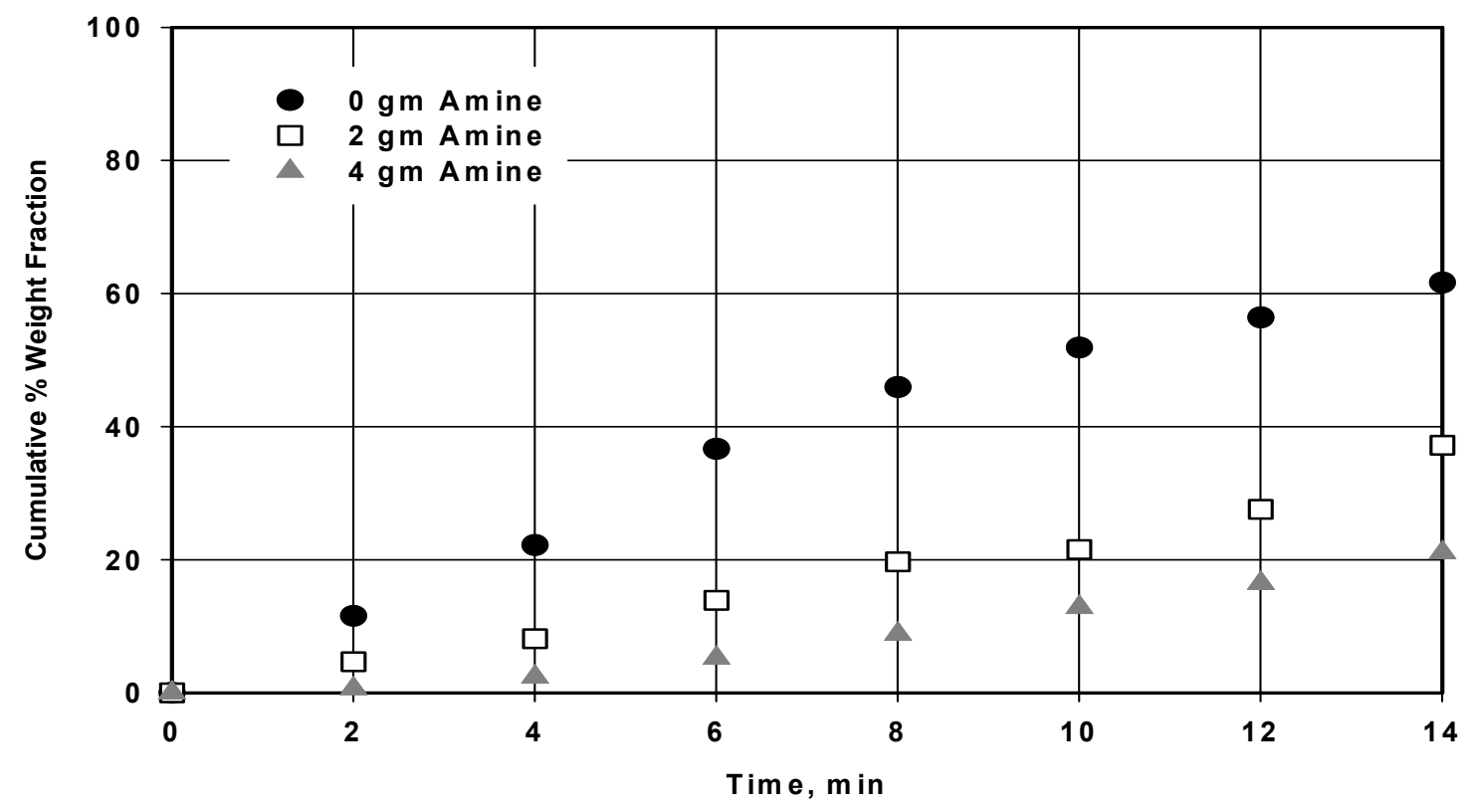

Figure 4.24 Effect of Dodecylamine Hydrochloride on ABS Floatability

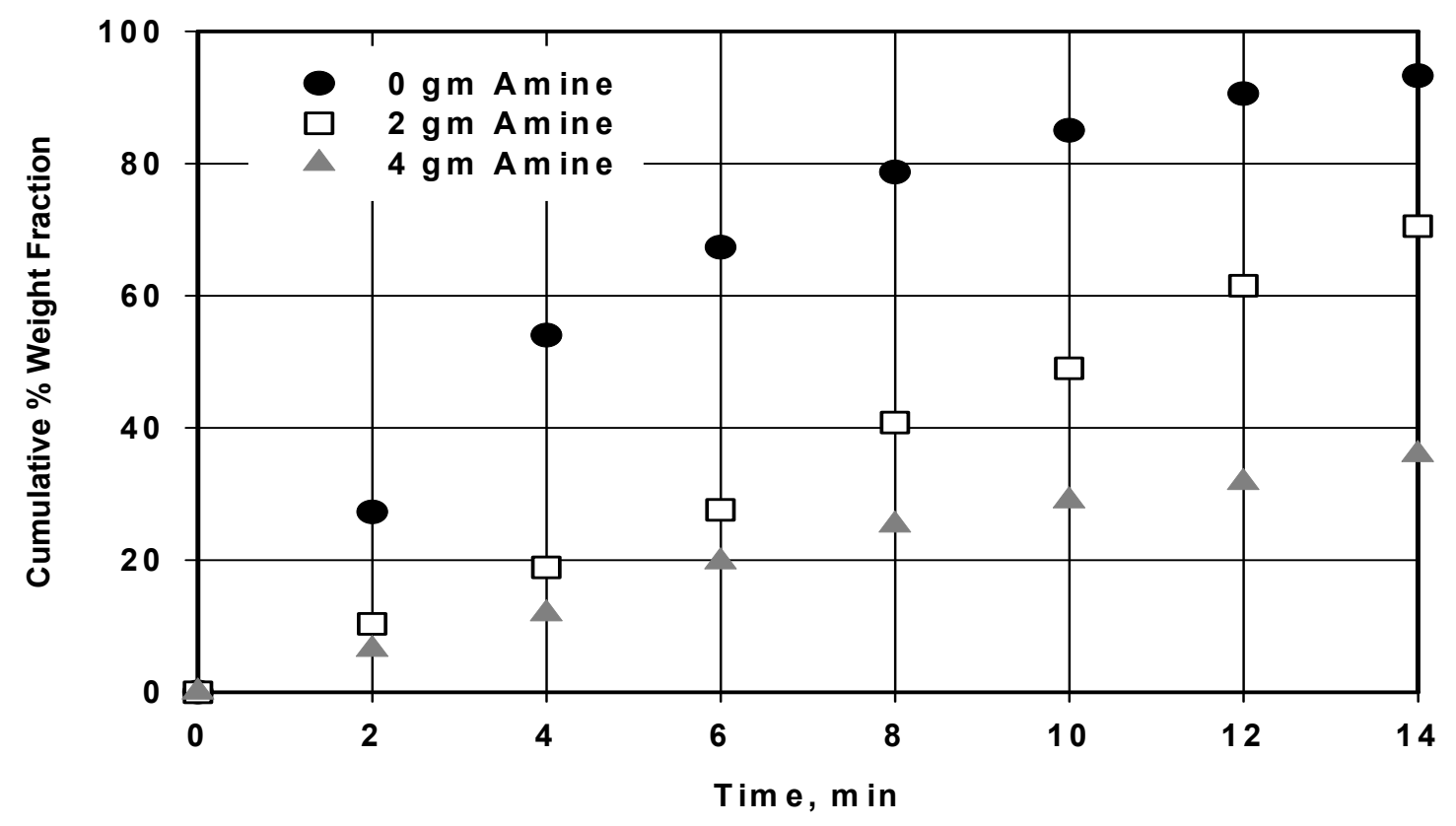

Figure 4.25 Effect of Dodecylamine Hydrochloride on PS Floatability 


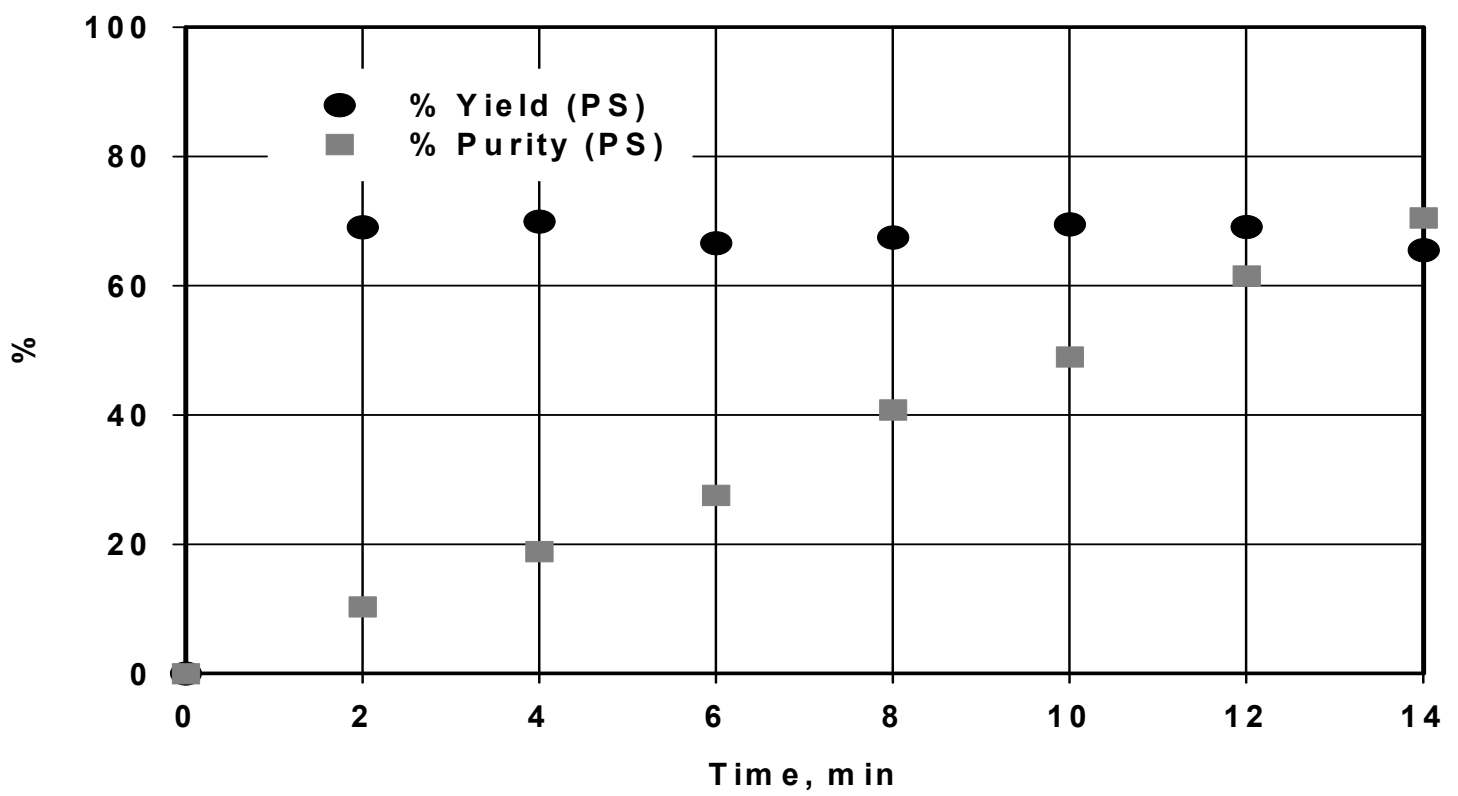

Figure $4.26 \%$ Yield and \% Purity of PS in the top fraction when using $1 \mathrm{ml}$ MIBC and 2 gm amine

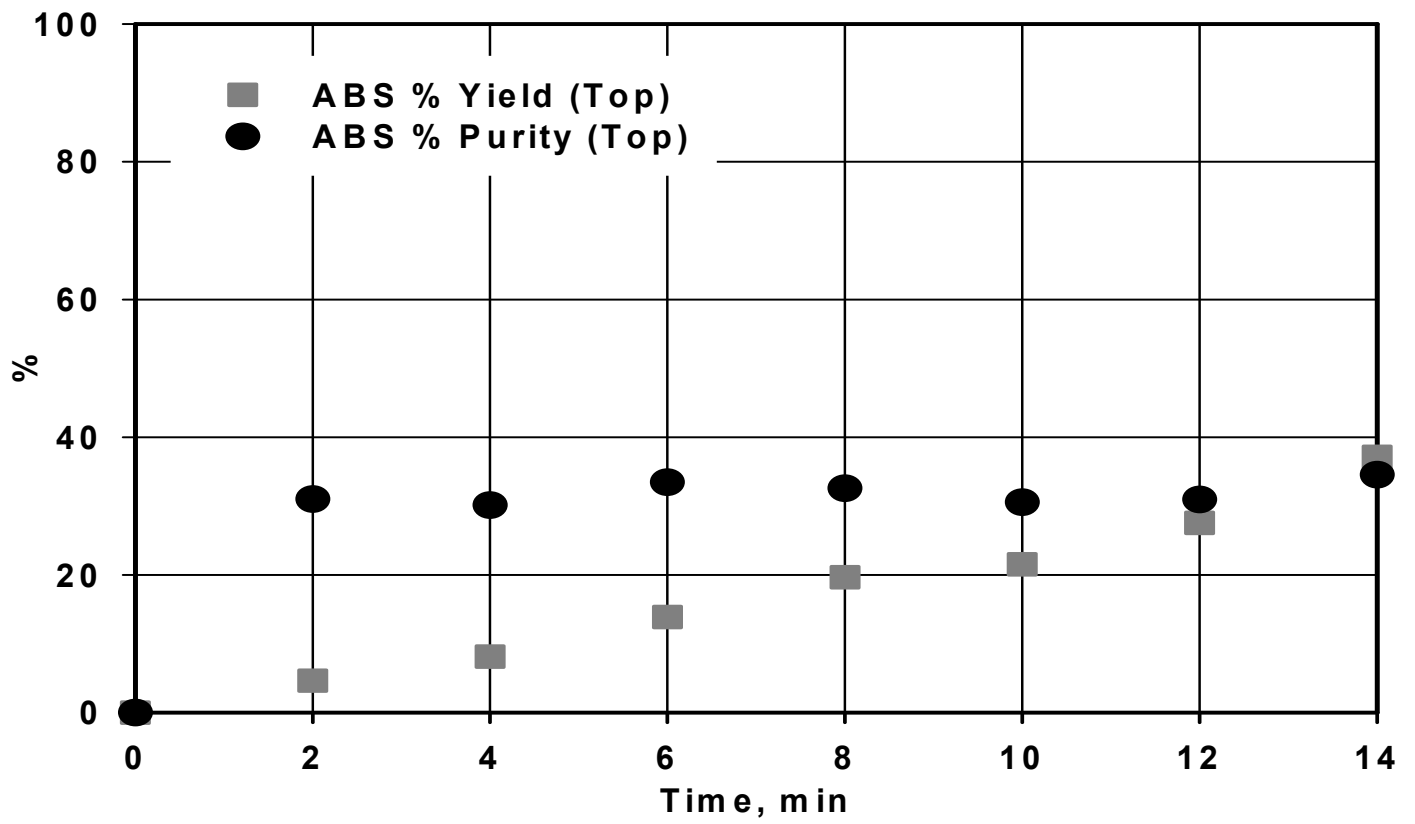

Figure $4.27 \%$ Yield and \% Purity of ABS in the top fraction when using $1 \mathrm{ml}$ MIBC and 2 gm amine 


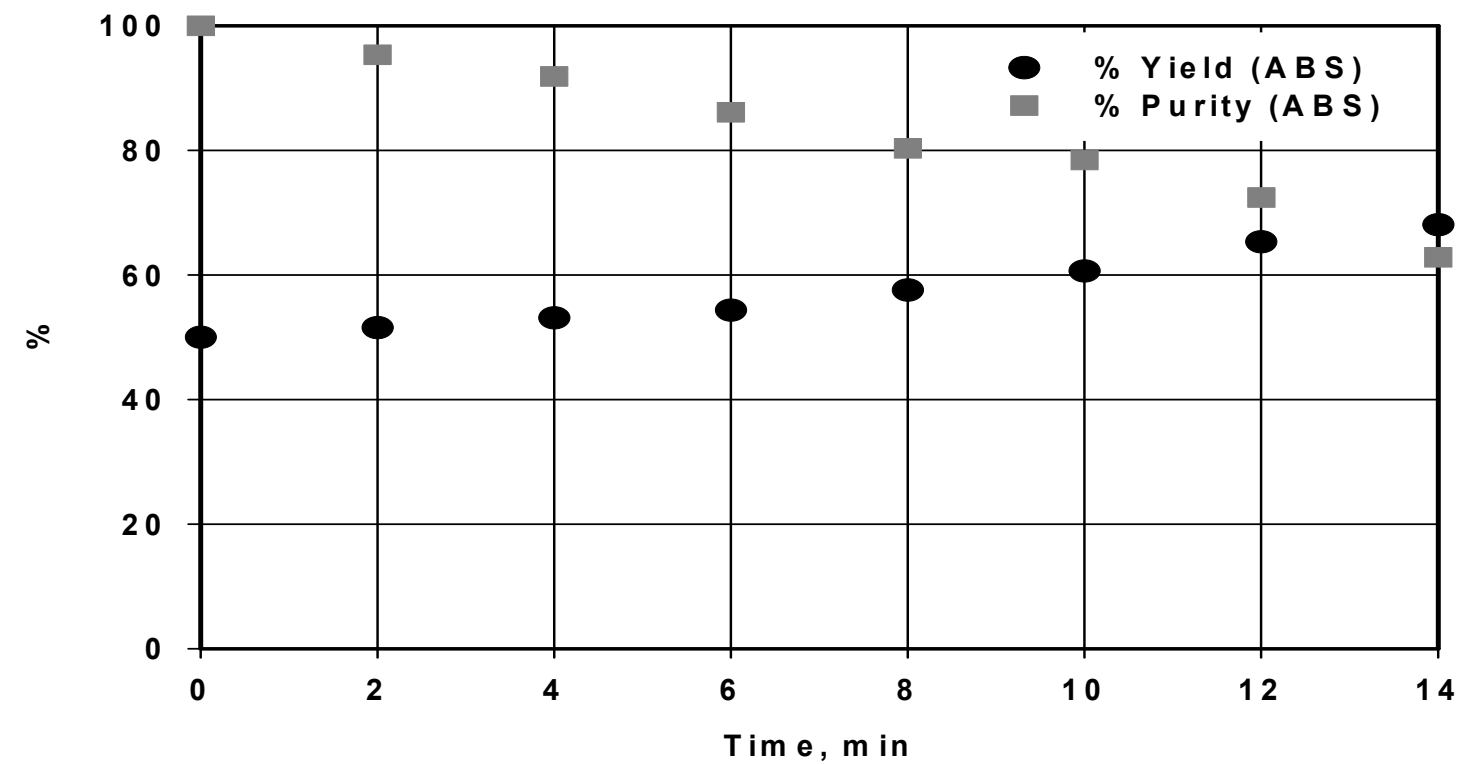

Figure $4.28 \%$ Yield and \% Purity of ABS in the bottom fraction when using $1 \mathrm{ml}$ MIBC and 2 gm amine

Table 4.6 Purity and Yield for ABS and PS in various multi-stage floatation set-ups (with recycle) using $1 \mathrm{ml}$ MIBC and $2 \mathrm{gm}$ amine

\begin{tabular}{|c|c|c|c|c|c|c|c|c|}
\hline & \multicolumn{4}{|c|}{ Batch time $=12$ minutes } & \multicolumn{4}{|c|}{ Batch time $=14$ minutes } \\
\hline & \multicolumn{2}{|c|}{ 2-Stage } & \multicolumn{2}{|c|}{ 3-Stage } & \multicolumn{2}{|c|}{ 2-Stage } & \multicolumn{2}{|c|}{ 3-Stage } \\
\hline & Yield & Purity & Yield & Purity & Yield & Purity & Yield & Purity \\
\hline PS & $72 \%$ & $85 \%$ & $80 \%$ & $94 \%$ & $85 \%$ & $77 \%$ & $93 \%$ & $85 \%$ \\
\hline $\mathrm{ABS}$ & $87 \%$ & $76 \%$ & $95 \%$ & $83 \%$ & $74 \%$ & $83 \%$ & $83 \%$ & $92 \%$ \\
\hline
\end{tabular}

It is observed that depending on the batch time of operation, ABS or PS is obtained at a higher purity. 


\subsubsection{Comparison of Results}

As seen from the previous sections, oleic acid and amine tend to have opposing effects on the plastic floatabilities. Hence, only one of them was used as surfactant in addition to MIBC frother in the experimental matrix. Figure 4.29 shows a comparison of the purity and yield of PS obtained in 3-stage setups using the experimental matrix described earlier.

The comparison is made at the batch times indicated in the Tables 4.4, 4.5 and 4.6 for MIBC, oleic acid and amine respectively. It is seen that using amine as surfactant with MIBC as frother and operating the flotation cells for 14 minutes each gives $85 \%$ pure PS at a yield of $93 \%$, the best possible combination for the cases studied in this work, while oleic acid seems to be a bad choice. A similar comparison for ABS is shown in Figure 4.30. It is seen that as in the case with PS, amine as surfactant with MIBC as frother and a batch time of 14 minutes gives the best possible quality of ABS, viz. $93 \%$ purity and $83 \%$ yield. It is also seen that use of oleic acid gives significantly lower quality of ABS. 


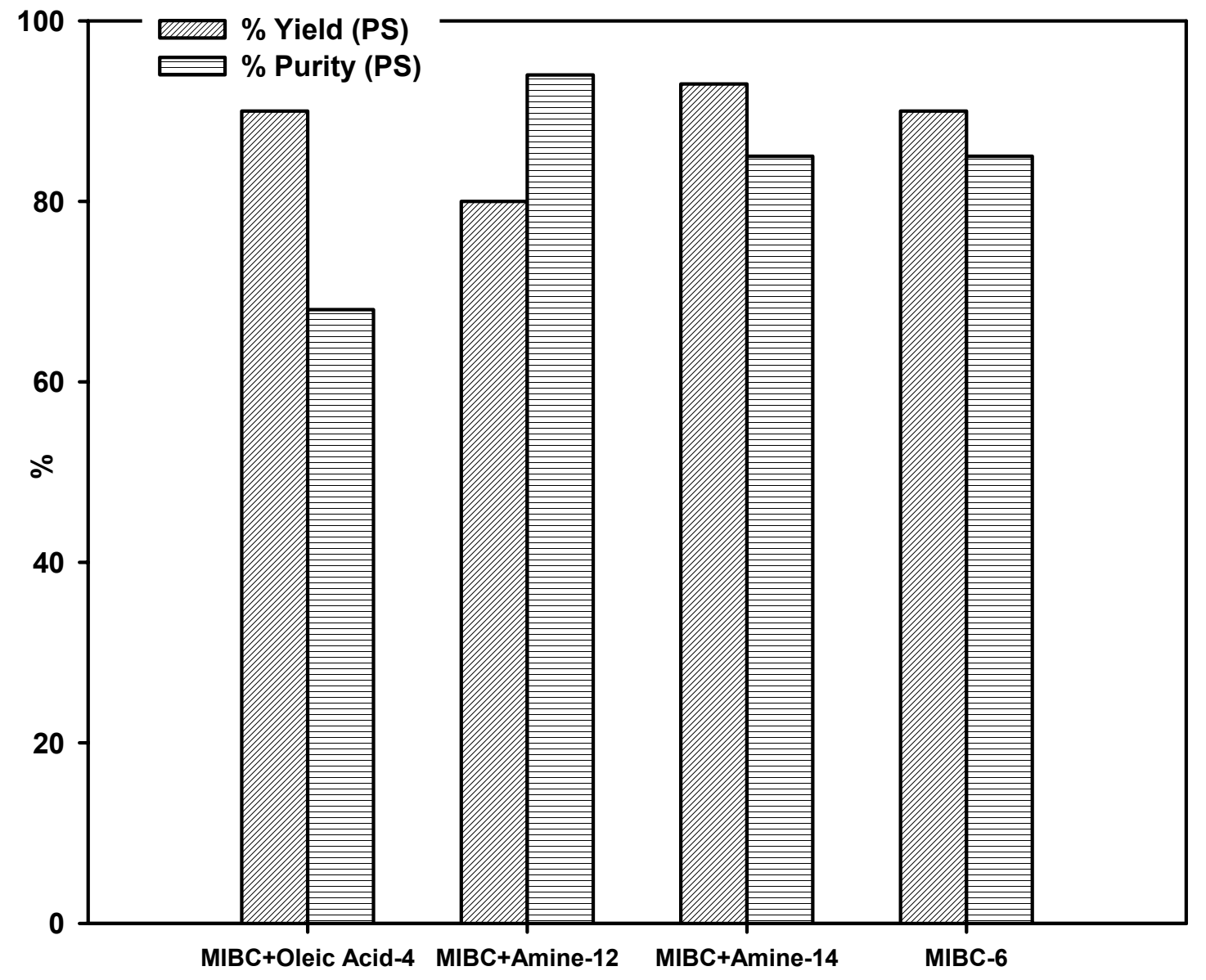

Figure 4.29 Yields and Purities for PS with different surfactant-frother combinations 


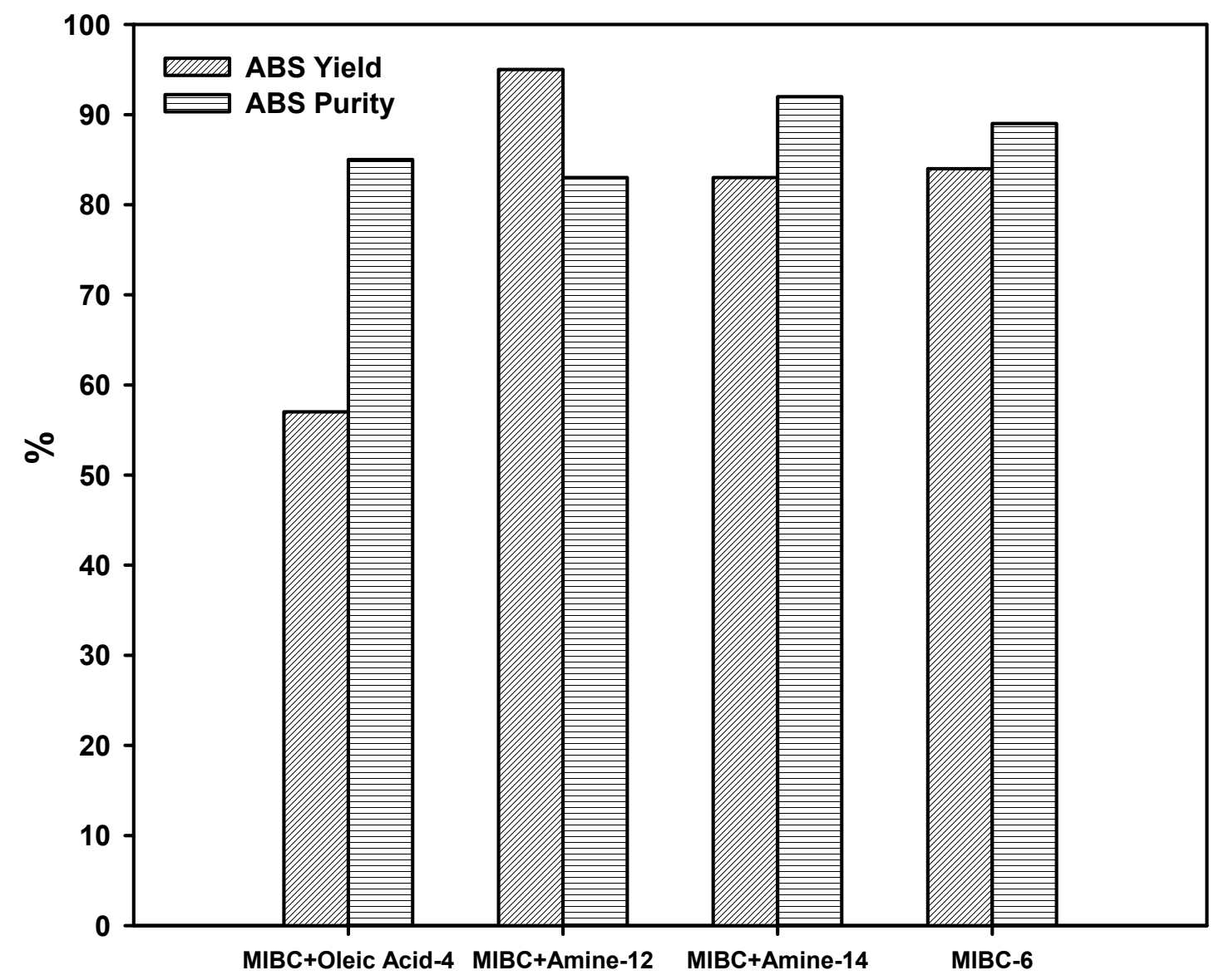

Figure 4.30 Yields and Purities for ABS with different surfactant-frother combinations

\subsection{5 'Mixed Plastics' Results}

A set of experiments was performed to confirm that flotation with both ABS and PS did not affect the multi-stage yields and purities predicted by the experiments performed using individual plastics. Figure 4.31 shows the calibration data for testing the complete dissolution of PS in $\mathrm{CS}_{2}$ from a given mixture of PS and ABS. As seen in the figure, the experimentally observed points almost overlap with that expected from theory assuming complete dissolution of PS and no dissolution of $\mathrm{ABS}$ in $\mathrm{CS}_{2}$. A slight 
variation is observed due the presence of $0.5 \%$ ash in the PS samples which remains undissolved. However, due to such low ash content, the theoretical values were used to calculate the amount of PS present in mixtures of PS and ABS obtained from 'mixed' flotation. Table 4.7 shows the actual experimental data with amount of ABS and PS taken in each known mixture and the amount of solids recovered in each case after dissolution in $\mathrm{CS}_{2}$.

Figures 4.32 and 4.33 show a comparison of flotation results obtained using 20 grams of ABS and PS (10 grams each) and those obtained from individual experiments using 10 grams of ABS and 10 grams of PS, respectively. A set of experiments using 5 grams of each plastic was also carried out to verify the effect of 'mixed' flotation. This was done so as to maintain the overall solid loading constant at 10 grams. However, due to the small amounts of each plastic, small experimental errors were magnified and the results obtained were inconclusive. Hence, 10 grams of each plastic was used to verify inter-particle interaction, albeit at a higher overall solid loading.

Table 4.7 Calibration Data for PS Solubility in $\mathbf{C S}_{2}$

\begin{tabular}{|c|c|c|c|c|c|}
\hline $\begin{array}{c}\text { PS } \\
\text { Weight } \\
(\mathrm{gm})\end{array}$ & $\begin{array}{c}\text { ABS } \\
\text { Weight } \\
(\mathrm{gm})\end{array}$ & $\begin{array}{c}\mathrm{CS}_{2} \\
\text { Volume } \\
(\mathrm{ml})\end{array}$ & $\begin{array}{c}\text { Experimental } \\
\text { Recovery } \\
(\mathrm{gm})\end{array}$ & $\% \mathrm{PS}$ & $\begin{array}{c}\text { Theoretical } \\
\text { Recovery } \\
(\mathrm{gm})\end{array}$ \\
\hline 2.0 & 0.0 & 50 & 0.01 & 100 & 0.0 \\
\hline 1.5 & 0.5 & 50 & 0.508 & 75 & 0.5 \\
\hline 1.0 & 1.0 & 50 & 1.005 & 50 & 1.0 \\
\hline 0.5 & 1.5 & 50 & 1.503 & 25 & 1.5 \\
\hline 0.0 & 2.0 & 50 & 2 & 0 & 2.0 \\
\hline
\end{tabular}




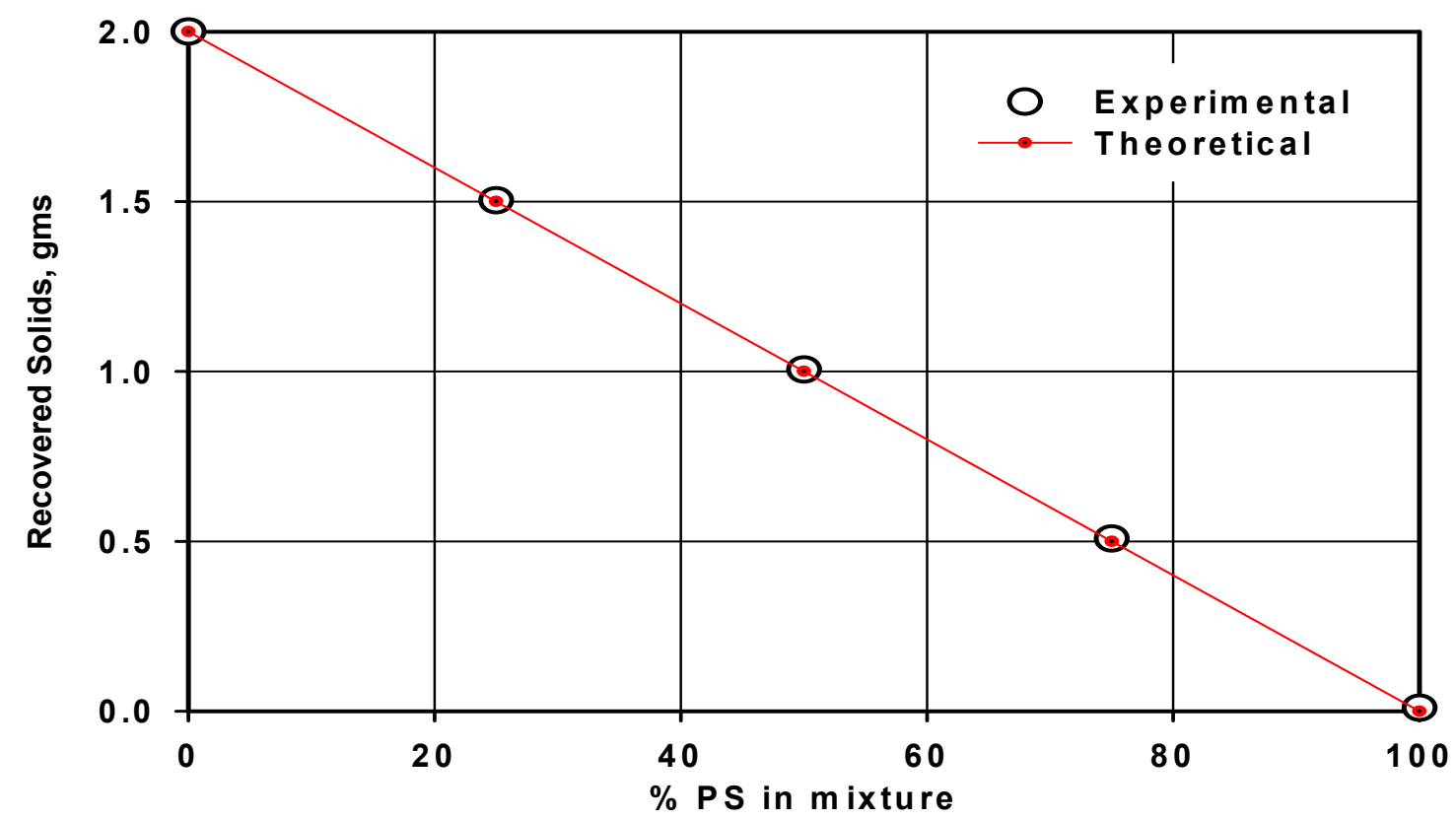

Figure 4.31 Calibration curve for PS solubility in $\mathrm{CS}_{2}$

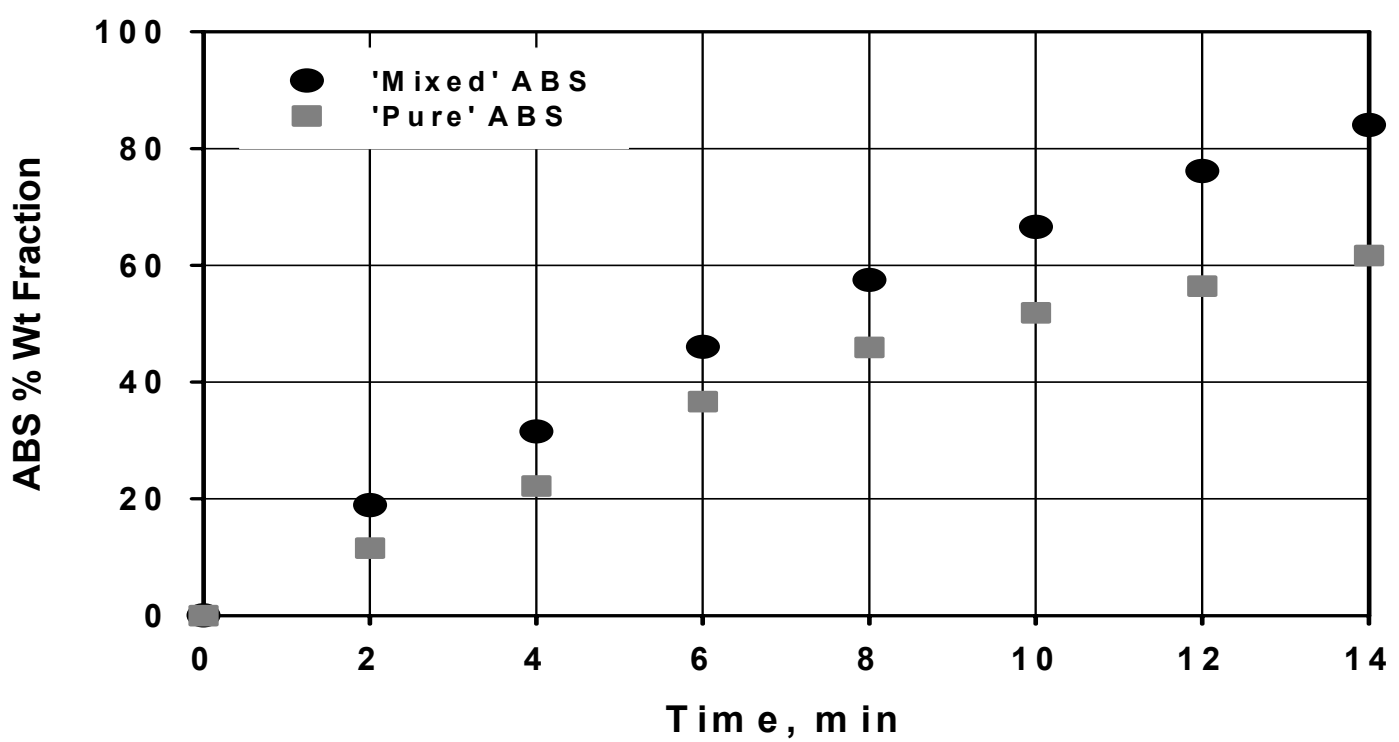

Figure 4.32 Flotation results for 'pure' and 'mixed' ABS using only $1 \mathrm{ml}$ MIBC 


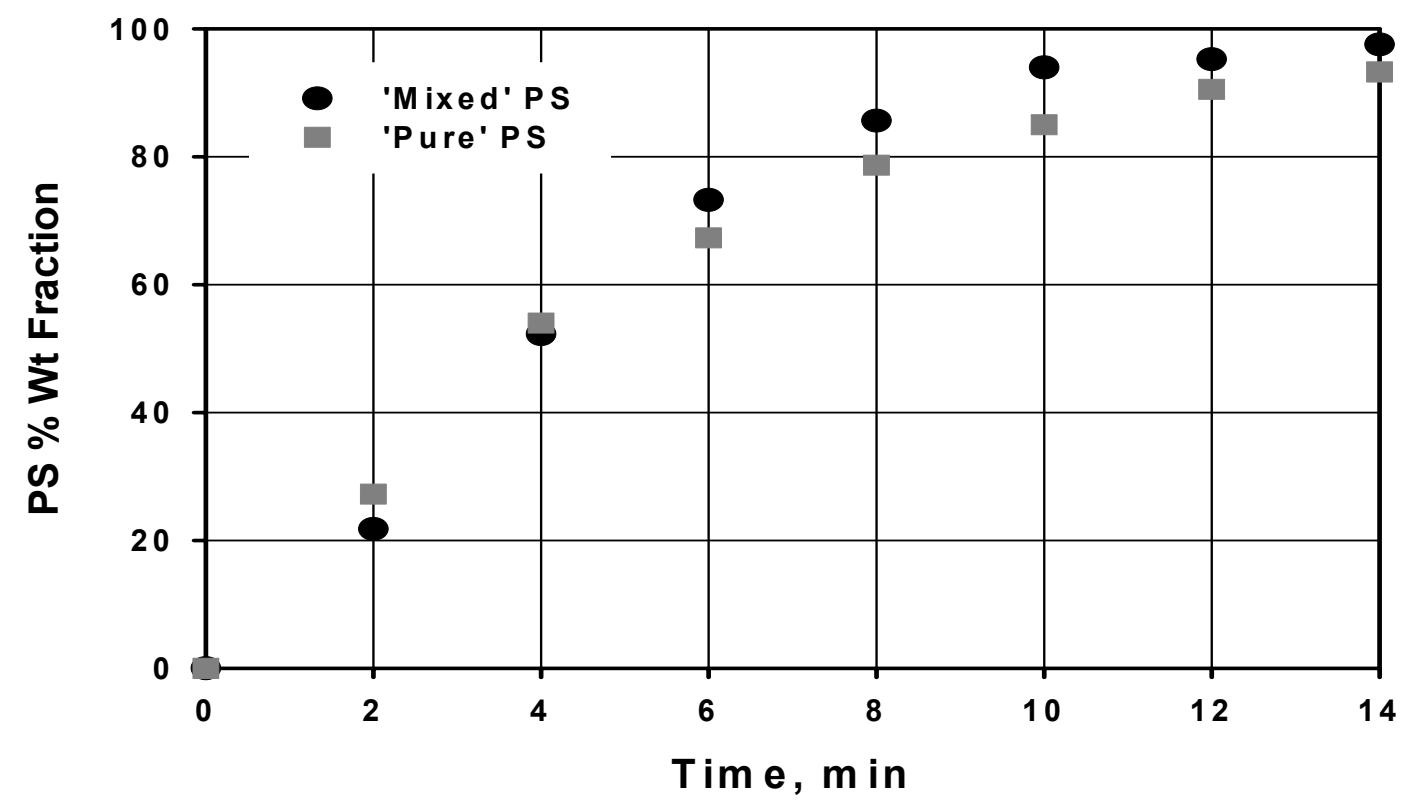

Figure 4.33 Flotation results for 'pure' and 'mixed' PS using only 1 ml MIBC

A multi-stage analysis performed for the flotation results using 'mixed' plastics is shown in Table 4.8.

Table 4.8 Comparison of purity and yield for 'pure' and 'mixed' ABS and PS in multi-stage flotation set-ups using only $1 \mathrm{ml} \mathrm{MIBC}$ at a batch time of 6 minutes

\begin{tabular}{|c|c|c|c|c|c|c|c|c|}
\cline { 2 - 8 } \multicolumn{1}{|c|}{} & \multicolumn{3}{c|}{ Individual Plastics } & \multicolumn{3}{c|}{ 'Mixed' Plastics } \\
\cline { 2 - 8 } & \multicolumn{2}{|c|}{ 2-Stage } & \multicolumn{2}{c|}{ 3-Stage } & \multicolumn{2}{c|}{ 2-Stage } & \multicolumn{2}{c|}{ 3-Stage } \\
\cline { 2 - 8 } & Yield & Purity & Yield & Purity & Yield & Purity & Yield & Purity \\
\hline PS & $81 \%$ & $76 \%$ & $90 \%$ & $85 \%$ & $88 \%$ & $68 \%$ & $95 \%$ & $71 \%$ \\
\hline ABS & $75 \%$ & $80 \%$ & $84 \%$ & $89 \%$ & $58 \%$ & $83 \%$ & $62 \%$ & $93 \%$ \\
\hline
\end{tabular}

It is seen that in most cases, both ABS and PS are obtained at lower yield and purity when flotation is carried out using both plastics, as compared to those obtained 
when floated separately. This could be due to inter-particle interactions causing more ABS to float than would normally do when floated individually. 


\section{Trends Explanation and Conclusions}

\subsection{EOL Equipment Material Balances and Plastic Identification}

- Five CPU models were dismantled and their material balances were established. ABS and HIPS were observed to be present in most CPU cases.

- Material balances for eleven keyboard models were established. HIPS was found in most keyboard casings, while the most keys seemed to be made up of ABS.

- Similar material balances were established for two HP printers. In addition to HIPS and $\mathrm{ABS}, \mathrm{PC}$ was also observed to be present in them.

Due to a substantial presence of HIPS and ABS in almost all EOL equipment, the focus of this research work was directed towards design of a separation scheme for these two specific EOL plastics.

\subsection{Summary of Ash Analysis and Density Results}

- PC from printers was observed to contain the highest ash content ( $25 \%)$, resulting in a high density of $1.35 \mathrm{gm} / \mathrm{cm}^{3}$.

- Polyacetal key supports had zero ash content with the highest density of $1.41 \mathrm{gm} / \mathrm{cm}^{3}$.

- Most HIPS and ABS samples were found to have $<1 \%$ ash content. However, due to very close density ranges, float sink technique would not be a viable method to separate HIPS and ABS. A froth flotation technique was investigated instead. 


\subsection{Froth Flotation Results}

\subsubsection{Single stage vs multi-stage flotation setups}

- A multi-stage flotation setup gives a higher purity for both plastics. This is however at the cost of lower yields. For example, using $1 \mathrm{ml}$ MIBC for a batch time of 6 minutes, in a 3 -stage setup, the $\%$ yield is a dismal $31 \%$ and $25 \%$ for PS and ABS respectively, albeit at an increased purity of $86 \%$ and $88 \%$.

- Recycling the intermediate streams to previous stages increases the yield significantly at almost the same purity obtained for the corresponding multi-stage process without recycle. The results indicated above are those for without recycle. With recycle, a 3stage setup gives HIPS at the same $85 \%$ purity, but at an increased yield of $90 \%$. The ABS obtained in this case is about $89 \%$ pure at an increased yield of $84 \%$.

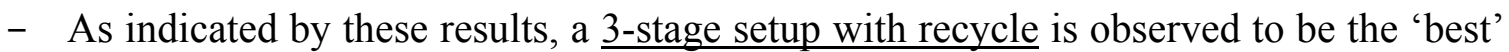
flotation setup for obtaining a high yield and purity for both plastics for a particular batch time for a given surfactant / frother combination.

\subsection{2 $\mathrm{MIBC}\left[\left(\mathrm{CH}_{3}\right)_{2} \mathrm{CH}-\mathrm{CH}_{2}-\mathrm{CH}(\mathrm{OH})-\mathrm{CH}_{3}\right]$}

- MIBC is a frother whose primary purpose is to stabilize the air bubbles so that they are capable of carrying the hydrophobic particles to the surface. MIBC increases the hydrophobicity of HIPS up to a certain stage beyond which HIPS floatability reverts to its original state (flotation without any surfactants / frother added) with no further effect in its floatability on MIBC addition. As MIBC is added, stability of air bubbles increase thereby facilitating floatability of the more hydrophobic plastic, HIPS. This is evident from the fact that almost $95 \%$ of HIPS is observed to float to the top after 
14 minutes of flotation using $1 \mathrm{ml}$ MIBC. However, on further addition of MIBC, organic part of MIBC interacts with the hydrophobic HIPS molecule, thereby decreasing its net hydrophobicity and hence lowering its floatability. This is evident as HIPS floatability decreases to $80 \%$ after 14 minutes when more than $1 \mathrm{ml}$ of MIBC is added.

- It is observed that MIBC decreases hydrophobicity of ABS causing it to sink. Increasing MIBC concentration, apart from stabilizing the air bubbles, also tends to interact with the hydrophobic part of ABS. However, as the ABS molecule has a larger hydrophobic part compared to HIPS, organic-organic interaction is stronger and hence, there is a steady decrease in ABS floatability. For example, after 14 minutes of flotation, addition of $5 \mathrm{ml}$ of MIBC causes only $43 \%$ of ABS to float.

- Using $1 \mathrm{ml}$ MIBC, a batch time of 6 minutes was arbitrarily chosen for performing multi-stage calculations as there is $67 \%$ HIPS recovery and $37 \%$ ABS recovery at the top leading to sufficient difference in the separabilities of the two plastics.

\subsubsection{Oleic acid Emulsion in $\mathrm{NaOH}\left[\mathrm{C}_{17} \mathrm{H}_{33} \mathrm{COO}^{-} \mathrm{Na}^{+}\right]$}

- Oleic acid increases the hydrophobicity of both HIPS and ABS causing both to rise to the surface. Moreover, oleic acid also acts as an effective frother stabilizing the air bubbles. The organic part of oleic acid molecule seems to have a dominant effect on hydrophobic parts of both plastics. As a result, at the end of 14 minutes, almost $85 \%$ of ABS and $95 \%$ of HIPS float to the surface on using only $10 \mathrm{ml}$ of oleic acid emulsion. This effect is further magnified when using $20 \mathrm{ml}$ of oleic acid.

- When using $10 \mathrm{ml}$ oleic acid emulsion, both HIPS and ABS are obtained at reasonable yields and purities at an arbitrarily chosen batch time of about 4 minutes 
as $60 \%$ pure HIPS is obtained at $65 \%$ yield, while $\mathrm{ABS}$ obtained is about $62 \%$ purity and $54 \%$ yield.

\subsubsection{Dodecylamine Hydrochloride $\left[\mathrm{C}_{12} \mathrm{H}_{25} \mathrm{NH}_{3}{ }^{+} \mathrm{Cl}^{-}\right]$}

- The amine salt decreases the hydrophobicity of both HIPS and ABS causing both to sink. The organic part of the amine interacts more favorably with the organic parts of HIPS and ABS. On the other hand, the positively charged alkyl ammonium ion weakenes the stabilization of the air bubbles by MIBC, thereby resulting in a net decrease in the floatability of both HIPS and ABS. This is evident in the observation that only $38 \%$ of ABS and about $70 \%$ of HIPS float to the top after 14 minutes of flotation when using 2 grams of amine salt. The effect gets further reinforced when using 4 grams of amine.

- Batch times of 12 minutes and 14 minutes show comparable yields and purities for HIPS and ABS. At 12 minutes, HIPS is obtained at $60 \%$ purity with $65 \%$ yield, while ABS obtained is $70 \%$ pure at a yield of about $65 \%$. At 14 minutes, HIPS obtained is $70 \%$ pure at about $64 \%$ yield, while ABS purity is $62 \%$ at a yield of $68 \%$.

\subsubsection{Comparison of flotation results in a 3-stage flotation setup with recycle}

- When using $1 \mathrm{ml}$ MIBC with a batch time of 6 minutes, HIPS is obtained at $85 \%$ purity at $90 \%$ yield, while ABS obtained is $89 \%$ pure at $85 \%$ yield. On the other hand, when using $2 \mathrm{gm}$ amine $+1 \mathrm{ml}$ MIBC, depending on the batch time of operation (12 minutes or 14 minutes), HIPS or ABS is obtained at a higher purity and lower yield. 
- Very poor yields and purities are obtained using $10 \mathrm{ml}$ oleic acid emulsion with a batch time of 4 minutes. For example, HIPS is obtained only $68 \%$ pure although at $90 \%$ yield, while ABS obtained is $84 \%$ yield at a very low yield of $57 \%$.

\subsubsection{Froth flotation of 'Mixed' Plastic}

- Inter-particle interaction is evident in performing froth flotation with both plastics. The presence of HIPS seems to increase the floatability of ABS and vice versa. For example, at the end of 14 minutes, in the case of 'mixed' flotation, about $82 \%$ ABS and $98 \%$ HIPS float to the top of the column as compared to $62 \%$ ABS and $95 \%$ HIPS when floated individually.

- However, corresponding to the multi-stage flotation setup using $1 \mathrm{ml}$ MIBC, a comparison at a batch time of 6 minutes shows that ABS is obtained at a higher purity with a lower yield, while HIPS collected at the top is of a higher yield with a decrease in its purity. For example, for a 3-stage setup with recycle, ABS is obtained at $93 \%$ purity at a yield of $62 \%$ in 'mixed' plastic flotation as against its purity and yield being $89 \%$ and $84 \%$ respectively when floated by itself. A similar comparison for HIPS shows that 'mixed' flotation gives $71 \%$ pure HIPS at $95 \%$ yield as against $85 \%$ pure HIPS at $90 \%$ yield when floated individually. 


\section{Future Work and Recommendations}

- A disadvantage of using cationic surfactants is that a large batch time is required to arrive at suitable separation efficiency. This could be overcome by investigating a variety of cationic surfactants to arrive at an optimum amount / blends to be used to increase the separation efficiency at lower batch times. The amine salt used in this work is effective in hindering the flotation of both HIPS and ABS because of large hydrophobic part. Increasing the size of the hydrophobic part would have a counter effect as ABS has a larger organic group compared to HIPS, thereby lowering the yield and increasing the batch times even further. Hence, it is suggested that amine salts with lower number of carbon atoms could be tried. Chloride salts of lower fatty amines such as hexyl amine and octyl amine could be investigated.

- An extremely high purity of $99 \%$ is required for recycled polymers to be used as feedstock to replace virgin polymers or for them to be mixed with virgin polymers during the processing stages. A chemical method to further purify HIPS and ABS from $90 \%$ to $98-99 \%$ could be investigated using a variety of solvents such as NMP, cyclohexane, butanol and acetone.

- It is observed that for different volumes of MIBC used, $1 \mathrm{ml}$ of MIBC yields the best results. However, intermediate volumes of MIBC such as $0.25 \mathrm{ml}, 0.5 \mathrm{ml}$ and 1.25 $\mathrm{ml}$ needs to be tested to verify the exact position of the maxima that is observed at 1 $\mathrm{ml}$ in the current work.

- All results for multi-stage flotation were obtained assuming similar yields and purities as those obtained for a single stage. However, length of exposure to the aqueous 
media and surfactants could have an effect on the surface properties of the plastics. Multi-stage flotation data needs to be verified by performing experiments using the same batch of plastics repeatedly to simulate the working of several stages.

- Additional experiments could be carried out to further quantify the effect of inter particle interactions during froth floatation. The different results obtained during 'mixed' plastics floatation could be either due to a higher solid loading or due to the simultaneous flotation of both plastics. This could be verified and quantified by varying the individual as well as combined solid loading during each run.

- Other parameters such as $\mathrm{pH}$, density, air flow rate and surface tension can be varied to study their effects on the separation efficiencies. 


\section{Nomenclature}

Acronyms:

ASR

ASTM

CPU

DOE

EOL

EPA

FCC

NETL

PAZ

SCFM

Polymers:

ABS

EDC

HIPS

MIBC

NMP

PA

PBT

PC
Automobile Shredder Residue

American Society for Testing and Materials

Central Processing Unit

Department of Energy

End of Life

Environmental Protection Agency

Federal Communications Commission

National Energy Technology Laboratory

Polymer Alliance Zone

Standard cubic foot per minute

Acrylonitrile Butadiene Styrene copolymer

Ehtylene dichloride

High Impact Polystyrene

Methyl isobutyl carbinol

N-methyl pyrrolidone

Polyacetal

Polybutyl terephthalate

Polycarbonate 


$\begin{array}{ll}\text { PE } & \text { Polyethylene } \\ \text { PET } & \text { Polyethyl terephthalate } \\ \text { PP } & \text { Polypropylene } \\ \text { PPO } & \text { Polypropylene oxide } \\ \text { PS } & \text { Polystyrene } \\ \text { PVC } & \text { Polyvinyl chloride } \\ \text { SAN } & \text { Styrene Acrylonitrile copolymer } \\ \text { S-B } & \text { Styrene }- \text { Butadiene copolymer } \\ \text { THF } & \text { Tetrhydrofuran } \\ \text { VA } & \text { Vinyl acetate } \\ \text { VC } & \text { Vinyl chloride } \\ \text { V-OH } & \text { Vinyl alcohol }\end{array}$

Analytical Instruments / Techniques:

CCD

DDA

FTIR

MIR

NMR

UV
Charged Coupled Device

Differential Density Alteration

Fourier Transform Infra Red

Mid Infra Red

Neutron Magnetic Resonance

Ultra-violet 


\section{References}

1. "Plastics: A Material of Choice for the Electrical and Electronic Industry--Plastics Consumption and Recovery in Western Europe", Association of Plastics Manufacturers in Europe, 1995.

2. Headley Pratt Consulting, "Plastics from Residential Electronics Recycling: Report 2000", A Summary Report from the Electrical and Electronics Group of the American Plastics Council, April 2000.

3. "Residential Collection of Household End-of-Life Electrical and Electronic Equipment: Pilot Collection Project", U.S. Environmental Protection Agency, February 1998.

4 Amos M. J., "Cleaning Up the Waste Stream - Recycling Plastics", Waste Management Publication WM2, October 1993.

5 Buchan R. and Yarar B., "Application of Mineral - Processing Technology to Plastics Recycling”, Mining Engineering, November 1996, 69 - 72.

6 "Recovery of Plastics from Municipally Collected Electrical and Electronic Goods", Summary Report of Research done by MBA Polymers Inc. and sponsored by APC and The Materials for Future Foundation (MFF), March 1999.

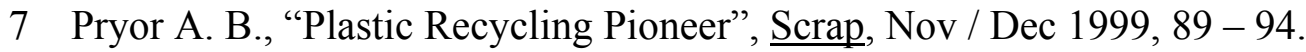

8 Bradley D., "The Hydrocyclone”, Pergamon Press., 1965, p. 45.

9 "Development of Hydrocyclones for Use in Plastics Recycling", Summary Report of Research done by MBA Polymers Inc. and sponsored by APC, February 1999.

10 Wills B. A., "Mineral Processing Technology", $5^{\text {th }}$ Ed., Pergamon Press, 1992. 
11 Fuerstanau D. W., "Where We Are In Flotation Chemistry After 70 Years of Research", Proceedings of the XIX International Mineral Processing Congress, San Francisco, 1975.

12 WVU Final Report (1999) for MBA Polymers Inc.

13 Wasan T. Darsh, Ginn E. Martin and Shah O. Dinesh, "Surfactants in Chemical / Process Engineering", Surfactant Science Series, Vol 28, Marcel Dekker Inc., NY, 200 (1988).

14 Ahmed N. and Jameson G. J., "Flotation Kinetics", Mineral Processing and Extractive Metallurgy Review, Volume 5, 1989, pp. 77 - 99.

15 Miller J. D. and Ye Y., "Froth Characteristics in Air - Sparged Hydrocyclone Flotation", Mineral Processing and Extractive Metallurgy Review, Vol 5, $307-329$ (1989).

16 Jody, B. J., Karvelas, D. E., Daniels, E. J. and Pomykala Jr., J. A., "Separation and Recovery of Thermoplastics by Froth Flotation", Argonne National Laboratory Energy Systems Division, Presented at 1999 DEER-2 Conference, Tampa, FL, Oct 26-27 (1999).

17 Bassam J. Jody, Bayram Arman, Dimitrios E. Karvelas, Downers Grove, Joseph A. Pomykala, Jr., Edward J. Daniels, "Method for Separation of High Impact Polystyrene (HIPS) and Acrylonitrile Butadiene Styrene (ABS) Plastics", $\underline{\text { U. S. Patent }}$ 5,653,867. Patented August 5, 1997.

18 Drelich J., Payne T., Kim J. H., Miller J. D., Kobler R. and Christiansen S., "Selective Froth Flotation of PVC from PVC / PET Mixtures for the Plastic Recycling Industry", Polymer Engg. and Science, 38 (9), September 1998, (1378 - 1386) 
19 Chuanfu (Chuck) Xiao, Laurence E. Allen, Michael B. Biddle and Michael M. Fisher, "Electrostatic Separation and Recovery of Mixed Plastics", Proceedings ARC Conference, Detroit, MI, November 1999.

20 Allen III, Lawrence E., Arola and Darren F., "Apparatus and Method for Enhancing Partitioning of Different Polymeric Materials From a Mixture by Density Differential Alteration", U. S. Patent 6,335,376, Patented January 1, 2002.

21 Jody B. J., Daniels E. J. and Bonsignore P. V., "Process to Recycle Shredder Residue", U. S. Patent 6,329,436, Patented December 11, 2001. 


\section{Appendix}

\section{A.1 Material Balance Data}

\section{A.1.1 CPU Material Balances}

$\operatorname{ccs} 386$

\begin{tabular}{|c|c|c|c|c|c|}
\hline $\begin{array}{l}\text { Plastic } \\
\text { Type }\end{array}$ & $\begin{array}{l}\text { Weight } \\
\text { (gms) }\end{array}$ & $\begin{array}{c}\% \\
\text { Weight }\end{array}$ & & $\begin{array}{l}\text { Weight } \\
\text { (gms) }\end{array}$ & $\begin{array}{c}\% \\
\text { Weight }\end{array}$ \\
\hline Green & 206 & 2.649 & \multirow{2}{*}{ Plastic } & \multirow{2}{*}{276} & \multirow{2}{*}{3.55} \\
\hline Gray & 70 & 0.9001 & & & \\
\hline $\begin{array}{l}\text { Rem } \\
\text { weight }\end{array}$ & 7501 & 96.45 & & & \\
\hline Net & 7777 & 100 & & & \\
\hline
\end{tabular}

Gateway 2000 New Tower

FCC ID:

HWYALP5100T

\begin{tabular}{|c|c|c|c|c|c|}
\hline $\begin{array}{c}\text { Plastic } \\
\text { Type }\end{array}$ & $\begin{array}{l}\text { Weight } \\
\text { (gms) }\end{array}$ & $\begin{array}{c}\% \\
\text { Weight }\end{array}$ & & $\begin{array}{l}\text { Weight } \\
\text { (gms) }\end{array}$ & $\begin{array}{c}\% \\
\text { Weight }\end{array}$ \\
\hline White & 1012 & 6.4090 & \multirow{4}{*}{ Plastic } & \multirow{4}{*}{1181} & \multirow{4}{*}{7.4793} \\
\hline $\begin{array}{l}\text { Greenish } \\
\text { White }\end{array}$ & 32 & 0.2027 & & & \\
\hline Black & 37 & 0.2343 & & & \\
\hline $\begin{array}{c}\text { Floppy } \\
\text { Drive }\end{array}$ & 100 & 0.6333 & & & \\
\hline $\begin{array}{l}\text { Rem } \\
\text { weight }\end{array}$ & 14609 & 92.521 & & & \\
\hline Net & 15790 & 100 & & & \\
\hline
\end{tabular}


GIC 486 GIC S/N No.: 002537

\begin{tabular}{|c|c|c|c|c|c|}
\hline $\begin{array}{l}\text { Plastic } \\
\text { Type }\end{array}$ & $\begin{array}{l}\text { Weight } \\
\text { (gms) }\end{array}$ & $\begin{array}{c}\% \\
\text { Weight }\end{array}$ & & $\begin{array}{c}\text { Weight } \\
\text { (gms) }\end{array}$ & $\%$ Weight \\
\hline $\begin{array}{l}\text { Muddy } \\
\text { White }\end{array}$ & 288 & 3.541 & \multirow[t]{2}{*}{ Plastic } & \multirow[t]{2}{*}{318} & \multirow[t]{2}{*}{3.910} \\
\hline Yellow & 30 & 0.3689 & & & \\
\hline $\begin{array}{c}\text { Rem } \\
\text { weight }\end{array}$ & 7814 & 96.09 & & & \\
\hline Net & 8132 & 100 & & & \\
\hline
\end{tabular}

PC Importers $\quad$ FCC ID: LCYIMP08500 - MINI

\begin{tabular}{|c|c|c|c|c|c|}
\hline $\begin{array}{c}\text { Plastic } \\
\text { Type }\end{array}$ & $\begin{array}{c}\text { Weight } \\
\text { (gms) }\end{array}$ & $\begin{array}{c}\% \\
\text { Weight }\end{array}$ & & $\begin{array}{c}\text { Weight } \\
\text { (gms) }\end{array}$ & $\begin{array}{c}\% \\
\text { Weight }\end{array}$ \\
\hline $\begin{array}{l}\text { Front } \\
\text { Panel } \\
\end{array}$ & 280 & 4.341 & \multirow[t]{2}{*}{ Plastic } & \multirow[t]{2}{*}{335} & \multirow[t]{2}{*}{5.1934} \\
\hline Yellow & 55 & 0.8526 & & & \\
\hline $\begin{array}{c}\text { Rem } \\
\text { weight }\end{array}$ & 6116 & 94.81 & & & \\
\hline Net & 6451 & 100 & & & \\
\hline
\end{tabular}

Professional Computer Systems $\quad$ FCC ID: HZ6MPMFDJMRIV

S/N No.: 196454954

\begin{tabular}{|c|c|c|c|c|c|}
\hline $\begin{array}{l}\text { Plastic } \\
\text { Type }\end{array}$ & $\begin{array}{l}\text { Weight } \\
\text { (gms) }\end{array}$ & $\begin{array}{c}\% \\
\text { Weight }\end{array}$ & & $\begin{array}{l}\text { Weight } \\
\text { (gms) }\end{array}$ & $\begin{array}{c}\% \\
\text { Weight }\end{array}$ \\
\hline Greyish & 28 & 0.307 & \multirow{4}{*}{ Plastic } & \multirow{4}{*}{394} & \multirow{4}{*}{4.3229} \\
\hline Creamish & 290 & 3.182 & & & \\
\hline $\begin{array}{c}\text { Floppy } \\
\text { Drive }\end{array}$ & 30 & 0.329 & & & \\
\hline Black & 46 & 0.505 & & & \\
\hline $\begin{array}{c}\text { Rem } \\
\text { weight }\end{array}$ & 8720.25 & 95.677 & & & \\
\hline
\end{tabular}

\begin{tabular}{l|l|l|} 
Net & 9114.25 & 100 \\
\hline
\end{tabular} 


\section{A.1.2 Keyboard Material Balances}

Apple Design Keyboard (1)

FCC ID: BCGM2980

\begin{tabular}{|c|c|c|c|c|c|}
\hline Component & $\begin{array}{l}\text { Weight } \\
\text { (gm) }\end{array}$ & Weight \% & Component & $\begin{array}{l}\text { Weight } \\
(\mathrm{gm})\end{array}$ & Weight \% \\
\hline Metal & 256 & 23.49 & & & \\
\hline \multirow{3}{*}{ Plastic } & \multirow{3}{*}{669} & \multirow{3}{*}{61.38} & $\begin{array}{l}\text { Keyboard } \\
\text { Casing }\end{array}$ & 528 & 48.44 \\
\hline & & & Keys & 103 & 9.45 \\
\hline & & & Key Supports & 38 & 3.49 \\
\hline Circuit Board + Wiring & 100 & 9.17 & & & \\
\hline \multirow[t]{2}{*}{$\begin{array}{l}\text { Misc (plastic film, } \\
\text { rubber cushions, etc) }\end{array}$} & 65 & 5.96 & & & \\
\hline & 1090 & 100.00 & & & \\
\hline
\end{tabular}

Apple Design Keyboard (2)

FCC ID: BCGM2980

\begin{tabular}{|c|c|c|c|c|c|}
\hline Component & $\begin{array}{c}\text { Weight } \\
(\mathrm{gm})\end{array}$ & Weight $\%$ & Component & $\begin{array}{l}\text { Weight } \\
\text { (gm) }\end{array}$ & Weight $\%$ \\
\hline Metal & 301 & 24.81 & & & \\
\hline \multirow{4}{*}{ Plastic } & \multirow{4}{*}{756} & \multirow{4}{*}{62.32} & $\begin{array}{l}\text { Keyboard } \\
\text { Casing }\end{array}$ & 424 & 34.95 \\
\hline & & & Keys & 129 & 10.63 \\
\hline & & & Black Plastic & 152 & 12.53 \\
\hline & & & Key Supports & 51 & 4.20 \\
\hline Circuit Board + Wiring & 114 & 9.40 & & & \\
\hline \multirow[t]{2}{*}{$\begin{array}{l}\text { Misc (plastic film, } \\
\text { rubber cushions, etc) }\end{array}$} & 42 & 3.46 & & & \\
\hline & 1213 & 100.00 & & & \\
\hline
\end{tabular}



Dell Quietkey
Model: SK - 1000 REW
ID: GYUR57SK

\begin{tabular}{|c|c|c|c|c|c|}
\hline Component & $\begin{array}{l}\text { Weight } \\
\text { (gm) }\end{array}$ & Weight \% & Component & $\begin{array}{c}\text { Weight } \\
\text { (gm) }\end{array}$ & Weight \% \\
\hline \multirow{2}{*}{ Metal } & \multirow{2}{*}{367} & \multirow{2}{*}{31.30} & Screws & 9 & 0.80 \\
\hline & & & Plate & 357 & 30.49 \\
\hline \multirow{2}{*}{ Plastic } & \multirow{2}{*}{666} & \multirow{2}{*}{56.84} & Keyboard Casing & 532 & 45.40 \\
\hline & & & Keys & 134 & 11.44 \\
\hline Circuit Board + Wiring & 103 & 8.79 & & & \\
\hline \multirow[t]{2}{*}{$\begin{array}{l}\text { Misc (plastic film, } \\
\text { rubber cushions, etc) }\end{array}$} & 36 & 3.07 & & & \\
\hline & 1172 & 100.00 & & & \\
\hline
\end{tabular}

Fujitsu Limited S/N No: F3001385

FC ID:

C9S4D5KB4700

\begin{tabular}{|c|c|c|c|c|c|}
\hline Component & $\begin{array}{l}\text { Weight } \\
\text { (gm) }\end{array}$ & Weight \% & Component & $\begin{array}{l}\text { Weight } \\
\text { (gm) }\end{array}$ & Weight $\%$ \\
\hline Metal & 731 & 36.66 & & & \\
\hline \multirow{4}{*}{ Plastic } & \multirow{4}{*}{946} & \multirow{4}{*}{47.44} & Keyboard Casing & 527 & 26.43 \\
\hline & & & Keys & 133 & 6.67 \\
\hline & & & Key Supports & 133 & 6.67 \\
\hline & & & Black Key Base & 153 & 7.67 \\
\hline Circuit Board + Wiring & 242 & 12.14 & & & \\
\hline \multirow[t]{2}{*}{$\begin{array}{l}\text { Misc (plastic film, } \\
\text { rubber cushions, etc) }\end{array}$} & 75 & 3.76 & & & \\
\hline & 1994 & 100.00 & & & \\
\hline
\end{tabular}


Gateway Anykey 2000

Model: 2194002-00-02

ID: D7J2194001-XX

\begin{tabular}{|c|c|c|c|c|c|}
\hline Component & $\begin{array}{l}\text { Weight } \\
\text { (gm) }\end{array}$ & Weight \% & Component & $\begin{array}{c}\text { Weight } \\
\text { (gm) }\end{array}$ & Weight \% \\
\hline Metal & 350 & 24.79 & & & \\
\hline \multirow[t]{2}{*}{ Plastic } & \multirow[t]{2}{*}{904} & \multirow[t]{2}{*}{64.02} & $\begin{array}{l}\text { Keyboard } \\
\text { Casing }\end{array}$ & 746 & 52.83 \\
\hline & & & Keys & 158 & 11.19 \\
\hline $\begin{array}{c}\text { Circuit Board + } \\
\text { Wiring }\end{array}$ & 121 & 8.57 & & & \\
\hline \multirow[t]{2}{*}{$\begin{array}{l}\text { Misc (plastic film, } \\
\text { rubber cushions, } \\
\text { etc) }\end{array}$} & 37 & 2.62 & & & \\
\hline & 1412 & 100.00 & & & \\
\hline
\end{tabular}

IBM 2235

ID No.: 3988916

Part No.: 1391401

\begin{tabular}{|c|c|c|c|c|c|}
\hline Component & $\begin{array}{l}\text { Weight } \\
\text { (gm) }\end{array}$ & Weight \% & Component & $\begin{array}{l}\text { Weight } \\
\text { (gm) }\end{array}$ & Weight \% \\
\hline \multirow{3}{*}{ Metal } & \multirow{3}{*}{617} & \multirow{3}{*}{27.66} & Screws & 9 & 0.38 \\
\hline & & & Plate & 577 & 25.89 \\
\hline & & & Springs (with base) & 31 & 1.39 \\
\hline \multirow{2}{*}{ Plastic } & \multirow{2}{*}{1354} & \multirow{2}{*}{60.76} & Keyboard Casing & 1073 & 48.15 \\
\hline & & & Keys & 281 & 12.61 \\
\hline $\begin{array}{c}\text { Circuit Board + } \\
\text { Wiring }\end{array}$ & 200 & 8.97 & & & \\
\hline \multirow[t]{2}{*}{$\begin{array}{l}\text { Misc (plastic film, } \\
\text { rubber sheet, etc) }\end{array}$} & 58 & 2.60 & & & \\
\hline & 2229 & 100.00 & & & \\
\hline
\end{tabular}


Micron Keytronic

CPN: KBR001037-00

\begin{tabular}{|c|c|c|c|c|c|}
\hline Component & $\begin{array}{c}\text { Weight } \\
\text { (gm) }\end{array}$ & Weight $\%$ & Component & $\begin{array}{c}\text { Weight } \\
\text { (gm) }\end{array}$ & Weight \% \\
\hline Metal & 392 & 33.00 & & & \\
\hline \multirow{3}{*}{ Plastic } & \multirow{3}{*}{663} & \multirow{3}{*}{55.81} & Keyboard Casing & 404 & 34.01 \\
\hline & & & Keys & 132 & 11.11 \\
\hline & & & White board base & 127 & 10.69 \\
\hline Circuit Board + Wiring & 75 & 6.31 & & & \\
\hline \multirow[t]{2}{*}{$\begin{array}{c}\text { Misc (plastic film, } \\
\text { rubber cushions, etc) }\end{array}$} & 58 & 4.88 & & & \\
\hline & 1188 & 100.00 & & & \\
\hline
\end{tabular}

Microsoft Monoblock Model No: KB-0045

Product ID: 71305-545-0354646-00116

\begin{tabular}{|c|c|c|c|c|c|}
\hline Component & $\begin{array}{l}\text { Weight } \\
\text { (gm) }\end{array}$ & Weight \% & Component & $\begin{array}{l}\text { Weight } \\
\text { (gm) }\end{array}$ & Weight \% \\
\hline Metal & 10 & 1.05 & & & \\
\hline \multirow{2}{*}{ Plastic } & \multirow{2}{*}{808} & \multirow{2}{*}{84.61} & Keyboard Casing & 672 & 70.37 \\
\hline & & & Keys & 136 & 14.24 \\
\hline Circuit Board + Wiring & 79 & 8.27 & & & \\
\hline \multirow[t]{2}{*}{$\begin{array}{l}\text { Misc (plastic film, } \\
\text { rubber cushions, etc) }\end{array}$} & 58 & 6.07 & & & \\
\hline & 955 & 100.00 & & & \\
\hline
\end{tabular}


Mitsumi Keyboard

Model: KPQ-E99ZC-13

FCC ID: CMYKPQ7461

\begin{tabular}{|c|c|c|c|c|c|}
\hline Component & $\begin{array}{l}\text { Weight } \\
\text { (gm) }\end{array}$ & $\begin{array}{l}\text { Weight } \\
\%\end{array}$ & Component & $\begin{array}{l}\text { Weight } \\
\text { (gm) }\end{array}$ & Weight $\%$ \\
\hline Metal & 277 & 28.44 & & & \\
\hline \multirow{2}{*}{ Plastic } & \multirow{2}{*}{564} & \multirow{2}{*}{57.91} & Keyboard Casing & 469 & 48.15 \\
\hline & & & Keys & 95 & 9.75 \\
\hline Circuit Board + Wiring & 78 & 8.01 & & & \\
\hline \multirow[t]{2}{*}{$\begin{array}{l}\text { Misc (plastic film, } \\
\text { rubber cushions, etc) }\end{array}$} & 55 & 5.65 & & & \\
\hline & 974 & 100.00 & & & \\
\hline
\end{tabular}

PC Concepts i MMT

S/N No:

9F20614523B

\begin{tabular}{|c|c|c|c|c|c|}
\hline Component & $\begin{array}{l}\text { Weight } \\
\text { (gm) }\end{array}$ & $\begin{array}{c}\text { Weight } \\
\%\end{array}$ & Component & $\begin{array}{l}\text { Weight } \\
\text { (gm) }\end{array}$ & Weight \% \\
\hline Metal & 13 & 2.11 & Screws & 13 & 2.11 \\
\hline \multirow{2}{*}{ Plastic } & \multirow{2}{*}{495} & \multirow{2}{*}{80.23} & Keyboard Casing & 391 & 63.37 \\
\hline & & & Keys & 104 & 16.86 \\
\hline $\begin{array}{c}\text { Circuit Board + } \\
\text { Wiring }\end{array}$ & 57 & 9.24 & & & \\
\hline \multirow[t]{2}{*}{$\begin{array}{l}\text { Misc (plastic film, } \\
\text { rubber cushions, } \\
\text { etc) }\end{array}$} & 52 & 8.43 & & & \\
\hline & 617 & 100 & & & \\
\hline
\end{tabular}

$\begin{array}{cc}\text { Zenith Data } & \text { FCC ID: IF0- } \\ \text { Systems } & \text { 557KBD17 }\end{array}$

\begin{tabular}{|c|c|c|c|c|c|}
\hline Component & $\begin{array}{c}\text { Weight } \\
(\mathrm{gm})\end{array}$ & $\begin{array}{c}\text { Weight } \\
\%\end{array}$ & Component & $\begin{array}{l}\text { Weight } \\
\text { (gm) }\end{array}$ & Weight \% \\
\hline Metal + Misc & 42 & 2.24 & & & \\
\hline \multirow{2}{*}{ Plastic } & \multirow{2}{*}{823} & \multirow{2}{*}{43.85} & Keyboard Casing & 673 & 35.86 \\
\hline & & & Keys & 150 & 7.99 \\
\hline \multirow[t]{2}{*}{$\begin{array}{c}\text { Circuit Board + } \\
\text { Wiring }\end{array}$} & 1012 & 53.92 & & & \\
\hline & 1877 & 100.00 & & & \\
\hline
\end{tabular}




\section{A.1.3 Printer Material Balances}

HP DJ 870C S/N : US757110X3 $\quad$ FCC ID: B94C4555X

\begin{tabular}{|c|c|c|c|c|c|}
\hline Plastic Type & Weight (gm) & $\%$ Weight & & Weight (gm) & $\%$ Weight \\
\hline Grey & 2277 & 3926 & \multirow{4}{*}{ Plastic } & \multirow{4}{*}{2980} & \multirow{4}{*}{51.38} \\
\hline Blue & 81 & 1.397 & & & \\
\hline Black & 350 & 6.035 & & & \\
\hline Dark Grey & 272 & 4.690 & & & \\
\hline Rem weight & 2820 & 48.62 & & & \\
\hline Net & 5800 & 100 & & & \\
\hline
\end{tabular}

HP DJ 680C

S/N : CN6561R18P $\quad$ FCC ID: B94C2164X

\begin{tabular}{|c|c|c|c|c|c|}
\hline Plastic Type & Weight (gm) & $\%$ Weight & & Weight (gm) & $\%$ Weight \\
\hline Smooth Grey & 68 & 1.28 & \multirow{5}{*}{ Plastic } & \multirow{5}{*}{1696} & \multirow{5}{*}{31.86} \\
\hline Blue & 85 & 1.597 & & & \\
\hline Black & 145 & 2.724 & & & \\
\hline Rough Grey & 280 & 5.260 & & & \\
\hline Creamish & 1118 & 21.00 & & & \\
\hline Rem weight & 3627 & 68.14 & & & \\
\hline Net & 5323 & 100 & & & \\
\hline
\end{tabular}




\section{A.2 Ash Analysis, Density and FTIR Plastic Identification Data}

\section{A.2.1 CPU Summary}

\begin{tabular}{|c|c|c|c|c|}
\hline \multicolumn{5}{|c|}{ CCS 386} \\
\hline & Match & Density (gm/cc) & $\%$ Ash & $\begin{array}{c}\text { Material Balance } \\
\text { (\% weight) }\end{array}$ \\
\hline $\begin{array}{l}\text { Grey } \\
\text { Green }\end{array}$ & $\begin{array}{c}\text { SAN }(20 \% A) \\
\text { PS }\end{array}$ & $\begin{array}{l}1.1299 \\
1.0344\end{array}$ & $\begin{array}{l}2.2387 \\
0.5679\end{array}$ & 3.55 \\
\hline
\end{tabular}

Gateway 2000 New Tower

FCC ID: HWYALP5100T

\begin{tabular}{|c|c|c|c|c|}
\hline & Match & Density (gm/cc) & $\%$ Ash & $\begin{array}{c}\text { Material Balance (\% } \\
\text { weight) }\end{array}$ \\
\hline Black & PBT & 1.5312 & 23.7269 & \multirow{4}{*}{4.3229} \\
\hline $\begin{array}{l}\text { Greenish } \\
\text { White }\end{array}$ & Polypropylene Oxide & 1.3292 & 31.2259 & \\
\hline $\begin{array}{l}\text { CD - Floppy } \\
\text { Drives }\end{array}$ & $\begin{array}{c}\text { Styrene - Butadiene } \\
(85 \% \mathrm{~S})\end{array}$ & 1.1624 & 2.1030 & \\
\hline White & $\begin{array}{c}\text { Styrene - Butadiene } \\
(85 \% \mathrm{~S})\end{array}$ & 1.1734 & 1.9740 & \\
\hline
\end{tabular}

GIC 486

S/N No.: 002537

\begin{tabular}{|c|c|c|c|c|}
\cline { 2 - 4 } \multicolumn{1}{c|}{} & Match & Density (gm/cc) & $\%$ Ash & $\begin{array}{c}\text { Material Balance } \\
(\% \text { weight })\end{array}$ \\
\hline Yellow & SAN $(20 \%$ A) & 1.0456 & 0.1809 & \multirow{2}{*}{3.91} \\
\cline { 2 - 4 } Muddy White & PS & 1.0405 & 0.4133 & \\
\hline
\end{tabular}

PC Importers

FCC ID: LCYIMP08500 - MINI

\begin{tabular}{|c|c|c|c|c|}
\cline { 2 - 4 } \multicolumn{1}{c|}{} & Match & Density $(\mathrm{gm} / \mathrm{cc})$ & $\%$ Ash & $\begin{array}{c}\text { Material Balance } \\
\text { (\% weight) }\end{array}$ \\
\hline $\begin{array}{c}\text { Yellow } \\
\text { Front Panel }\end{array}$ & SAN $(20 \% \mathrm{~A})$ & 1.0515 & 0.0771 & \multirow{2}{*}{5.1934} \\
\cline { 2 - 4 } & SAN $(20 \% \mathrm{~A})$ & 1.0755 & 3.5237 & \\
\hline
\end{tabular}




\begin{tabular}{|c|c|c|c|c|}
\hline \multicolumn{2}{|c|}{ Professional Computer Systems } & \multicolumn{2}{|c|}{ FCC ID: HZ6MPMFDJMRIV } & \\
\hline & Match & Density (gm/cc) & $\%$ Ash & $\begin{array}{c}\text { Material Balance } \\
\text { (\% weight) }\end{array}$ \\
\hline Grey & SAN $(20 \% A)$ & 1.0582 & 0.8825 & \multirow{4}{*}{4.3229} \\
\hline Creamish & SAN $(20 \% A)$ & 1.0583 & 0.8726 & \\
\hline Floppy Drive & $\begin{array}{c}\text { Styrene - Butadiene } \\
(85 \% \mathrm{~S})\end{array}$ & 1.1843 & 2.246 & \\
\hline Black & SAN $(20 \% A)$ & 1.0857 & 0.8913 & \\
\hline
\end{tabular}

\section{A.2.2 Keyboards Summary}

Apple Design Keyboard (1)

FCC ID: BCGM2980

\begin{tabular}{|c|c|c|c|c|}
\hline & Match & Density (gm/cc) & $\%$ Ash & $\begin{array}{l}\text { Material Balance } \\
\text { (\% weight) }\end{array}$ \\
\hline Keys: & SAN $(20 \% A)$ & 1.0588 & 0.8219 & \multirow{3}{*}{61.38} \\
\hline Keyboard: & Polystyrene & 1.0579 & 3.3165 & \\
\hline Key Supports & Polyacetal & 1.4209 & - & \\
\hline
\end{tabular}

Apple Design Keyboard (2)

FCC ID: BCGM2980

\begin{tabular}{|c|c|c|c|c|}
\cline { 2 - 4 } \multicolumn{1}{c|}{} & Match & Density (gm/cc) & $\%$ Ash & $\begin{array}{c}\text { Material Balance } \\
\text { (\% weight) }\end{array}$ \\
\hline Keys: & SAN (20\%A) & 1.0821 & 5.2186 & \multirow{2}{*}{62.32} \\
\hline Keyboard: & Polystyrene & 1.0651 & 4.0643 & \\
\hline
\end{tabular}

\begin{tabular}{|c|c|c|c|c|}
\multicolumn{1}{c|}{ Dell Quietkey } & Model: SK - 1000 REW & \multicolumn{1}{c|}{ ID: GYUR57SK } \\
\cline { 2 - 4 } \multicolumn{1}{c|}{} & Match & Density (gm/cc) & $\%$ Ash & $\begin{array}{c}\text { Material Balance } \\
\text { (\% weight) }\end{array}$ \\
\hline Keys: & SAN (20\%A) & 1.0577 & 0.7355 & \multirow{2}{*}{56.84} \\
\hline Keyboard: & Polystyrene & 1.0345 & 0.4979 & \\
\hline
\end{tabular}




\begin{tabular}{|c|c|c|c|c|}
\multicolumn{1}{c|}{ Fujitsu Limited } & \multicolumn{2}{c}{ S/N No: F3001385 } & FCC ID: & C9S4D5KB4700 \\
\cline { 2 - 4 } \multicolumn{1}{c|}{} & Match & Density (gm/cc) & $\%$ Ash & $\begin{array}{c}\text { Material Balance } \\
\text { (\% weight) }\end{array}$ \\
\hline Keys & PBT & 1.3025 & 2.0628 & \multirow{2}{*}{47.44} \\
\hline Keyboard & Polystyrene & 1.0418 & 0.9549 & \multirow{2}{*}{ Key Supports } \\
\cline { 1 - 4 } & Polyacetal & 1.4142 & - & \\
\hline Black & Polystyrene & 1.0336 & 0.5768 & \\
\hline
\end{tabular}

\begin{tabular}{|c|c|c|c|c|}
\hline \multirow[t]{2}{*}{ Gateway } & \multicolumn{3}{|c|}{ Model: 2194002-00-02 } & \multirow{2}{*}{$\begin{array}{c}\text { ID: D7J2194001- } \\
\text { XX } \\
\text { Material Balance } \\
\text { (\% weight })\end{array}$} \\
\hline & Match & Density $(\mathrm{gm} / \mathrm{cc})$ & $\%$ Ash & \\
\hline Keys & SAN $(96 \% ; 20 \%$ A) & 1.0561 & 0.9329 & \multirow{2}{*}{64.02} \\
\hline Keyboard & Polystyrene (91\%) & 1.0345 & 0.6792 & \\
\hline
\end{tabular}

\begin{tabular}{|c|c|c|c|c|}
\multicolumn{1}{c|}{ IBM 2235} & \multicolumn{2}{c|}{ ID No.: 3988916 } & Part No.: 1391401 \\
\cline { 2 - 5 } \multicolumn{1}{c|}{} & Match & Density (gm/cc) & $\%$ Ash & $\begin{array}{c}\text { Material Balance } \\
\text { (\% weight) }\end{array}$ \\
\hline Keys & PBT & 1.3231 & 1.096 & 60.76 \\
\hline Keyboard & VC / VA / V-OH & 1.3607 & 4.309 & \\
\hline
\end{tabular}

\begin{tabular}{|c|c|c|c|c|}
\hline \multirow{2}{*}{ Micron Keytronic } & \multicolumn{2}{c}{ CPN: KBR001037-00 } \\
\cline { 2 - 4 } & Match & $\begin{array}{c}\text { Density } \\
(\mathrm{gm} / \mathrm{cc})\end{array}$ & $\begin{array}{c}\text { Material Balance } \\
\text { (\% weight) }\end{array}$ \\
\hline Keys & SAN $(20 \% \mathrm{~A})$ & 1.0653 & 2.4339 & \multirow{2}{*}{55.81} \\
\hline Keyboard & PS & 1.0461 & 1.455 & \\
\hline $\begin{array}{c}\text { White } \\
\text { Keybase }\end{array}$ & PS & 1.0386 & 0.0446 & \\
\hline
\end{tabular}

\begin{tabular}{|c|c|r|c|c|}
\multicolumn{1}{c|}{ Microsoft Monoblock } & \multicolumn{2}{c|}{ Model No: KB-0045 } & \multicolumn{2}{c|}{ Product ID: 71305-545-0354646-001 } \\
\cline { 2 - 5 } \multicolumn{1}{c|}{ Match } & $\begin{array}{r}\text { Density } \\
(\mathrm{gm} / \mathrm{cc})\end{array}$ & $\%$ Ash & $\begin{array}{c}\text { Material Balance } \\
(\% \text { weight })\end{array}$ \\
\hline Keys & SAN (20\% A) & 1.0543 & 1.7728 & \multirow{2}{*}{84.61} \\
\hline Keyboard & PS & 1.0438 & 0.8026 & \\
\hline
\end{tabular}




\begin{tabular}{|c|c|c|c|c|}
\multicolumn{1}{c}{} & \multicolumn{2}{c}{ Model: KPQ-E99ZC-13 } & \multicolumn{2}{c|}{ FCC ID: CMYKPQ7461 } \\
\cline { 2 - 5 } \multicolumn{1}{c|}{} & Match & $\begin{array}{c}\text { Density } \\
\text { (gm/cc) }\end{array}$ & $\%$ Ash & $\begin{array}{c}\text { Material Balance } \\
\text { (\% weight) }\end{array}$ \\
\hline Keys & SAN $(20 \% A)$ & 1.0608 & 1.6154 & \multirow{2}{*}{57.91} \\
\hline Keyboard & Polystyrene & 1.0517 & 1.6908 & \\
\hline
\end{tabular}

\begin{tabular}{|c|c|c|c|c|}
\hline \multicolumn{2}{|c|}{ PC Concepts i - MMT } & Model: KWD - 820 & \multicolumn{2}{|c|}{ S/N No: 9F20614523B } \\
\hline & Match & $\begin{array}{l}\text { Density } \\
\text { (gm/cc) }\end{array}$ & $\%$ Ash & $\begin{array}{l}\text { Material Balance } \\
\text { (\% weight) }\end{array}$ \\
\hline Keys & SAN $(20 \% A)$ & 1.0499 & 0.9346 & \\
\hline Keyboard & Styrene - Butadiene & 1.0384 & 0.9438 & \\
\hline
\end{tabular}

Zenith Data Systems FCC ID: IF0-557KBD17

\begin{tabular}{|c|c|c|c|c|}
\cline { 2 - 4 } \multicolumn{1}{c|}{ Match } & $\begin{array}{r}\text { Density } \\
\text { (gm/cc) }\end{array}$ & $\%$ Ash & $\begin{array}{c}\text { Material Balance } \\
\text { (\% weight) }\end{array}$ \\
\hline Keys & PBT & 1.3041 & 1.6323 & \multirow{2}{*}{43.85} \\
\hline Keyboard & SAN (20\% A) & 1.2693 & 7.0607 & \\
\hline
\end{tabular}

\section{A.2.3 Printers Summary}

\begin{tabular}{|c|c|c|c|c|}
\multicolumn{1}{c}{ HP DJ 680C } & \multicolumn{2}{c}{ S/N : CN6561R18P } & FCC ID: B94C2164X \\
\cline { 2 - 4 } \multicolumn{1}{c|}{} & Match & $\begin{array}{c}\text { Density } \\
\text { (gm/cc) }\end{array}$ & $\%$ Ash & $\begin{array}{c}\text { Material Balance } \\
\text { (weight) }\end{array}$ \\
\hline Creamish & PS & 1.0425 & 2.0870 & \multirow{2}{*}{} \\
\hline Blue & SAN (20\% A) & 1.1095 & 5.0127 & \multirow{2}{*}{31.86} \\
\hline Rough Grey & PC & 1.3839 & 25.2895 & \\
\hline Smooth Grey & PC & 1.2607 & 4.0992 & \\
\hline Black & PC & 1.2458 & 5.4185 & \\
\hline
\end{tabular}

\begin{tabular}{|c|c|c|c|c|}
\multicolumn{2}{c}{ HP DJ 870C } & \multicolumn{2}{c}{ S/N : US757110X3 } & \multicolumn{1}{c}{ FCC ID: } \\
\multicolumn{1}{c|}{} & Match & $\begin{array}{c}\text { Density } \\
\text { (gm/cc) }\end{array}$ & $\%$ Ash & $\begin{array}{c}\text { Material Balance } \\
\text { (\% weight) }\end{array}$ \\
\cline { 2 - 4 } & SAN (20 \%A) & 1.0795 & 2.2298 & \multirow{2}{*}{51.38} \\
\hline Blue & PC & 1.3925 & 25.5822 & \\
\hline Dark Grey & PS & 1.1173 & 1.8076 & \\
\hline Grey & PC & 1.3156 & 14.4103 & \\
\hline Black & & & & \\
\hline
\end{tabular}




\section{A.3 Settling Velocity Data}

Table A.1 Settling Velocity Data for Dell QuietKey Keyboard Casing (HIPS)

$\begin{array}{ccccc}\text { Frame } & \begin{array}{c}\text { X coord } \\ (\mathrm{mm})\end{array} & \begin{array}{c}\text { Y Coord } \\ (\mathrm{mm})\end{array} & \begin{array}{c}\text { time } \\ (\mathrm{sec})\end{array} & \begin{array}{c}\mathrm{dy} / \mathrm{dt} \\ (\mathrm{mm} / \mathrm{sec})\end{array} \\ 1 & 37.78 & 41.82 & 0.0000 & \\ 2 & 37.85 & 42.59 & 0.0333 & 23.40 \\ 3 & 37.92 & 43.38 & 0.0667 & 23.25 \\ 4 & 38.01 & 44.14 & 0.1000 & 22.65 \\ 5 & 38.07 & 44.89 & 0.1333 & 22.35 \\ 6 & 38.07 & 45.63 & 0.1667 & 22.65 \\ 7 & 38.1 & 46.4 & 0.2000 & 22.80 \\ 8 & 38.11 & 47.15 & 0.2333 & 22.80 \\ 9 & 38.18 & 47.92 & 0.2667 & 23.25 \\ 10 & 38.29 & 48.7 & 0.3000 & 22.80 \\ 11 & 38.35 & 49.44 & 0.3333 & 21.90 \\ 12 & 38.4 & 50.16 & 0.3667 & \end{array}$

Table A.2 Settling Velocity Data for PCS CPU Unit Creamish Plastic (ABS)

$\begin{array}{crrrr}\text { Frame } & \begin{array}{c}\text { X coord } \\ (\mathrm{mm})\end{array} & \begin{array}{c}\text { Y Coord } \\ (\mathrm{mm})\end{array} & \begin{array}{c}\text { time } \\ (\mathrm{sec})\end{array} & \begin{array}{c}\mathrm{dy} / \mathrm{dt} \\ (\mathrm{mm} / \mathrm{sec})\end{array} \\ 1 & 69.52 & 41.46 & 0.0000 & \\ 2 & 69.44 & 42.16 & 0.0333 & 23.10 \\ 3 & 69.25 & 43 & 0.0667 & 22.65 \\ 4 & 69.2 & 43.67 & 0.1000 & 20.10 \\ 5 & 69.11 & 44.34 & 0.1333 & 20.55 \\ 6 & 68.89 & 45.04 & 0.1667 & 21.90 \\ 7 & 68.66 & 45.8 & 0.2000 & 22.95 \\ 8 & 68.35 & 46.57 & 0.2333 & 24.30 \\ 9 & 68.05 & 47.42 & 0.2667 & 25.50 \\ 10 & 67.71 & 48.27 & 0.3000 & 26.85 \\ 11 & 67.38 & 49.21 & 0.3333 & 27.75 \\ 12 & 67.06 & 50.12 & 0.3667 & \end{array}$




\section{A.4 Froth Flotataion Data}

Table A.3 Flotation Data for ABS with only MIBC frother

\begin{tabular}{|c|cccc|}
\cline { 2 - 5 } \multicolumn{1}{c|}{} & \multicolumn{4}{c|}{ Cumulative \% wt fraction } \\
\hline $\begin{array}{c}\text { Time } \\
(\mathrm{min})\end{array}$ & $0 \mathrm{ml}$ & $1 \mathrm{ml}$ & $3 \mathrm{ml}$ & $5 \mathrm{ml}$ \\
\hline 0 & 0.00 & 0.00 & 0.00 & 0.00 \\
2 & 13.41 & 11.54 & 15.09 & 11.00 \\
4 & 27.31 & 22.18 & 22.45 & 18.77 \\
6 & 46.70 & 36.64 & 34.83 & 24.34 \\
8 & 57.37 & 45.92 & 40.20 & 29.61 \\
10 & 60.94 & 51.86 & 46.74 & 36.09 \\
12 & 71.16 & 56.41 & 52.74 & 37.56 \\
14 & 76.44 & 61.65 & 55.15 & 46.31 \\
\hline
\end{tabular}

Table A.4 Flotation Data for PS with only MIBC frother

\begin{tabular}{|c|cccc|}
\cline { 2 - 5 } \multicolumn{1}{c|}{} & \multicolumn{4}{c|}{ Cumulative \% wt fraction } \\
\hline $\begin{array}{c}\text { Time } \\
(\mathrm{min})\end{array}$ & $0 \mathrm{ml}$ & $1 \mathrm{ml}$ & $3 \mathrm{ml}$ & $5 \mathrm{ml}$ \\
\hline 0 & 0.00 & 0.00 & 0.00 & 0.00 \\
2 & 18.90 & 27.25 & 20.15 & 13.96 \\
4 & 30.14 & 53.98 & 36.15 & 30.67 \\
6 & 41.11 & 67.30 & 46.34 & 44.40 \\
8 & 60.96 & 78.66 & 60.82 & 54.36 \\
10 & 68.27 & 84.99 & 68.52 & 67.54 \\
12 & 78.40 & 90.52 & 73.46 & 73.78 \\
14 & 85.08 & 93.24 & 76.61 & 81.17 \\
\hline
\end{tabular}

Table A.5 Flotation Data for ABS with MIBC Frother and Dodecylamine Hydrochloride surfactant

\begin{tabular}{|c|cccc|c|}
\cline { 2 - 5 } \multicolumn{1}{c|}{} & \multicolumn{3}{c|}{ Cumulative \% wt fraction } & \multirow{2}{*}{ MIBC } \\
Time & $0 \mathrm{ml}$ & $1 \mathrm{ml}$ & $1 \mathrm{ml}$ & $1 \mathrm{ml}$ & Amine \\
\hline 0 & 0.00 & 0.00 & 0.00 & 0.00 & \\
2 & 13.41 & 11.54 & 4.64 & 0.62 & \\
4 & 27.31 & 22.18 & 8.13 & 2.39 & \\
6 & 46.70 & 36.64 & 13.88 & 5.20 & \\
8 & 57.37 & 45.92 & 19.68 & 8.84 & \\
10 & 60.94 & 51.86 & 21.54 & 12.83 & \\
12 & 71.16 & 56.41 & 27.55 & 16.46 & \\
14 & 76.44 & 61.65 & 37.17 & 21.05 & \\
\cline { 1 - 4 } & & & & &
\end{tabular}


Table A.6 Flotation Data for PS with MIBC Frother and Dodecylamine Hydrochloride as surfactant

\begin{tabular}{|c|cccc|c|}
\cline { 2 - 5 } \multicolumn{1}{c|}{} & \multicolumn{3}{c|}{ Cumulative \% wt fraction } & \multirow{2}{*}{ MIBC } \\
Time & $0 \mathrm{ml}$ & $1 \mathrm{ml}$ & $1 \mathrm{ml}$ & $1 \mathrm{ml}$ & Amine \\
\hline 0 & 0.00 & 0.00 & 0.00 & 0.00 & \\
2 & 18.90 & 27.25 & 10.33 & 6.44 & \\
4 & 30.14 & 53.98 & 18.89 & 11.84 & \\
6 & 41.11 & 67.30 & 27.60 & 19.70 & \\
8 & 60.96 & 78.66 & 40.78 & 25.27 & \\
10 & 68.27 & 84.99 & 48.99 & 28.92 & \\
12 & 78.40 & 90.52 & 61.49 & 31.71 & \\
14 & 85.08 & 93.24 & 70.50 & 35.92 & \multicolumn{1}{c}{} \\
& & & &
\end{tabular}

Table A.7 Flotation Data for ABS with MIBC Frother and Oleic Acid - NaOH emulsion

\begin{tabular}{|c|c|c|c|c|c|}
\hline & \multicolumn{4}{|c|}{ Cumulative \% wt fraction } & \\
\hline $\begin{array}{l}\text { Time } \\
(\min )\end{array}$ & $\begin{array}{l}0 \mathrm{ml} \\
0 \mathrm{ml}\end{array}$ & $\begin{array}{l}1 \mathrm{ml} \\
0 \mathrm{ml}\end{array}$ & $\begin{array}{c}1 \mathrm{ml} \\
10 \mathrm{ml}\end{array}$ & $\begin{array}{c}1 \mathrm{ml} \\
20 \mathrm{ml}\end{array}$ & $\begin{array}{c}\text { MIBC } \\
\text { Oleic Acid }\end{array}$ \\
\hline 0 & 0.00 & 0.00 & 0.00 & 0.00 & \\
\hline 2 & 13.41 & 11.54 & 21.99 & 45.12 & \\
\hline 4 & 27.31 & 22.18 & 47.71 & 60.52 & \\
\hline 6 & 46.70 & 36.64 & 66.69 & 73.04 & \\
\hline 8 & 57.37 & 45.92 & 75.31 & 83.30 & \\
\hline 10 & 60.94 & 51.86 & 83.21 & 87.64 & \\
\hline 12 & 71.16 & 56.41 & 89.67 & 91.73 & \\
\hline 14 & 76.44 & 61.65 & 89.82 & 93.24 & \\
\hline
\end{tabular}

Table A.8 Flotation Data for PS with MIBC Frother and Oleic Acid - NaOH emulsion

\begin{tabular}{|c|c|c|c|c|c|}
\hline & \multicolumn{4}{|c|}{ Cumulative $\%$ wt fraction } & \\
\hline $\begin{array}{l}\text { Time } \\
(\mathrm{min})\end{array}$ & $\begin{array}{l}0 \mathrm{ml} \\
0 \mathrm{gm}\end{array}$ & $\begin{array}{l}1 \mathrm{ml} \\
0 \mathrm{gm} \\
\end{array}$ & $\begin{array}{r}1 \mathrm{ml} \\
2 \mathrm{gm} \\
\end{array}$ & $\begin{array}{r}1 \mathrm{ml} \\
4 \mathrm{gm} \\
\end{array}$ & $\begin{array}{c}\text { MIBC } \\
\text { Oleic Acid }\end{array}$ \\
\hline 0 & 0.00 & 0.00 & 0.00 & 0.00 & \\
\hline 2 & 18.90 & 27.25 & 34.16 & 38.09 & \\
\hline 4 & 30.14 & 53.98 & 67.70 & 64.42 & \\
\hline 6 & 41.11 & 67.30 & 82.35 & 79.83 & \\
\hline 8 & 60.96 & 78.66 & 88.70 & 89.78 & \\
\hline 10 & 68.27 & 84.99 & 92.66 & 94.74 & \\
\hline 12 & 78.40 & 90.52 & 96.59 & 98.42 & \\
\hline 14 & 85.08 & 93.24 & 97.10 & 99.28 & \\
\hline
\end{tabular}


Table A.9 Flotation Data for 'Pure' and 'Mixed' ABS with $1 \mathrm{ml}$ MIBC Frother and no surfactant

\begin{tabular}{|c|c|c|}
\cline { 2 - 3 } \multicolumn{1}{c|}{} & \multicolumn{2}{c|}{ Cumulative \% wt fraction } \\
\hline $\begin{array}{c}\text { Time } \\
\text { (min) }\end{array}$ & 'Pure' ABS & 'Mixed' ABS \\
\cline { 2 - 3 } 0 & 0.00 & 0.00 \\
2 & 11.54 & 18.86 \\
4 & 22.18 & 31.50 \\
6 & 36.64 & 45.97 \\
8 & 45.92 & 57.44 \\
10 & 51.86 & 66.54 \\
12 & 56.41 & 76.10 \\
14 & 61.65 & 83.97 \\
\hline
\end{tabular}

Table A.10 Flotation Data for 'Pure' and 'Mixed' PS with $1 \mathrm{ml}$ MIBC Frother and no surfactant

\begin{tabular}{|c|c|c|}
\cline { 2 - 3 } \multicolumn{1}{c|}{} & \multicolumn{2}{c|}{ Cumulative \% wt fraction } \\
\hline $\begin{array}{c}\text { Time } \\
(\min )\end{array}$ & 'Pure' & Mixed' \\
\hline 0 & 0.00 & 0.00 \\
2 & 27.25 & 21.75 \\
4 & 53.98 & 52.24 \\
6 & 67.30 & 73.22 \\
8 & 78.66 & 85.62 \\
10 & 84.99 & 93.92 \\
12 & 90.52 & 95.22 \\
14 & 93.24 & 97.52 \\
\hline
\end{tabular}

